\title{
A population genetic analysis of the New Zealand spotty (Notolabrus celidotus) using mitochondrial DNA and microsatellite DNA markers
}

Rachel Zoe Wilcox

A thesis submitted to the Victoria University of Wellington in fulfilment of the requirements for the degree of Master of Science

Victoria University of Wellington

2015 


\section{Abstract}

Notolabrus celidotus (the New Zealand spotty) is a common rocky reef species that is endemic to New Zealand. This species is the most abundant demersal reef fish in New Zealand, and is distributed throughout the North and South Islands, and Stewart Island. Notolabrus celidotus consumes a wide variety of small invertebrates, and juveniles are reliant on coastal kelp forests as nursery habitats. Because N. celidotus is such a common species on New Zealand rocky reefs it is a good model species for population genetic studies.

The primary goal of this research was to investigate new genetic markers and add new sample locations to bolster previous genetic population data from $N$. celidotus. The thesis research utilised DNA sequences obtained from a 454 massively parallel DNA sequencer and reports six new microsatellite loci for $N$. celidotus. These loci are the first microsatellite DNA markers to be developed for this species. Additional mitochondrial DNA (mtDNA) control region sequences were obtained from new samples of $N$. celidotus and combined with previously reported mtDNA sequences. Increasing the sample size improved the genetic coverage of $N$. celidotus populations around coastal New Zealand. The mtDNA sequences were analysed to examine the population connectivity and demographic history of $N$. celidotus. The microsatellite DNA loci reported in this study were also used to examine the levels of genetic diversity and population structure in N. celidotus.

Results of the combined genetic analyses revealed extremely high levels of genetic diversity among the population sample of the mtDNA control region. Both the mitochondrial DNA and microsatellite DNA analyses showed a distinct lack of population genetic structuring, which suggests there is constant mixing of $N$. celidotus among sites. The results of this study have the potential to inform the expectations about the genetic structure of closely related wrasse species, such as Notolabrus fucicola, as well as other coastal species that have a similar life history, dispersal power, and New Zealand-wide distribution. 


\section{Acknowledgements}

I would firstly like to thank Peter Ritchie, my supervisor, for all he has helped me with while completing my thesis: helping me navigate a topic change part way through the year, lots of help, and guidance on analyses and comments while writing up my work. Your support has truly been invaluable.

Thanks go to Angela Fleming, Jack Du and Hayden Smith for sample collection and laboratory analysis. Thank you also to all my lab mates, for help in the lab and with my data analysis - your assistance has been so helpful for getting the work done!

To all my family and friends - thank you all for your support through my thesis year. Thank you especially to Mum - for fostering a love of science and the outdoors in me, and to Dad for taking me fishing to catch my first spotty! Special thanks to Jon for your unwavering support, for keeping me smiling throughout this year, and for keeping me motivated - especially during these last few months.

I would also like to thank Victoria University of Wellington for financial assistance in completing my Master's degree, through the Victoria Graduate Award and the Fee Waiver Scholarship I was awarded. 


\section{Table of Contents}

\section{Chapter One}

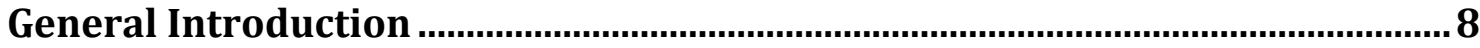

Connectivity and population structure ………………………………………………………….... 8

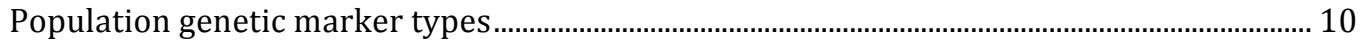

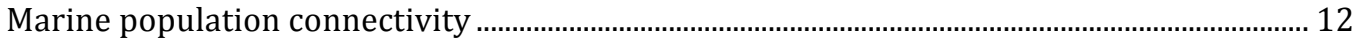

Study species: Notolabrus celidotus (New Zealand spotty) .......................................................... 16

The aims of the thesis research ............................................................................................................... 17

\section{Chapter Two}

Development of novel microsatellite markers for $N$. celidotus ......................... 19

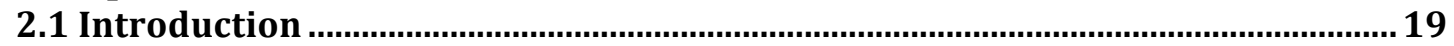

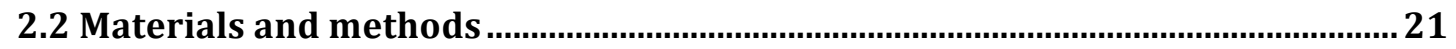

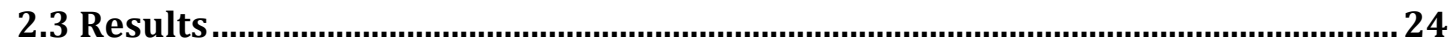

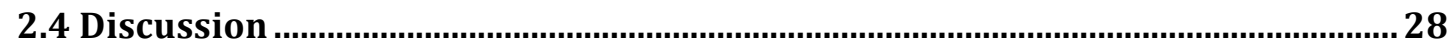

\section{Chapter Three}

Analysis of population structure and demographic history using mitochondrial DNA and microsatellite DNA markers ........................................ 30

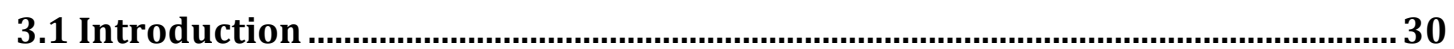

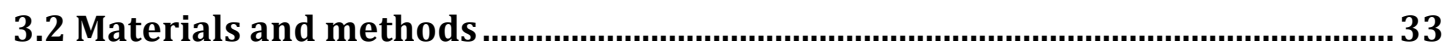

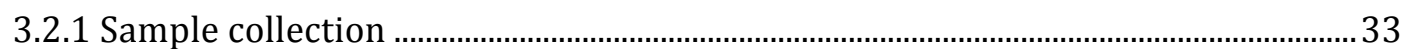

3.2.2 Mitochondrial DNA sequencing …………………................................................... 35

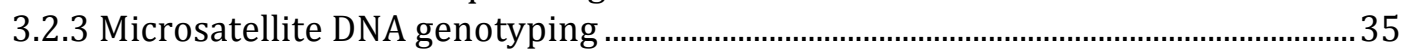

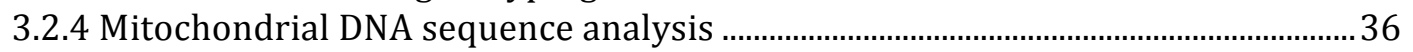

Genetic diversity ………………………………………………………………………………………... 36

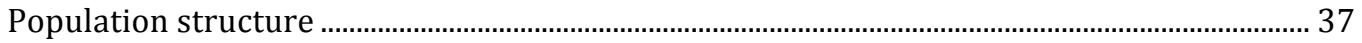

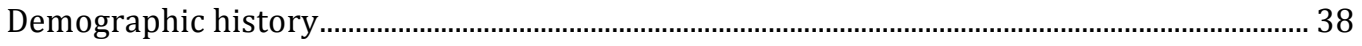

3.2.5 Microsatellite DNA genotype analysis …………............................................................. 39

Genetic diversity ………………………………………………………………………………………. 39

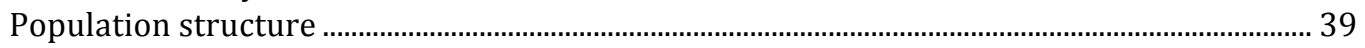

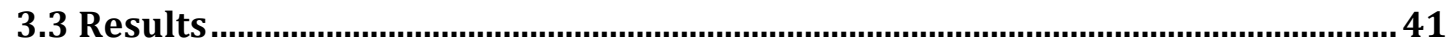

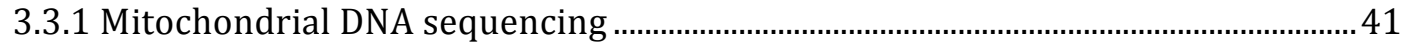

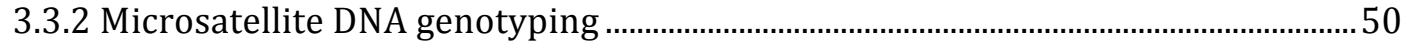

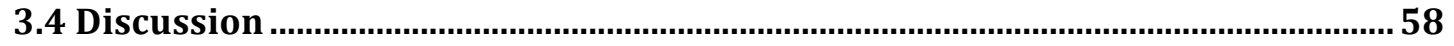

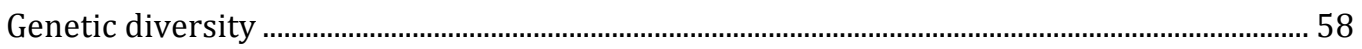

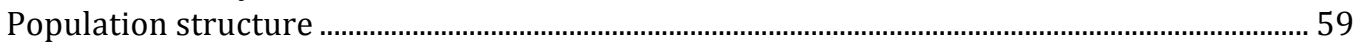

Demographic history.................................................................................................................. 60

\section{Chapter Four}

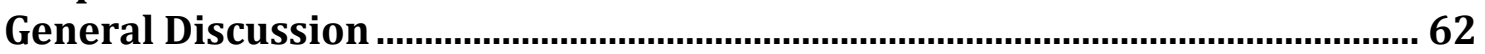

Genetic diversity of Notolabrus celidotus ..................................................................................... 62

Population structure of Notolabrus celidotus ................................................................................ 64

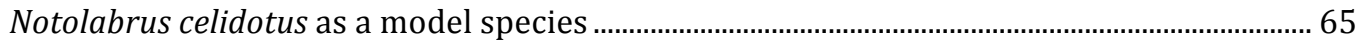

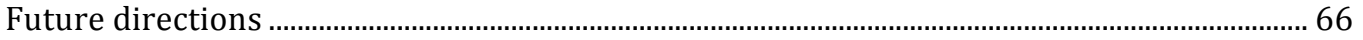

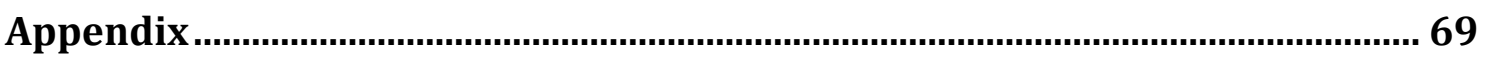

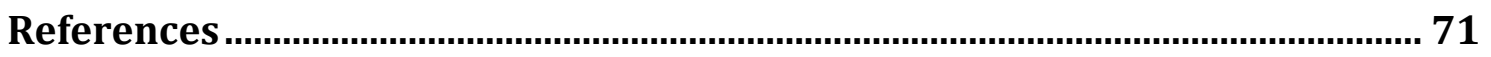




\section{List of Tables}

\section{Chapter Two}

2.3.1 Microsatellite primer information and annealing temperatures

\section{Chapter Three}

3.2.1 Sample collection sites within provinces 34

3.3.1 Outline of the new samples collected for this study 41

3.3.2 Summary of population information (mitochondrial DNA) 42

3.3.3 Measures of population differentiation using $\mathrm{G}_{\mathrm{ST}} \quad 44$

3.3.4 AMOVA results (mitochondrial DNA) 44

3.3.5 Results of Tajima's D and Fu's Fs tests 48

3.3.6 Summary of population information (microsatellite DNA) 50

3.3.7 Pairwise population comparisons using F $_{\mathrm{ST}} \quad 53$

3.3.8 Pairwise population comparisons using Jost's $D_{\text {est }}$ and G' ${ }_{\text {ST }}$

3.3.9 Population assignment, in provinces where $\mathrm{N}<20$

3.3.10 AMOVA results (microsatellite DNA) 55 


\section{List of Figures}

\section{Chapter One}

1.1

Three general types of population structure 9

1.2 Map of New Zealand showing major ocean currents

\section{Chapter Two}

Lengths of all 454 sequencing reads

\section{Chapter Three}

3.2 .1

3.3.2

3.3 .5

3.3 .6

3.3 .7

3.3 .8

3.3 .9

3.3.10

3.3 .11

3.3 .12

3.3 .13

3.3.14

\section{Appendix}

Appendix 1 Allele rarefaction curves for all microsatellite loci 69

Appendix 2 Visual comparison of haplotype networks
Delta K output from Structure analysis (Abel, Banks and Cook) 


\section{Chapter One}

\section{General Introduction}

\section{Connectivity and population structure}

Connectivity forms an important part of biological systems. It describes the connectedness of reproductive units (populations), which are the units of evolutionary change in a species. Connectivity links a variety of biological disciplines, including evolution, population genetics, dispersal and migration, as well as conservation (Kool et al., 2013). Historically, connectivity has been defined as the degree to which the landscape facilitates movement among resource patches (Taylor et al., 1993), but has since been revised to include the importance of larval settlement, post-larval survival and contribution to the gene pool in marine environments (Pineda et al., 2007). Population structure describes the degree to which populations are subdivided (Meirmans \& Hedrick, 2011). Species that exhibit population structure have some degree of disconnection from one another, and can therefore be genetically or demographically disconnected (Ovenden, 2013).

Understanding the levels of population connectivity of a species can have many useful applications. It can inform many aspects of the marine environment as oceanic dispersal cannot often be observed directly, due to the logistical challenges in studying the large and complex three-dimensional structure of the ocean (Unsworth et al., 2008). Identifying levels of connectivity has particular applications in the fishing industry: recent work to identify biological units, and matching them to managed units has gained popularity, as an attempt to reduce the likelihood of stock depletion from overfishing (Branch et al., 2011). Connectivity can inform the management of invasive species when the potential dispersal abilities of a species can be mapped, and management actions taken (Handley et al., 2011). In designing marine protected areas, information about connectivity can be used to predict levels of local recruitment and the carrying capacity of a particular protected area (Moland et al., 2013). 

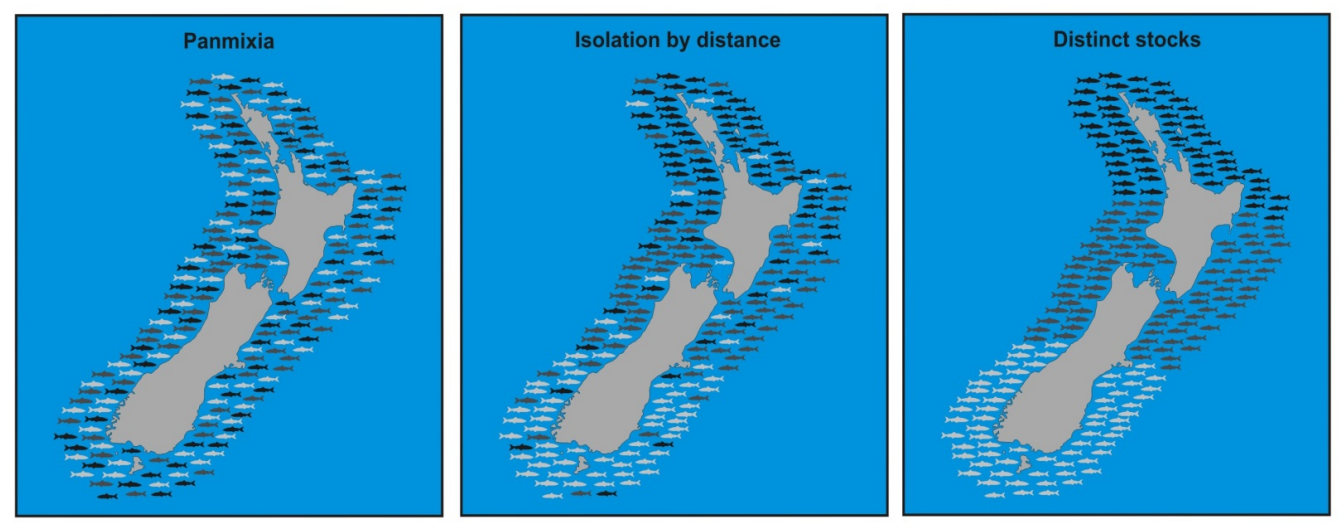

Figure 1.1 Three general types of population structure, as adapted from Laikre et al (2005). Representations of homogenous populations (panmixia, left), continuous variation (isolation by distance, centre) and genetically distinct stocks (right) are shown.

Patterns of population structure can generally be classified in three ways (Laikre et al., 2005). Firstly, populations can be genetically homogenous over space: this form of population structure contains large enough levels of gene flow that populations can be classified as a single panmictic unit. Secondly, the genetic composition of populations changes gradually over space: this is also known as isolation-by-distance. Thirdly, individuals can form distinct populations, where small levels of gene flow cause genetic divergence between populations (Figure 1.1). Phylogeographic splits between distinct populations can arise from ecological or historical separation, limiting gene flow from one population to another (Wallis \& Trewick, 2009).

Population structure and connectivity in marine environments can be studied in both direct and indirect ways. Direct methods of study can include tagging or tracking individuals, as well as isotopic analysis. Tagging and tracking individuals can be useful in identifying breeding grounds or migratory routes of a species (Drenner et al., 2012). Isotopic analysis, where the ratios of trace elements are analysed in an individual and matched to a location, such as a harbour or river, can reveal natal origins of individuals (Morrison, 2008). These direct methods of study tend to provide precise information about individual organisms, and do not necessarily reflect the behaviour of all individuals in that species. Additionally, 
these analyses can be time-consuming and costly, and logistically difficult in the case of tracking studies in particular (Drenner et al., 2012). Indirect methods of studying population structure and connectivity, such as genetic analyses, can provide a larger scope for analysis of a larger number of individuals (Ovenden, 2013). Genetic studies are often used to assess connectivity due to the difficulties in measuring dispersal at large spatial scales (Lowe \& Allendorf, 2010). Various genetic markers can be used to study population structure, and the ideal marker depends largely on the scope and aims of the project and the intended analyses (Schlotterer, 2004).

\section{Population genetic marker types}

The genetic marker used in a study can determine the resolution of population structure that can be detected. In the past, most population genetic studies have used neutral molecular markers, because the genetic patterns observed in these markers are expected to reflect the evolutionary processes of genetic and migration that act on the whole genome (Laikre et al., 2005). Loci influenced by selection can only provide information about the selective pressures acting on that particular part of the genome, and some of the patterns seen may only be applicable to the locus studied (Avise, 2004). However, studying markers under selection can reveal information about types of selective pressures and areas that promote local adaptation. In some cases, studying local adaptation can help to explain physiological differences within a species, by studying single nucleotide polymorphisms, and correlating them with environmental variation (Coop et al., 2010; Dionne et al., 2008).

It can be advantageous to use more than one type of molecular marker in genetic population analyses. Some studies that have used both mitochondrial DNA and nuclear DNA to estimate a population's effective size found discrepancies depending on the marker that was used. These differences were attributed to features of the species' life history and behaviour (Schlotterer, 2004). For example, in species with sex biased dispersal, where females are largely philopatric and males disperse, calculations of population size using mitochondrial DNA were 
smaller than when using nuclear DNA (Peters et al., 2012). Using multiple marker types in a study can be useful in species that have sex-biased dispersal or are hermaphroditic, since the different features of various marker types can reveal more information about patterns of inheritance, reproduction and dispersal (Kolleck et al., 2013).

The most common molecular markers used in studies of population structure are mitochondrial DNA and microsatellite DNA (Meirmans \& Hedrick, 2011). Mitochondrial DNA sequencing involves identifying haplotypes of a particular region of the mitochondrial genome. The non-coding control region (or D-loop) is popular, as it typically contains regions that are less constrained by negative mutations than protein-coding genes (Portnoy \& Heist, 2012). Mitochondrial DNA is maternally inherited, and is advantageous in that haplotypes are unlikely to be identical unless the individuals are related (Hughes et al., 2013). Mitochondrial DNA has been widely used in phylogeographic studies as it can detect genetic differences within a species. Comparing mitochondrial haplotypes can also have the power to detect populations that had been historically separated but have now re-joined, due to the unbroken and unrecombined matrilineal lineages of mitochondrial DNA (Avise, 2004).

Microsatellite DNA (also known as short tandem repeats) has gained popularity recently as a tool to study genetic structure (Selkoe \& Toonen, 2011). Microsatellite repeats tend to be highly polymorphic, which offers greater resolution when studying population structure, and are distributed throughout the genome. If levels of polymorphism are adequately high, it may be possible to conduct kinship analyses by comparing the genotypes of different loci (Waldbieser \& Bosworth, 2013). Microsatellites can be prone to homoplasy, where identical individuals are not necessarily identical due to descent, but due to converging mutations (Dickey et al., 2013). Additionally, it can be a costly process to screen for and develop microsatellite loci, since they are commonly species-specific; although recent work has focused on developing microsatellites that can be employed across a range of species in the same genus or family for this reason (Gardner et al., 2011). It can be unclear whether the number of repeats in a microsatellite locus 
changes in a step-wise way (the step-wise mutational model), or whether they can jump to any size (the infinite allele model), which is a limitation in the use of microsatellite markers. This limitation can be countered by applying both models during data analysis.

Fine-scale population differentiation can be more easily detected using markers with greater resolution, such as microsatellite markers (Harrison et al., 2014). However, the choice of molecular marker largely depends on the aims of the project. To fully understand connectivity in a species, it can be useful to employ both direct and indirect studies: such as genetics coupled with otolith microchemistry. Genetic methods can provide insight to demographic connectivity when genetics is combined with data about migratory behaviour, and reproductive success (Lowe \& Allendorf, 2010; Ovenden, 2013).

\section{Marine population connectivity}

In the past, it was generally held that populations of oceanic species were largely open, and therefore showed no population structure, due to the ability of ocean currents to disperse larvae or eggs from different populations over long distances, and the ability for the adults of some species to swim from one location to another (Kool et al., 2013). The opposite has been found in coral reefs: a study that involved chemical tagging of tropical clownfish and butterflyfish found that up to $60 \%$ of larvae self-recruited to the natal reef (Almany et al., 2007). Several factors have been suggested as important in determining whether a population will show population structure or not, including the pelagic larval duration and reproductive habits of a species, habitat patchiness and the oceanic currents around particular habitats (Pinsky et al., 2012). It is not yet clear which of these factors is more important, since it is impossible to study these factors in isolation, and the interactions between life history and environment can be difficult to untangle (Lowe \& Allendorf, 2010).

Biological factors that can determine population structure are related to a species' life history. One of the most commonly suggested factors is the pelagic larval 
duration (PLD), since an organism that spends a longer period of time in the plankton will have a greater chance of being dispersed further (Mora et al 2012; Treml et al., 2012). The PLD is sometimes cited as the only factor that influences population structure, but there are several other factors of a species' life cycle and life history that also influence population structuring. Firstly, species that have actively swimming larvae (larvae that are able to swim against water movements, rather than passively swimming larvae which cannot) are more able to select a habitat, and therefore may show less connectivity with other populations (McManus \& Woodson, 2012). It is also important to know about the spawning patterns of a species. Spawning aggregations, in which individuals from many different locations gather to spawn at an established site, can allow for gene flow between individuals from many geographically disparate populations. For example, shallow population structure was observed in the grouper Hyporthodus acanthistius, and this was linked to the species' spawning aggregations (Beldade et al., 2014). Additionally, philopatric species, in which individuals return to natal grounds for spawning, limits the degree of connectivity between populations, and is therefore expected to result in stronger genetic structuring (Kinitz et al., 2013).

Habitats that already have a well-established population of a particular species may limit genetic connectivity between habitats because there are limit opportunities for migrants to successfully integrate into the resident population (Waters et al., 2013). This is possible if a population has reached its carrying capacity in an area: even if an individual has dispersed to this habitat, it may not be able to recruit successfully due to the lack of available space, resources or available mates (Abesamis \& Russ, 2005). The amount of physical space available for an organism to occupy limits successful recruitment: in the case of sessile or territorial species, all available physical spaces in an environment may be occupied, and very little or no successful recruitment will occur. The amount of food that is available to a population can also limit the degree of successful recruitment. Limited food supplies can cause intraspecific competition, and recruits are likely to be excluded from access to food resources (Bertness, 1989). For example, populations of California spiny lobster are genetically differentiated even though they have a long PLD and no geographic barriers to gene flow were 
observed (Iacchei et al., 2013). It was thought that high levels of local recruitment restricted the number of larvae from other populations that were able to settle in each habitat, thereby reducing the level of observed genetic connectivity, even though current flows facilitated connectivity.

Non-biological factors can also determine levels of population connectivity. An important factor is the system of currents that operate around the species' range: strong offshore currents can sweep larvae away from natal grounds, and currents may restrict the range of locations that an individual from a particular population can be dispersed to (Galarza et al., 2009).

Connectivity in the marine environment has been studied extensively in New Zealand. New Zealand waters encompass sub-tropical, temperate and subAntarctic climates (Ross et al., 2009). Major current systems divide as they reach New Zealand, creating smaller surface currents, shown in Figure 1.2. These currents interact with local geography, as well as variable tides, winds and waves, making phylogeography difficult to predict (Ross et al., 2009). Deeper water currents around New Zealand can also carry larvae: whether a species has larvae that inhabit shallow or deep waters will influence the phylogeography of the species. Ocean current patterns in New Zealand have been hypothesised as the cause of phylogeographic breaks in species that have low dispersal abilities (Apte \& Gardner 2002; Wallis \& Trewick, 2009).

A review of genetic population structure studies in New Zealand found that of the 29 species analysed, eight taxa showed no genetic differentiation, 16 taxa showed north-south differentiation, and four taxa showed east-west differentiation (Ross et al., 2009). This result suggests that population structure is influenced strongly by the life history of a species: the pelagic larval duration, whether larvae are active or passive swimmers, and the presence or absence of mass spawning aggregations. 


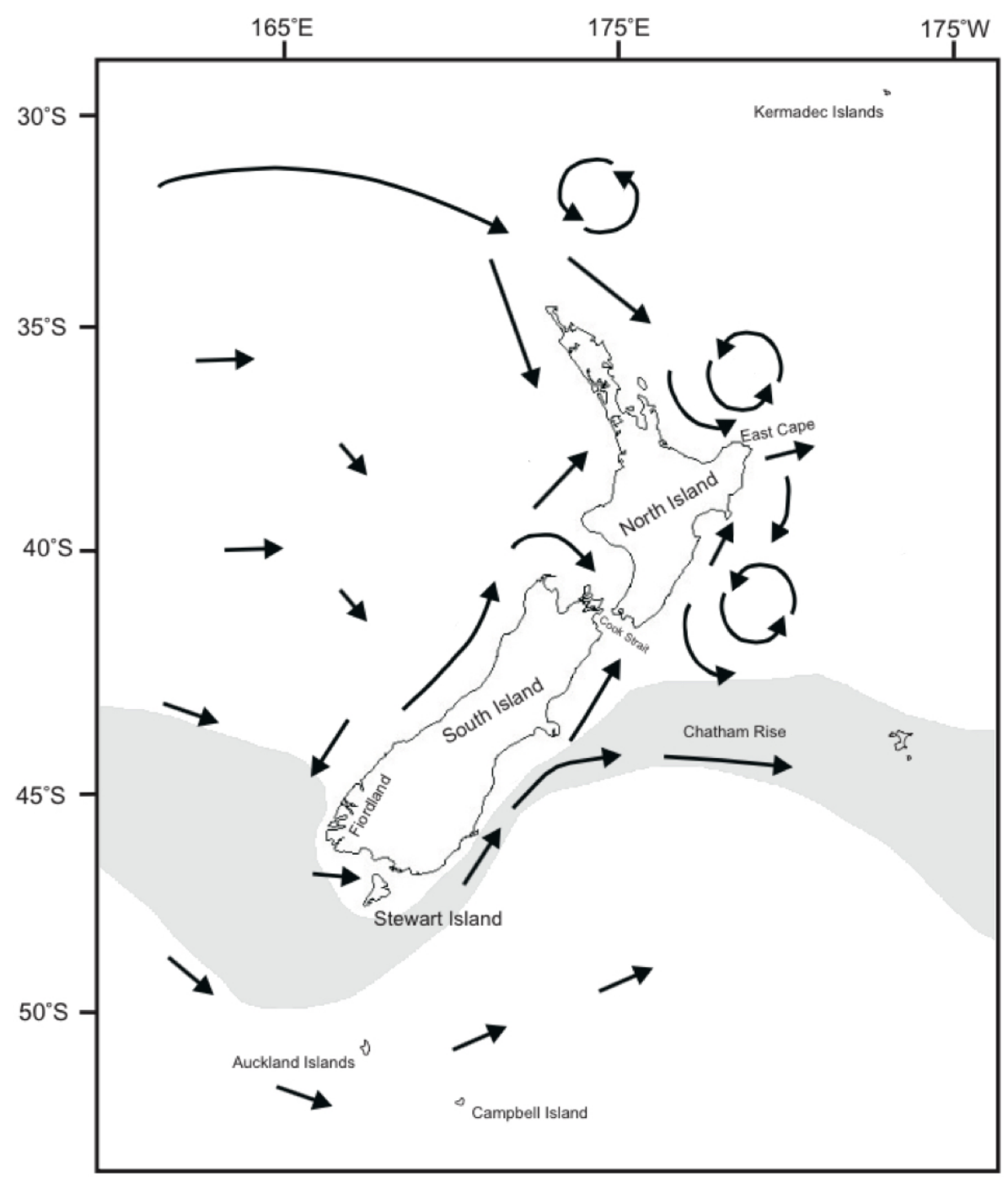

Figure 1.2 Map of New Zealand showing major ocean currents (adapted from Ross et al., 2009). The grey band represents the sub-tropical convergence, a joining of sub-Antarctic and sub-tropical waters.

In a review by Ross et al (2009), phylogeographic breaks were identified in several species, where gene flow is restricted over a particular area. Various causes of these phylogeographic breaks have been suggested, including the strong tidal flows and turbulent mixing of Cook Strait, and regions of upwelling. Cook Strait is the most commonly cited cause of phylogeographic breaks (Waters \& Roy, 2004). It has been suggested that regions of upwelling around the $42^{\circ} \mathrm{S}$ latitude line, which crosses the northern part of the South Island, act as a barrier to gene flow between North Island and South Island populations of certain species (Apte \& Gardner, 2002). However, in the multiple studies of invertebrates and vertebrates, 
no phylogeographic breaks have been identified that are common to all species (Ross et al., 2009).

Study species: Notolabrus celidotus (New Zealand spotty)

The New Zealand spotty, Notolabrus celidotus, is an endemic member of the wrasse family (Labridae). The Labridae family is the second largest marine fish family, and is one of the most diverse families in terms of morphology and ecology in the world, containing over 500 species in 70 genera (Cowman et al., 2009; Westneat \& Alfaro, 2005). Notolabrus celidotus is distributed throughout New Zealand, including Stewart Island, but it has not been recorded in New Zealand subAntarctic Islands or the Chatham Islands. It is a sister species to the New Zealand banded wrasse (Notolabrus fucicola), another common reef species. Spotties can grow up to $25 \mathrm{~cm}$ in length, and are the most common demersal fish on coastal rocky reefs (Willis \& Anderson, 2003). Spotties are not commercially fished in New Zealand, due to the small size and the difficulty of removing the flesh from the bones (Scott, 2010), but are often caught by children fishing from wharves (personal observations).

Notolabrus celidotus is a protogynous hermaphroditic species, a reproductive feature that is common to other wrasse species. All $N$. celidotus fish begin life as females, and the sex change is usually accompanied by a change in colour (Jones, 1980). Almost all male $N$. celidotus individuals occupy the 'terminal phase' of the life cycle: some fish change sex prematurely to become males, and are able to mimic females to gain access to territories and mating opportunities (Jones, 1980). The sex change occurs around 4-5 years of age. Notolabrus celidotus eggs hatch after 5-10 days (Welsford et al., 2004), and the larval duration of $N$. celidotus is estimated to be as long as five months (Scott, 2010). Juvenile fish are dependent on macroalgal forests on rocky reefs as a nursery habitat, particularly Ecklonia radiata algae (Choat \& Ayling, 1987; Jones, 1984a). Higher levels of juvenile recruitment have been observed in kelp forests than rocky reefs or sediment flats, and the fish are negatively affected by decreases in kelp density (Anderson \& Millar, 2004). There is also some association with seagrass beds as juvenile 
habitats (Parsons et al., 2013). Notolabrus celidotus utilise a wider range of habitats as they grow, and adults are most closely associated with rocky reefs (Jones, 1984b). Density-dependent growth and mortality appear to restrict the input of juveniles to adult populations when recruitment is high (Jones, 1984a).

Notolabrus celidotus feed on a wide range of small invertebrates, including copepods, amphipods and small molluscs (Jones, 1980). Certain bivalves and crabs account for a large part of the diet (Russell, 1983). Juveniles tend to feed on amphipods in kelp forests, while adult $N$. celidotus use their forward-jutting teeth to rake food from rocky reef substrates. The diet of $N$. celidotus was found to differ between shallow turf flats and deeper reef flats (Jones, 1988). The first detailed analyses of a New Zealand rocky reef species, in terms of its population dynamics and demography, were conducted on $N$. celidotus, due to its ubiquity in reef communities (Jones, 1988).

Only one study to date has investigated the population genetics of $N$. celidotus. An analysis of the mitochondrial genome control region found no differentiation between populations around New Zealand (Scott, 2010), and the results suggested that $N$. celidotus populations were expanding. The suggested explanation for the expanding populations of $N$. celidotus was the long pelagic larval duration allowing for high levels of gene flow.

The aims of the thesis research

The general aim of this thesis study is to increase understanding of the population genetics of Notolabrus celidotus. The first section of this study, Chapter Two, describes the development of novel microsatellite markers for $N$. celidotus. Nextgeneration sequencing methods were used to identify 17 potential microsatellite loci, which were tested for polymorphisms and amplification success. This resulted in the successful development of six microsatellite loci.

Chapter Three expands the previous genetic work of Scott (2010) in analysing the genetic population structure of $N$. celidotus. Individuals were added to previously 
reported sequence data for more thorough analyses of mitochondrial DNA, including individuals from regions that had not been previously sampled. This chapter also details the genetic analyses of the microsatellite loci developed in Chapter Two. This chapter aims to determine the levels of genetic diversity, as well as investigate the population structure and demographic history of $N$. celidotus populations based on various analyses of mitochondrial DNA and microsatellite loci. Chapter Four discusses the results and applications of this study. 


\section{Chapter Two}

\section{Development of novel microsatellite markers for $\boldsymbol{N}$. celidotus}

\subsection{Introduction}

Since their discovery around 30 years ago, microsatellite markers have become a popular genetic marker for ecological and evolutionary studies (Guichoux et al., 2011). They have become popular for a number of reasons: firstly, they are highly polymorphic. Secondly, microsatellites are abundant and widely distributed throughout a genome, which means they give a general impression of the levels of variation across the genome, and are not biased towards particular regions of the genome (Avise, 2004). However, there are often high costs associated with developing microsatellite markers, as they tend to be species-specific. There can also be some technical difficulties associated with designing and optimising primers (Miah et al., 2013). Recent work has focussed on markers that can be used across species and genera, in order to reduce the cost and time of developing new microsatellite markers (Barbara et al., 2007).

Many applications of microsatellite DNA genotyping have been reviewed in the literature (Chistiakov et al., 2006; Dudgeon et al., 2012). Particularly in regard to fish species, microsatellite DNA has been able to offer insights into population connectivity, relatedness indices of natural populations and population dynamics. These markers have been used in identifying genetic structure to inform fisheries management (Ensing et al., 2013), as well as aiding in discriminating cryptic species (Harrison et al., 2014). The polymorphic and codominant features of microsatellite markers offer information about patterns of reproduction and recruitment in species where this cannot often be studied directly. These include parentage analysis, identifying natal populations, and measuring levels of larval transport (Berry et al., 2012). 
Next-generation sequencing is a technique that offers rapid and cost-effective processing of genomic DNA, compared to older microsatellite identification techniques. Previous methods involved highly labour-intensive cloning methods that could only target a few types of microsatellite marker: next-generation sequencing can detect all types of microsatellite, and is usually conducted by an external sequencing service (Kang et al., 2013). This technique consists of digesting a whole genome into small fragments or reads, which are then sequenced (Ellis et al., 2011). A previously popular sequencing method was Roche 454 Sequencing: this method tends to produce larger average size fragments than other methods, which increases the likelihood of a fragment containing a repeating section having adequate space on the flanking regions of the repeat to allow for primer design (Abdelkrim et al., 2009). However, this method is now obsolete, and other methods such as Illumina Sequencing have become popular due to the low costs and high sequence yields that can be obtained (Zavodna et al., 2014).

The aim of the research presented in this chapter was to develop novel microsatellite markers for Notolabrus celidotus, for use in genotyping analysis. 


\subsection{Materials and methods}

This chapter describes the process of developing microsatellite loci for Notolabrus celidotus. Selection of suitable loci and optimisation of laboratory protocols were completed by Angela Fleming and Jack Du. Additional analyses of the original dataset were completed by the author.

DNA was extracted from one $N$. celidotus individual using a standard phenolchloroform protocol (Sambrook et al., 1989). The purified DNA was sent to Otago University's High Throughput DNA Sequencing Unit, and run on the Roche 454 Genome Sequencer FLX system. The resulting library consisted of over 160,000 reads. These reads were analysed in Geneious 8.0.5 (Kearse et al., 2012) to determine appropriately sized reads containing repeating sections. The Geneious plug-in Phobos (http://www.rub.de/spezzoo/cm/cm_phobos.html) was used to identify the number and type of repeat sequences. Sequence reads containing repeating sections were detected with QDD (Meglecz et al., 2010), and primers were designed for the selected reads by Primer3 (Koressaar \& Remm, 2007; Untergasser et al., 2012). Primer3 returned the data in an Excel file, consisting of around 22,000 repeats with primer pairs. The number of repeat motifs in each sequence read was calculated in Tandem Repeats Finder (Benson, 1999).

Potential microsatellite candidate loci were ranked based on a number of factors. These included the length and motif type of the repeating sequence, as well as features of the primers: the matching of forward and reverse primer melting temperatures and GC content. The position of the repeat sequence in the genome was also considered, to allow for pool-plexing design. Imperfectly repeating sequences (such as (AT) ${ }_{7} \mathrm{GC}(\mathrm{AT})_{10}$ ) can lead to some inconsistencies in identifying alleles, since multiple sequences can correspond to a single length fragment

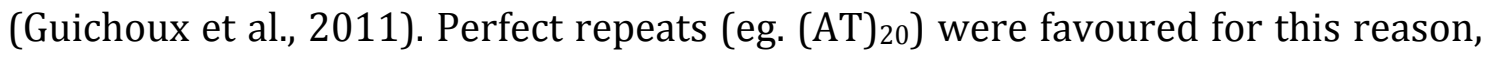
and perfect repeats mean the microsatellite locus follows the stepwise mutational model, which is useful in further analysis of genetic structure and relatedness. Smaller motif types (such as dinucleotide and trinucleotide repeats) are often preferred when designing multiple microsatellite loci for one species: it allows for 
greater efficiency when designing multiplexing or poolplexing combinations (Guichoux et al., 2011). However, small motifs, particularly dinucleotide repeats, are prone to stutter bands, which are often attributed to DNA polymerase slippage during amplification. Stutter bands make allele peaks difficult to discern. Larger motif types, such as pentanucleotide and hexanucleotide repeats, allow for clearer interpretation of allele sizes, due to the gaps between possible allele sizes being greater (Chistiakov et al., 2006).

Seventeen potential microsatellite loci were selected for further analysis based on these factors, and the computed primer sequences were synthesised. The locus primer pairs were tested by PCR amplification of 20 individuals from six locations. Firstly, loci were amplified separately for PCR optimisation, then a M13 fluorescently-labelled primer labelled with VIC, FAM or PET dyes was added, and the samples sent for genotyping at Massey University Genome Service. This step was carried out to analyse loci separately for the range of allele sizes present, and to identify polymorphic loci.

PCRs consisted of $67 \mathrm{mM}$ Tris- $\mathrm{HCl} \mathrm{pH} 8.8,16 \mathrm{mM}\left(\mathrm{NH}_{4}\right)_{2} \mathrm{SO}_{4}, 2.0 \mathrm{mM} \mathrm{MgCl}, 0.2$ mM dNTPs, $0.1 \mathrm{mM}$ forward primer, $0.3 \mathrm{mM}$ reverse primer, $0.3 \mathrm{mM}$ fluorescentlylabelled M13 primer, $0.4 \mu \mathrm{g} / \mu \mathrm{L}$ Bovine Serum Albumin (BSA), one unit of BIOTAQ $^{\mathrm{TM}}$ DNA Polymerase (Bioline) and $1 \mu \mathrm{L}$ of template DNA in $15 \mu \mathrm{L}$ volumes. Thermocycling conditions were $95^{\circ} \mathrm{C}$ for 10 minutes, 30 cycles of $94^{\circ} \mathrm{C}$ for 30 seconds, $54^{\circ} \mathrm{C}$ for 30 seconds and $74^{\circ} \mathrm{C}$ for 30 seconds, followed by an additional 8 cycles of $94^{\circ} \mathrm{C}$ for 30 seconds, $53^{\circ} \mathrm{C}$ for 30 seconds and $74^{\circ} \mathrm{C}$ for 30 seconds. The final eight cycles allowed for the binding of the fluorescently labelled M13 primer, when it was used. This was followed by a final extension time of 10 minutes at $72^{\circ} \mathrm{C}$. The amplified products were confirmed after electrophoresis in $3 \%$ agarose gel, staining in ethidium bromide and viewing under a UV light source.

Purified amplified products were then sent to Massey University Genome Service, and the allele sizes identified using an ABI3730 Genetic Analyzer. The GeneScan ${ }^{\mathrm{TM}}$ 500 LIZ $^{\text {TM }}$ Size Standard was used for fragment sizing, and allele peaks were viewed and analysed in Genemarker (http://www.softgenetics.com). Allele sizes 
were exported into an Excel worksheet, where the alleles were placed manually into 'bins' set for each allele. All loci were checked for the presence of null alleles, large allele dropout and scoring errors in Microchecker 2.2.3 (van Oosterhout et al., 2004). Deviation from Hardy-Weinberg equilibrium and linkage disequilibrium were measured in Arlequin 3.5 (Excoffier \& Lischer, 2010). After analysing the loci, pool-plexing combinations were identified by Multiplex Manager 1.2 (Holleley \& Geerts, 2009). 


\subsection{Results}

The sequence library generated from 454 sequencing contained 162,855 reads, ranging from 52 base pairs to 1200 base pairs in length. The reads had a mean length of 513.2 base pairs, with a standard deviation of 97.2 (Figure 2.3.1). Nucleotide frequencies for all reads were $\pi_{\mathrm{A}}=0.290, \pi_{\mathrm{C}}=0.206, \pi_{\mathrm{G}}=0.217, \pi_{\mathrm{T}}=$ 0.285 . Approximately 150,000 reads were over 400 base pairs in length, which is a suggested minimum read length to allow for primer design on either side of the repeat sequence. Searching the sequence reads in the Phobos 3.3.12 revealed 67,465 dinucleotide repeats, 80,269 trinucleotide repeats, 47,335 tetranucleotide repeats and 36,699 pentanucleotide repeats. Approximately 22,000 repeats were selected as potential candidates for microsatellite loci by QDD (Meglecz et al., 2010) and the corresponding primer pairs were identified by Primer3 (Untergasser et al., 2012). 44\% of these sequence reads contained one repeat motifs, $15 \%$ contained two separate repeat motifs and $9.6 \%$ contained three separate motifs. The frequency plot is shown in Figure 2.3.2. The largest number of repeats detected in one read was 34 .

Seventeen potential loci were selected for primer synthesis. These loci consisted of six dinucleotide repeats, eight trinucleotide repeats and three tetranucleotide repeats, and were labelled Spot01 to Spot17. Eleven loci failed to amplify or were found to not be polymorphic. The six polymorphic loci remaining that amplified correctly consisted of one dinucleotide repeat, three trinucleotide repeats and two tetranucleotide repeats. Optimisation of PCR thermocycling conditions identified the following annealing temperatures: $60^{\circ} \mathrm{C}$ for Spot07, Spot11, Spot13, Spot 14 and Spot17, and $54^{\circ} \mathrm{C}$ for Spot05. The six selected loci did not show any signs of null alleles or deviation from Hardy-Weinberg equilibrium. 


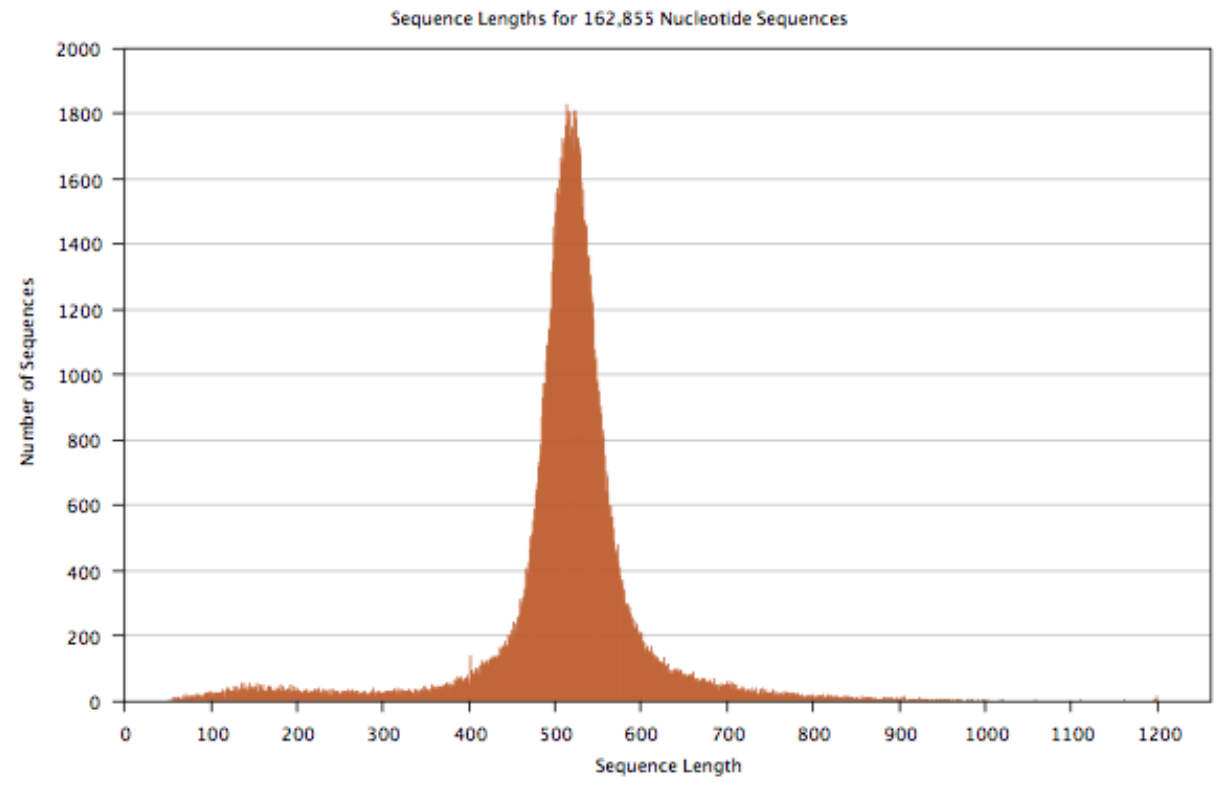

Figure 2.3.1 Sequence lengths for all 454 sequencing reads

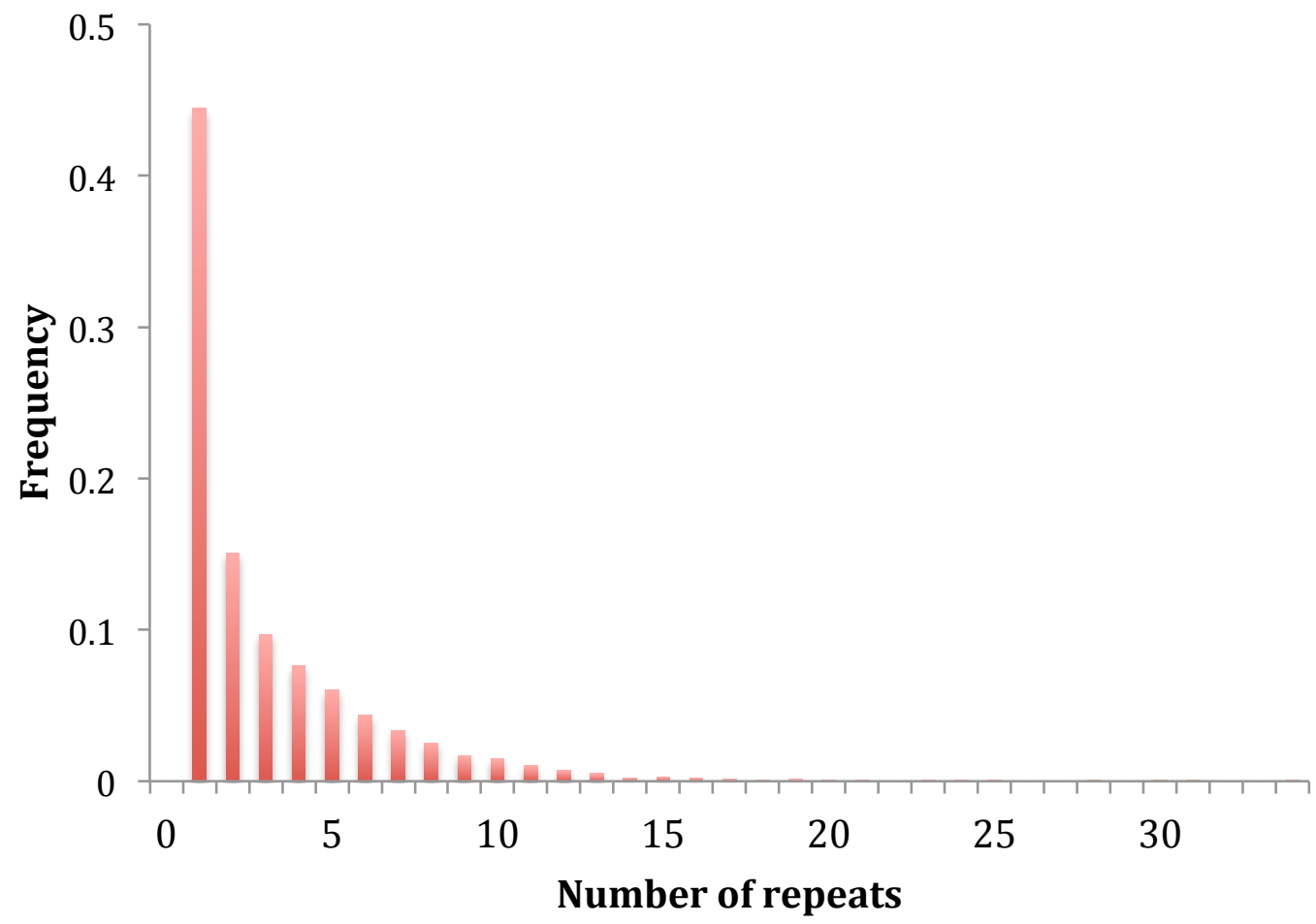

Figure 2.3.2 Frequency plot showing the number of repeat motifs within a sequence read, of the potential microsatellite loci that were evaluated. 


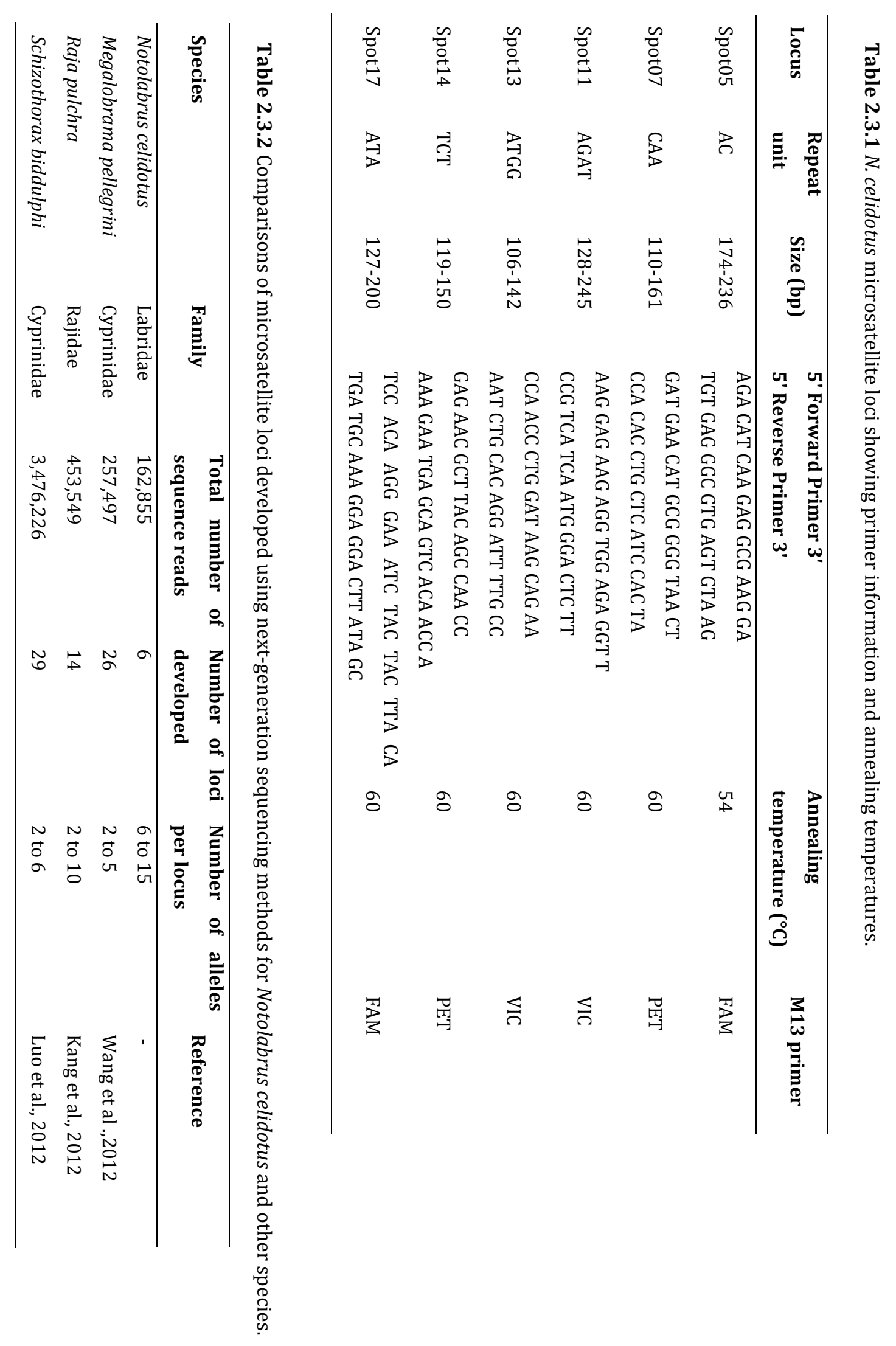


The results of this study reflect the microsatellite development of many other fish species (Table 2.3.2). The loci developed for Notolabrus celidotus in this study were found to be more polymorphic than other loci that have been developed using next-generation sequencing methods. The cyprinid species Megalobrama pellegrini and Schizothorax biddulphi had 26 and 29 loci developed respectively (Luo et al., 2012; Wang et al., 2012). However, the loci developed for these cyprinids showed low levels of polymorphism in these studies. The suggested causes of the low genetic diversity seen in $M$. pellengrini are the changes that in the Yangtze River (the species' native habitat), that arose from the construction of dams and from over-fishing (Wang et al., 2012). Fewer microsatellite loci were developed for Raja pulchra, but they were more polymorphic than the cyprinid species (Kang et al., 2012). 


\subsection{Discussion}

This study is the first to develop microsatellite loci for Notolabrus celidotus, with six microsatellite loci being successfully identified and developed. Over 162,000 Roche 454 sequencing reads revealed around 22,000 potential microsatellite loci, and 17 loci were selected for primer synthesis. The final selection of microsatellite loci showed adequate levels of polymorphism and no evidence of null alleles or deviation from Hardy Weinberg equilibrium.

In this study, loci were pool-plexed, which involved amplifying each locus separately then combining certain loci for analysis. A different method, known as multiplexing, where multiple loci are amplified in the same PCR reaction, is becoming increasingly popular (Guichoux et al., 2011). Developing suitable multiplexing combinations can be time-consuming and costly, but programs are available that can optimise primer design to allow for PCR condition matching, ultimately saving resources once they are developed (Jennings et al., 2011). Future work on $N$. celidotus could focus on developing multiplexes for genotyping: this may already be possible due to the relative consistency of annealing temperatures identified (Table 2.3.1).

In recent times, efforts have been made to develop microsatellite loci that are transferable between species (Kalia et al., 2011). The transferability of microsatellite markers can depend on features of the organism being studied: a review of transferable markers found that animal microsatellites generally have greater transferability than plant microsatellites (Barbara et al., 2007). Transferability of microsatellites is also more likely among closely related species (Kang et al., 2013). Success in developing transferable markers has been observed in some families of fish: Sparidae (Reid et al., 2012) and Cyprinidae (Gigliarelli et al., 2012). If the microsatellite markers developed in this study are found to be transferable, it is possible that genetic studies of closely related species, such as Notolabrus fucicola (New Zealand banded wrasse), could be undertaken using these loci, avoiding the costs and time required to develop novel microsatellites. There already appears to be evidence of marker transferability among different 
genera of wrasses (Gardner et al., 2011). This suggests that the loci developed in this study may have the potential to be used in other wrasses.

Next generation sequencing techniques have enabled the rapid and cost-effective development of microsatellite markers in a range of organisms (Treangen \& Salzberg, 2012). In fish, microsatellites are developed for a range of reasons: utilising microsatellite markers enables fine-scale population differentiation to be identified, and the resulting population genetic analyses can be applied to fisheries, conservation management and invasive species (Abdul-Muneer, 2014). The results of this study were compared with other fish species where microsatellites had been successfully developed using next-generation sequencing methods and found that although fewer loci were developed, they were found to contain higher levels of polymorphisms in initial analyses (Table 2.3.2). Loci that are highly polymorphic have the power to detect finer-scale population structuring than other markers (Guichoux et al., 2011). The levels of polymorphism found in this initial genotyping study suggest that the microsatellite loci that have been developed for Notolabrus celidotus will be able to detect any fine-scale population structure that is present in this species, when the markers are used in subsequent genetic population analyses. 


\section{Chapter Three}

\section{Analysis of population structure and demographic history using mitochondrial DNA and microsatellite DNA markers}

\subsection{Introduction}

Levels of genetic connectivity between populations are influenced by a number of factors. In the marine environment, the pelagic larval duration (PLD) is a commonly attributed factor for explaining differences in genetic connectivity: species with a longer PLD tend to have a weaker population structure, due to the ability of the larvae or eggs to move greater distances before maturation and recruitment (Selkoe \& Toonen, 2011). Non-biological factors that influence genetic connectivity relate to the physical conditions that an organism is exposed to during its dispersal phase. In marine systems, oceanic currents and upwelling patterns largely influence the dispersal of larvae, particularly those that cannot swim against currents: larval movement will be largely determined by currents and/or storm events, although in some cases larvae might only encounter suitable habitats for recruitment by chance (Huey et al., 2014). Additionally, the physical and chemical conditions encountered at sea can play a part in the connectivity of a species. If an organism can only survive in a narrow range of environmental conditions (eg. temperatures or salinity levels) it is more likely to show high levels of population structure because the risks of mortality or failed reproduction are high (Galarza et al., 2009).

Population genetic studies of fish have been used to understand how the marine environment appears to influence gene flow and levels of variation. The results for these types of studies have been used to inform fisheries and conservation management, and piece together how oceanographic processes structure the distribution of biota (Ovenden, 2013). The higher mutation rate, smaller effective population size and maternal inheritance of mitochondrial DNA (mtDNA) has made it a useful marker in studying gene flow (Okumus \& Ciftci, 2003). Because 
the mitochondrial genome is maternally inherited and does not undergo recombination, it can be used to study the demographic history of populations. For example, populations that were isolated thousands of years ago but have recently come back into contact, can still retain the historic patterns of isolation as distinct mtDNA lineages (Avise, 2004). Microsatellite DNA, a popular nuclear DNA marker used in population genetic studies, is bi-parentally inherited. These markers comprise short repeating sections of DNA, and are highly polymorphic, allowing for finer-scale detection of population differentiation compared to mtDNA markers (Guichoux et al., 2011). Microsatellite loci can be highly specific: often, microsatellite loci will need to be independently developed for each species, which adds considerable costs and time to the research (Morgan \& Rogers, 2001).

New Zealand has a complex coastal environment that includes rocky shores, sandy shores, mudflats and mangrove forests (Ross et al., 2009). Genetic studies have been carried out on a range of New Zealand coastal marine organisms, but there has been inconsistency among the reported positions of phylogeographic breaks (summarised by Ross et al., 2009). New Zealand spotties (Notolabrus celidotus) are an endemic species of wrasse (Family: Labridae) and the most common demersal fish in New Zealand rocky reef ecosystems. They are one of the most abundant benthic carnivores, and consume a variety of small invertebrates, including copepods, amphipods and small molluscs (Jones, 1984a). The adults can grow up to $25 \mathrm{~cm}$ long and the juveniles are largely dependent on kelp forests for nursery grounds (Perez-Matus \& Shima, 2010). The widespread distribution and common occurrence of this coastal, shallow water species make it an ideal model fish species for studying the population genetic structure of New Zealand coastal communities.

The first population genetic study of $N$. celidotus used mitochondrial DNA (mtDNA) control region sequencing and reported a lack of population differentiation between sampled locations around New Zealand (Scott, 2010). However, the scope of the analyses and genetic markers in that study was somewhat limited. The aim of the research presented in this chapter was to expand the sampling of the previous data set, conduct a more comprehensive set of analyses, and include 
nuclear microsatellite DNA markers. The specific aims of the research presented in this chapter were to:

1) Increase coverage of New Zealand $N$. celidotus populations by adding the mtDNA control region sequences from additional individuals and locations, and conducting a more comprehensive phylogeographic analysis.

2) Analyse genotyping data from nuclear microsatellite DNA loci to determine the levels of variation and gene flow among $N$. celidotus sample locations.

The sampling and laboratory methods reported in this chapter were carried out with the assistance of other researchers. 


\subsection{Materials and methods}

\subsubsection{Sample collection}

A total of 103 new individual $N$. celidotus samples were collected by Jack Du and Hayden Smith from nine sample sites across six biogeographic provinces in New Zealand, including the previously unsampled Banks province (Figure 3.2.1). Sample collection site information is shown in Table 3.2.1.

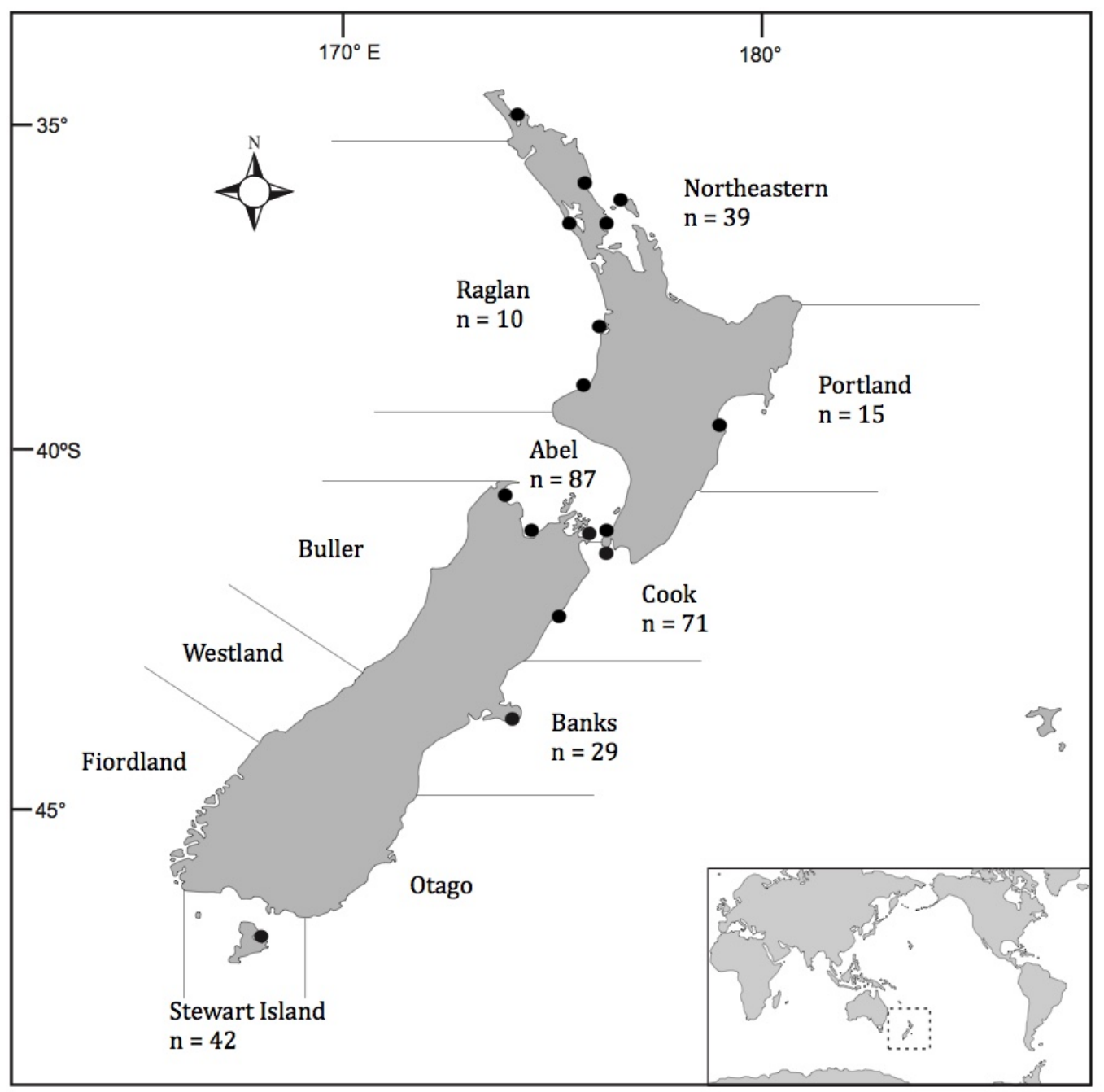

Figure 3.2.1 Map of New Zealand showing province boundaries (as proposed by Shears et al., 2008) and the number of samples collected from each province. Black dots represent sample collection sites. 


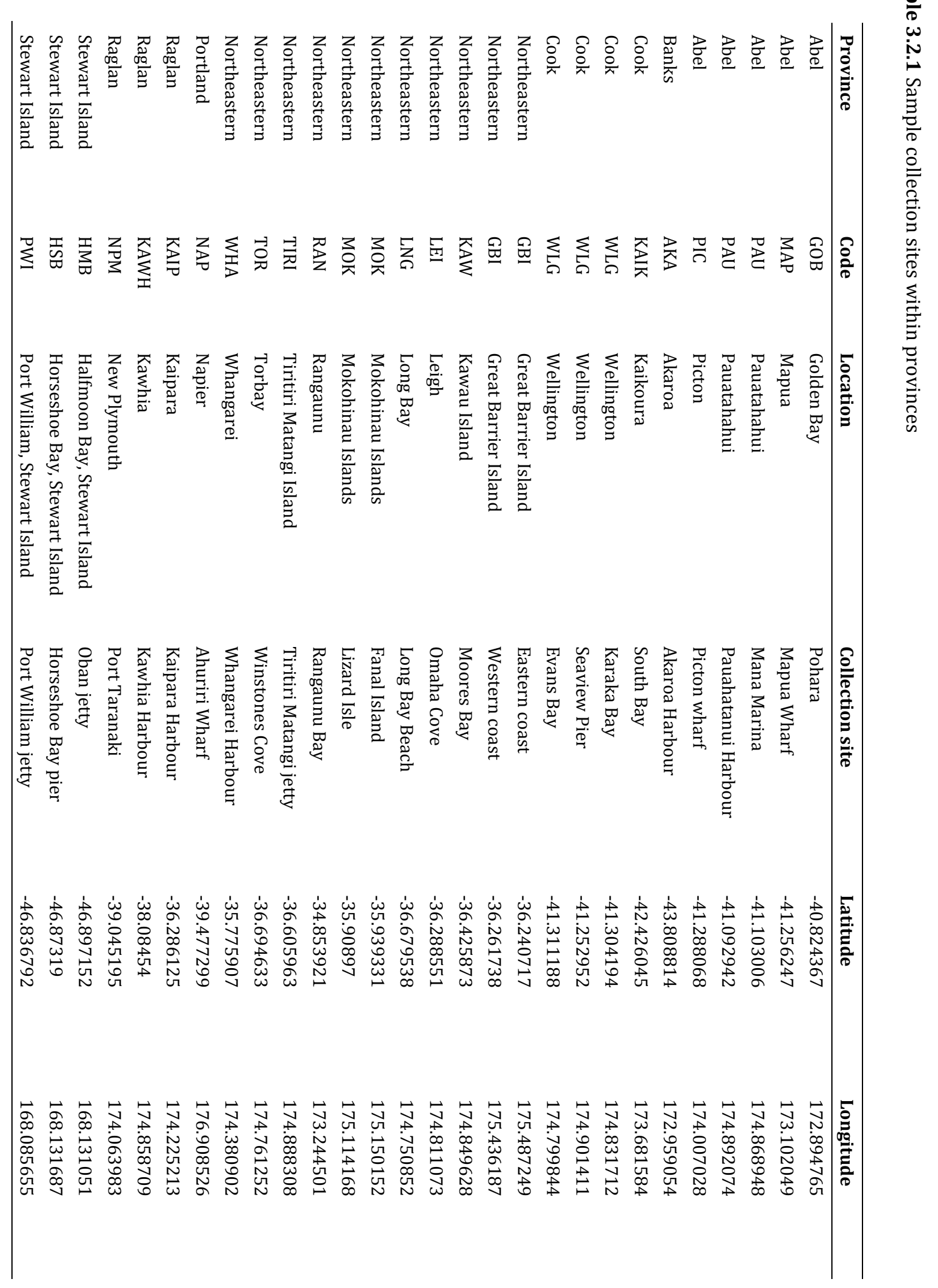




\subsubsection{Mitochondrial DNA sequencing}

With the assistance of Jack $\mathrm{Du}$, genomic DNA was extracted using a standard phenol-chloroform method (Sambrook et al., 1989). Species-specific mitochondrial DNA primers were used (Scott 2010). The forward primer (5'-AAT TAA GCT ACG CGA GCA GTT G-3') and reverse primer (5'-TYT AAC TCC CAC CCC TAA CTC C-3') were used to amplify a 790-base pair section of the mitochondrial control region between tRNA-Phe and tRNA-Pro. Polymerase chain reactions (PCR) consisted of $67 \mathrm{mM}$ Tris- $\mathrm{HCl} \mathrm{pH}$ 8.8, $16 \mathrm{mM}\left(\mathrm{NH}_{4}\right)_{2} \mathrm{SO}_{4}, 1.5 \mathrm{mM} \mathrm{MgCl}_{2}, 800 \mu \mathrm{M}$ dNTPs, $0.4 \mu \mathrm{M}$ each forward and reverse primers, $0.6 \mu \mathrm{g} / \mu \mathrm{L}$ Bovine Serum Albumin (BSA), 0.6 units of BIOTAQ ${ }^{\mathrm{TM}}$ DNA Polymerase (Bioline) and $1 \mu \mathrm{L}$ template DNA in $15 \mu \mathrm{L}$ volumes.

Thermocycling conditions consisted of an initial denaturation period of $94^{\circ} \mathrm{C}$ for 30 seconds, followed by 35 cycles of $94^{\circ} \mathrm{C}$ for 30 seconds, $52^{\circ} \mathrm{C}$ for 30 seconds and $74^{\circ} \mathrm{C}$ for one minute. This was followed by a final extension time of 10 minutes at $74^{\circ} \mathrm{C}$. Amplification was confirmed by electrophoresis of samples through a $1 \%$ agarose gel, staining with ethidium bromide and viewing under a UV light source. PCR products were purified with ExoSAP-it and sequenced using an ABI 3730 Genetic Analyzer (Massey University Genome Services).

\subsubsection{Microsatellite DNA genotyping}

With the assistance of Angela Fleming, DNA was extracted from samples using the same standard phenol-chloroform method described in Section 3.2.2. The PCR primers used for each locus are described in Table 2.3.1. All loci were amplified separately, in PCR reactions consisting of $67 \mathrm{mM}$ Tris- $\mathrm{HCl} \mathrm{pH} 8.8,16 \mathrm{mM}$ $\left(\mathrm{NH}_{4}\right)_{2} \mathrm{SO}_{4}, 2.0 \mathrm{mM} \mathrm{MgCl} 2,0.2 \mathrm{mM}$ dNTPs, $0.1 \mathrm{mM}$ forward primer, $0.3 \mathrm{mM}$ reverse primer, $0.3 \mathrm{mM}$ fluorescently-labelled M13 primer, $0.4 \mu \mathrm{g} / \mu \mathrm{L}$ Bovine Serum Albumin (BSA), one unit of BIOTAQ ${ }^{\mathrm{TM}}$ DNA Polymerase (Bioline) and $1 \mu \mathrm{L}$ of template DNA in $15 \mu \mathrm{L}$ volumes. 
Thermocycling conditions were $95^{\circ} \mathrm{C}$ for 10 minutes, 27 cycles of $94^{\circ} \mathrm{C}$ for 30 seconds, annealing temperature (Table 2.3.1) for 30 seconds and $74^{\circ} \mathrm{C}$ for 30 seconds, followed by an additional 8 cycles of $94^{\circ} \mathrm{C}$ for 30 seconds, $53^{\circ} \mathrm{C}$ for 30 seconds and $74^{\circ} \mathrm{C}$ for 30 seconds. The final eight cycles allowed for the binding of the fluorescently labelled M13 primer. This was followed by a final extension at $72^{\circ} \mathrm{C}$ for 10 minutes. The amplified products were viewed after electrophoresis in $3 \%$ agarose gel, staining in ethidium bromide and viewing under a UV light source.

The PCR products were pool-plexed into two combinations of loci, and the pooled amplicons were genotyped using an ABI3730 Genetic Analyzer (Massey University Genome Service). The GeneScan ${ }^{\mathrm{TM}} 500$ LIZ $^{\mathrm{TM}}$ Size Standard was used for fragment sizing, and allele peaks were viewed and analysed in Genemarker (http://www.softgenetics.com/GeneMarker.html). Allele sizes were exported into an Excel worksheet, where the alleles were placed manually into 'bins' set for each allele.

\subsubsection{Mitochondrial DNA sequence analysis}

\section{Genetic diversity}

Mitochondrial DNA control region sequences were aligned using the ClustalW algorithm implemented in MEGA6 (Tamura et al., 2013). Summary statistics for the levels of variation at each sample location were determined using DnaSP 5.10.1 (Librado \& Rozas., 2009): the number of polymorphic sites, the number of total and private haplotypes, the haplotypic diversity and average nucleotide diversity, and the average number of nucleotide differences among samples from each sample site. Haplotype rarefaction curves were calculated using Analytic Rarefaction 1.3 (http://strata.uga.edu/software). 


\section{Population structure}

The level of genetic differentiation between provinces was determined using pairwise calculations of GST (Nei, 1973). This estimate of differentiation determines the difference between sample locations based on the presence and absence (and the frequency) of haplotypes, rather than nucleotide-level differences between haplotypes. The analysis was conducted in Arlequin 3.5 (Excoffier \& Lischer., 2010) and levels of significant were assessed using 110 permutations. The values of $\mathrm{G}_{\mathrm{ST}}$ were also displayed in a multi-dimensional scaling plot, implemented in the Excel plug-in XLSTAT (http://www.xlstat.com/en/download.html).

Genetic diversity was measured among and within populations with Analyses of Molecular Variance (AMOVA) implemented in Arlequin 3.5. All population groupings were tested with 10,000 permutations. Three population groupings were tested: 1) Two regions: North Island and South/Stewart Island samples, 2) Two regions: Northern and Southern sample sites divided at the $42^{\circ}$ latitude line, 3) Two regions: Eastern and Western sample sites. These population subdivisions were based on putative phylogeographic breaks in New Zealand's coastal environment (Ross et al., 2009).

An isolation-by-distance (IBD) analysis was undertaken by comparing the pairwise $\mathrm{G}_{\text {ST }}$ with the shortest marine distance (measured in $\mathrm{km}$ ) between these sample sites. Previous analyses had only compared provinces; the analysis conducted in this study compared individual sample sites within those provinces. This approach was chosen because it was important to have a precise geographic location for the comparisons, instead of analysing the averaged distances between provinces. Samples from Stewart Island and the Auckland regions were each analysed as single sample sites, because of the close proximity of the sample locations within each area. Some sample sites were excluded from the IBD analysis because of the low number of samples available: locations with fewer than 10 samples (including New Plymouth, Pauahatanui and Kawhia) were not included in the IBD analysis to minimise the potential for bias, and because these sample sites were not in close proximity to any other sample locations. The pairwise comparisons were based on 
the $\mathrm{G}_{S \mathrm{~T}}$ estimates of genetic difference and the shortest marine geographic distances (measured in $\mathrm{km}$ ) estimated using Google Earth 7.1. The significance of the correlation between genetic and geographic distances was determined using a Mantel test with 10,000 replicates that was implemented on the Isolation by Distance Web Service (Mantel, 1967; Jensen et al., 2005).

A Minimum Spanning Network was constructed using PopART (http://popart.otago.ac.nz). Haplotype distribution was also displayed in a haplotype frequency distribution plot, showing the proportion of private haplotypes in each geographic province, as well as the proportion of haplotypes that are shared with other provinces.

\section{Demographic history}

Tests for a mutation-drift balance were conducted, which can be used to determine whether population size has been stable or there has been a significant bottleneck or expansion event. Tajima's D, Fu's $F_{S}$ statistics and a mismatch distribution were calculated using DnaSP 5.10.1.

Effective population size was calculated using the formula $\theta=2 \mathrm{~N}_{\mathrm{e}} \mu$, where $\theta$ is the level of diversity present, and $\mu$ is the mutation rate per site per generation. From a conservatively estimated 5\% change per million years in the wrasse family (Ludt et al., 2012) and a generation time of two years for $N$. celidotus (Scott, 2010), $\mu$ was estimated at $1.2 \times 10^{-5}$. The $\theta$ values used in the calculations were calculated in DnaSP, and were based on the nucleotide diversity, number of segregating sites and total number of mutations.

BEAST v1.8 was used to generate Bayesian skyline plots that showed a timestamped population history (Drummond et al., 2012). The chain length was 50 million iterations with a burn-in time of five million iterations. The mutational model that best fits that data set was determined using jModelTest (Darriba et al., 2012; Guindon \& Gascuel, 2003). Based on previous studies of Ludt et al (2012), the substitution rate was conservatively set to $5 \%$ per million years. The resulting 
skyline plot and the post-posterior Bayesian information were viewed using Tracer (http://beast.bio.ed.ac.uk/Tracer).

\subsubsection{Microsatellite DNA genotype analysis}

\section{Genetic diversity}

The presence of null alleles and scoring errors was assessed using Microchecker 2.2.3 (van Oosterhout et al., 2004). Deviations from Hardy-Weinberg Equilibrium in all populations and loci were tested in GenoDive 2.0b27 (Meirmans \& Van Tienderen, 2004) with $10^{4}$ permutations. Pairwise tests of linkage disequilibrium were carried out in Arlequin 3.5 (Excoffier \& Lischer, 2010).

Estimates of the level of genetic diversity, including allelic richness, observed and expected levels of heterozygosity, numbers of private alleles and allele frequencies, were determined using GenoDive. Rarefaction curves for each locus were obtained using Analytic Rarefaction 1.3 (http://strata.uga.edu/software) and indicated whether a sample size was adequately large to capture the genetic variation present.

\section{Population structure}

Population differentiation was measured using several calculations: firstly Weir and Cockham's (1984) $\mathrm{F}_{\text {ST }}(\theta)$ test; $\mathrm{G}_{\text {ST: }}$ a comparison of heterozygosity within and between population, with a correction for bias that may occur from sampling a limited number of populations (Nei, 1987), and Jost's D, a measure of population differentiation that is not dependent on the amount of within-population diversity (Jost, 2008).

A factorial components analysis (FCA) was also calculated in GenoDive, to examine relationships based on pairwise $\mathrm{F}_{\mathrm{ST}}$. A population assignment analysis was implemented in GenoDive. This analysis determines which population an 
individual is most likely to come from, given the allele frequencies of that population (Paetkau et al., 1995). Individuals can only be assigned to populations where $\mathrm{N}>5$, so individuals from the Northeastern, Portland, Raglan and Stewart Island provinces were excluded from this analysis.

Three analyses of molecular variance (AMOVA) were carried out in Arlequin 3.5, to measure genetic diversity within and between groups of populations. All groupings were tested with 10,000 permutations. These population groupings were: 1) Two regions: North Island and South Island/Stewart Island samples, 2) Two regions: Northern and Southern sample sites divided at the $42^{\circ}$ latitude line, 3) Two regions: Eastern and Western sample sites. The population groupings were based on previously suggested phylogeographic breaks around the New Zealand coastline (Ross et al., 2009).

Bayesian Structure analysis was carried out in STRUCTURE 2.3.4 (Pritchard et al., 2000). This analysis assigns individuals to population clusters (K) based on the similarity of that individual to the allele frequencies characteristic of the cluster. The simulations were carried out 10 times for each value of $\mathrm{K}$ (the number of clusters), which ranged from $\mathrm{K}=1$ to $\mathrm{K}=7$. Each Markov Chain Monte Carlo simulation ran for $10^{5}$ iterations, with a burn-in period of $10^{4}$ iterations. Structure Harvester (Earl \& vonHoldt, 2012) was used to identify the most probable value of $\mathrm{K}$. 


\subsection{Results}

\subsubsection{Mitochondrial DNA sequencing}

DNA sequences were obtained from 103 individuals from nine sample sites in six provinces: when combined with previously reported sequences the total data set comprised 293 individuals sampled from seven provinces.

Table 3.3.1 Outline of the new samples collected for this study, and how many were collected from each province.

\begin{tabular}{lccc}
\hline Province & $\begin{array}{c}\text { Number previously } \\
\text { reported }\end{array}$ & Number added & $\begin{array}{c}\text { Total number of } \\
\text { samples }\end{array}$ \\
\hline Northeastern & 37 & 2 & 39 \\
Raglan & 7 & 3 & 10 \\
Portland & 13 & 2 & 15 \\
Cook & 19 & 52 & 71 \\
Abel & 72 & 15 & 87 \\
Banks & 0 & 29 & 29 \\
Stewart Island & 42 & 0 & 42 \\
Total & 190 & 103 & 293 \\
\hline
\end{tabular}

The section of the mitochondrial control region sequenced was 791 base pairs in length, and had 268 variable sites. Nucleotide frequencies were: $\pi_{\mathrm{T}}=0.293, \pi_{\mathrm{C}}=$ $0.174, \pi_{A}=0.274, \pi_{G}=0.260$. Overall nucleotide diversity was 0.01341 . There were 247 haplotypes present in the sampled sequences, of which 224 were private (restricted to a single province). The average haplotypic diversity was 0.998 . The haplotype rarefaction plot (Figure 3.3.1) does not show flattening of curves, which indicates that the sample sizes are not large enough to capture all the haplotypic variation present in $N$. celidotus populations. 
Table 3.3.2 Summary of population information. N: number of samples; S: number of segregating sites; $\mathrm{H}$ : number of haplotypes; $\mathrm{H}_{\mathrm{P}}$ : number of private haplotypes; $\mathrm{H}_{\mathrm{D}}$ : haplotype diversity; $\pi$ : nucleotide diversity.

\begin{tabular}{ccccccc}
\hline Site & $\mathbf{N}$ & $\mathbf{S}$ & $\mathbf{H}$ & $\mathbf{H}_{\mathbf{P}}$ & $\mathbf{H}_{\mathbf{D}}$ & $\boldsymbol{\pi}$ \\
\hline Raglan & 10 & 46 & 10 & 9 & 1 & 0.015 \\
Northeastern & 39 & 73 & 37 & 32 & 0.996 & 0.0108 \\
Portland & 15 & 45 & 15 & 12 & 1 & 0.011 \\
Cook & 71 & 155 & 65 & 48 & 0.997 & 0.0175 \\
Abel & 87 & 114 & 82 & 73 & 0.998 & 0.0117 \\
Banks & 29 & 181 & 29 & 20 & 1 & 0.0245 \\
Stewart Island & 42 & 66 & 40 & 30 & 0.997 & 0.0095 \\
& & & & & & \\
Total & 293 & 284 & 247 & 224 & 0.998 & 0.01341 \\
\hline
\end{tabular}

Pairwise $\mathrm{G}_{\mathrm{ST}}$ comparisons showed only one significant difference at the $5 \%$ level between all populations compared. This was the comparison between the Northeastern province and the Stewart Island province $(p=0.036)$. However, this value was not significant after completing a Bonferroni correction (Rice, 1989). No other populations showed significantly different values of population differentiation. The multi-dimensional scaling plot showed strong clustering of samples, indicating that there is little genetic difference between them (Figure 3.3.2).

An analysis of molecular variance showed that over $99 \%$ of the observed variability was contained within a population in all scenarios that were tested. This suggests a lack of genetic differentiation between populations, contrary to suggested positions of phylogeographic breaks that have been observed in other species (Ross et al., 2009). 


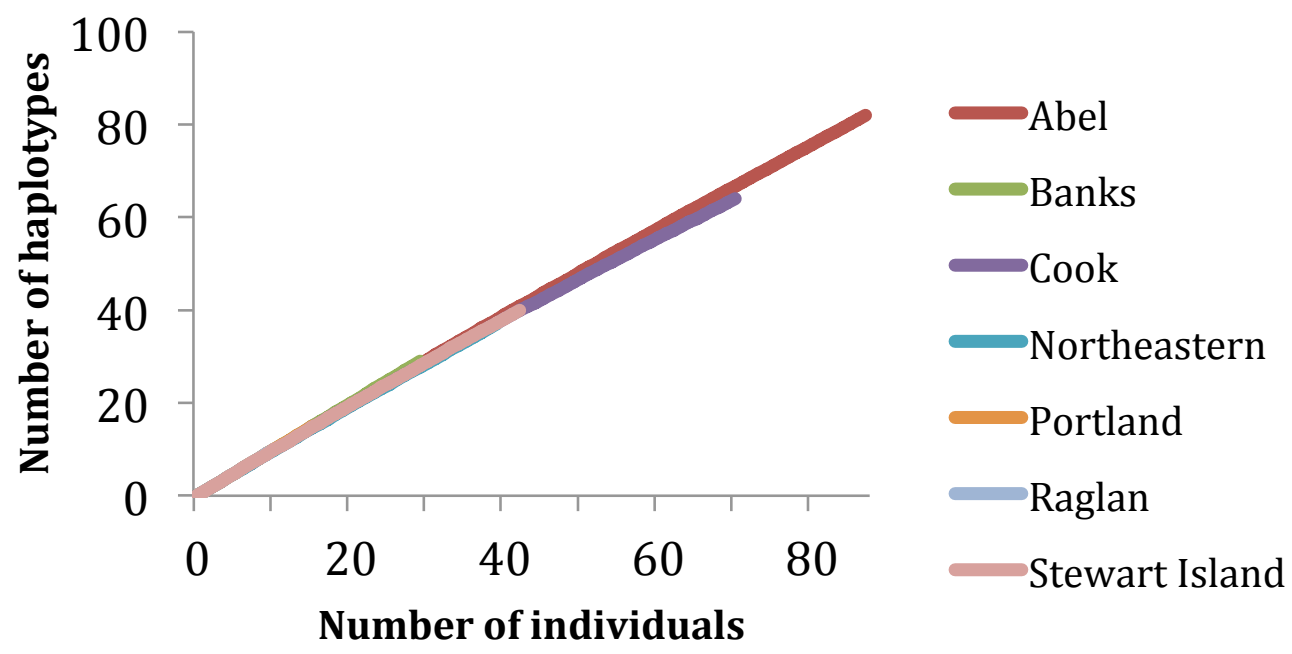

Figure 3.3.1 Haplotype rarefaction plot for $N$. celidotus individuals from various provinces.

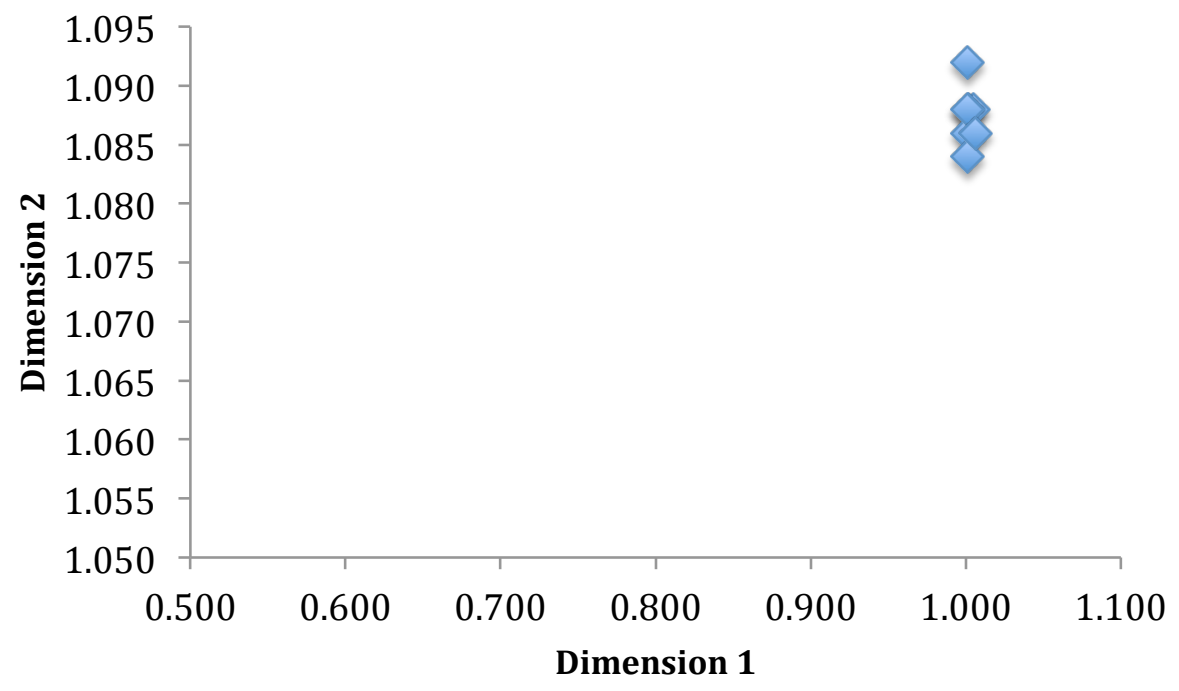

Figure 3.3.2 Multidimensional scaling plot of pairwise $G_{S T}$ values. Each dot represents a sample province. 


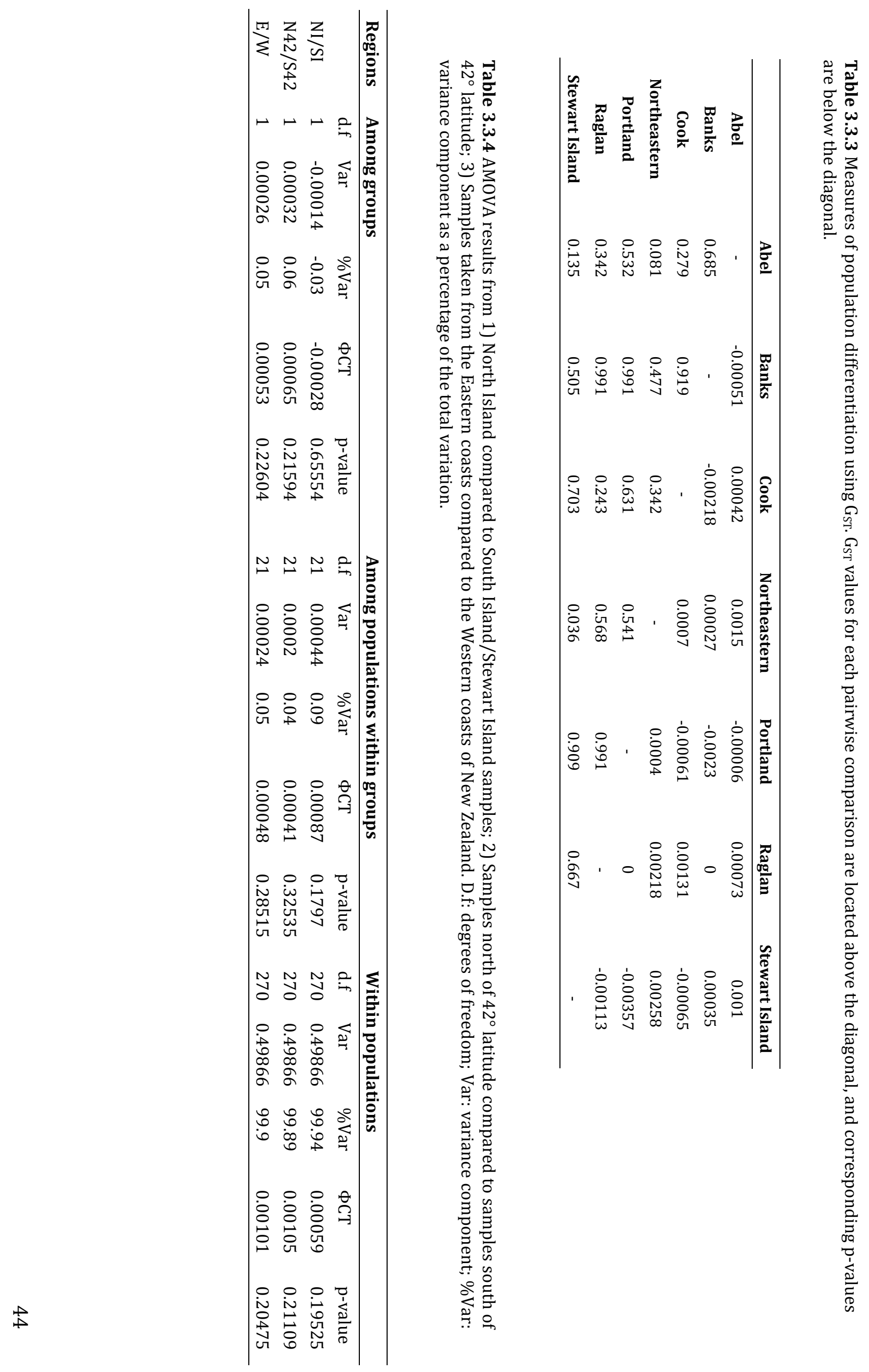


The isolation-by-distance analysis, presented in Figure 3.3.3, revealed no significant correlation between pairwise genetic differences and the shortest marine distance between the sample locations ( $p=0.7495)$. The Minimum Spanning Network calculated from the DNA sequences is complex, and shows the high number of haplotypes observed, and the low numbers of shared haplotypes (Figure 3.3.4). The haplotype distribution plot (Figure 3.3.5) shows high numbers of private haplotypes in each province; with a small number of haplotypes being shared among 2-4 other provinces.

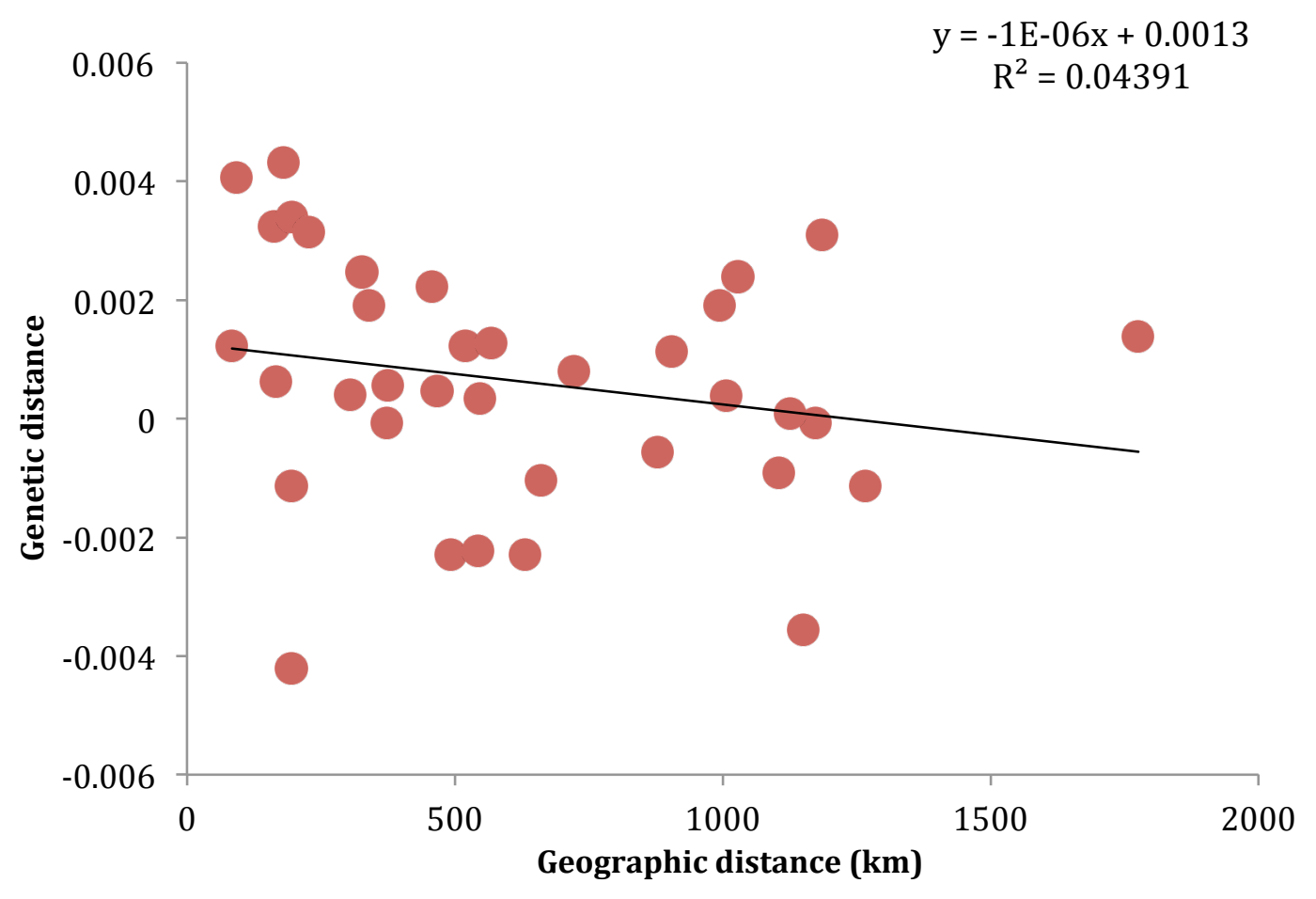

Figure 3.3.3 Isolation-by-distance graph comparing nearest geographic distance (kilometres) with genetic distance ( $\mathrm{G}_{\mathrm{ST}} / 1$ - $\mathrm{G}_{\mathrm{ST}}$ ) 


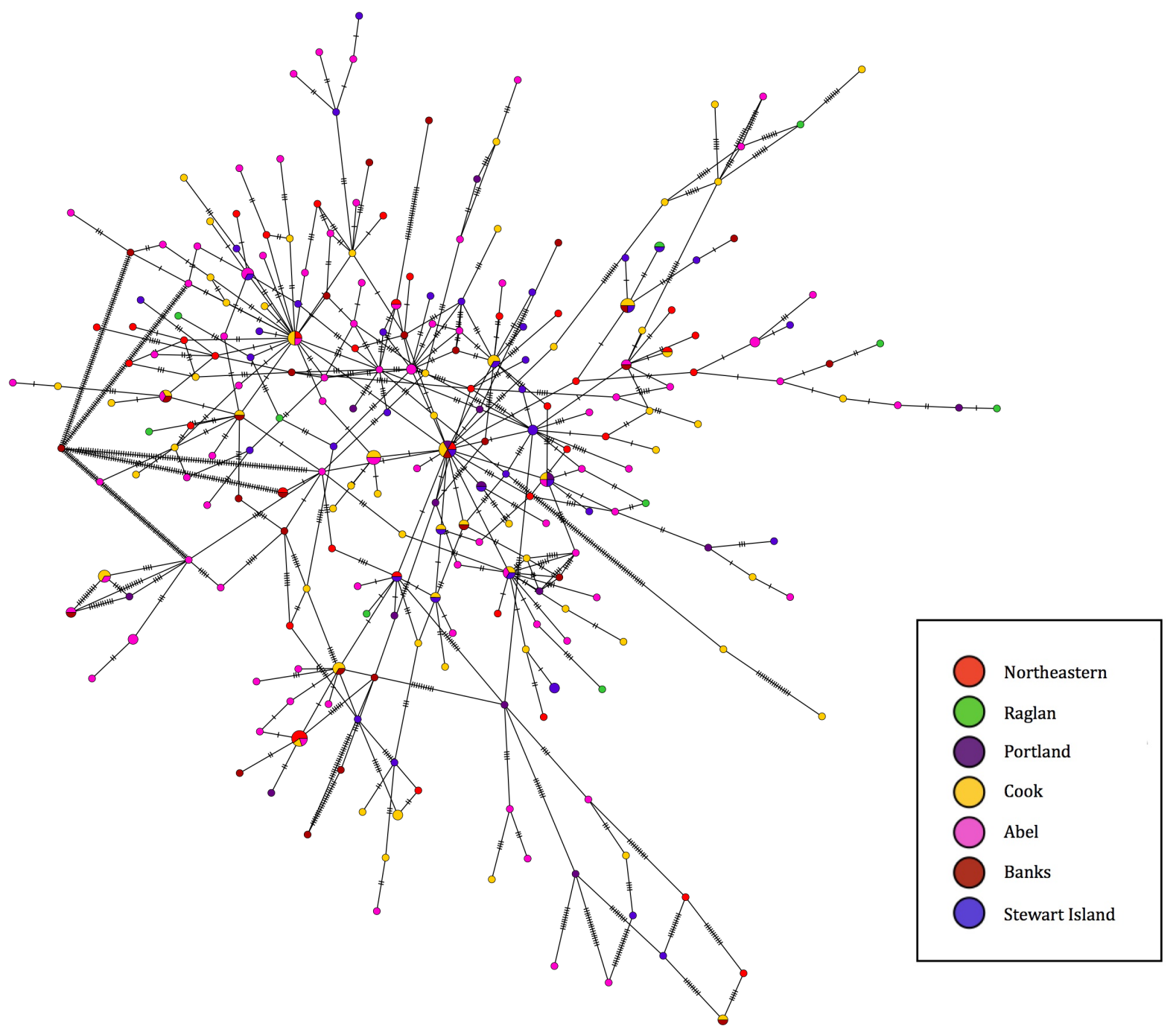

Figure 3.3.4 Minimum spanning network of all N. celidotus haplotypes. The size of the circle indicates the number of individuals that share the haplotype, and the colour of the circle represents the province the sample originated from. 


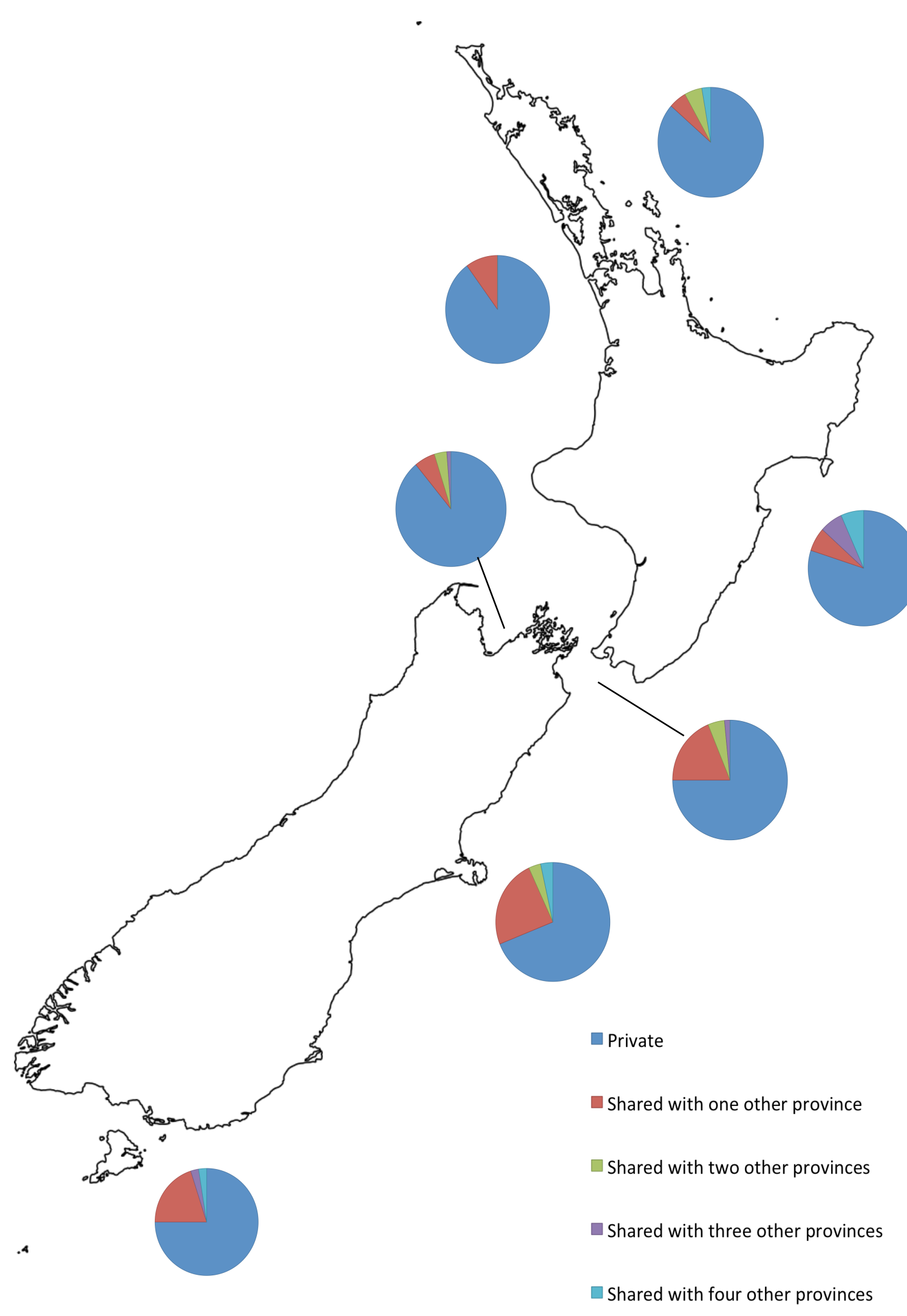

Figure 3.3.5 Private and shared haplotypes from each province. 
The results of Tajima's D and Fu's Fs tests show significantly negative values when all provinces are analysed together. However, when each province is analysed separately, the Raglan province does not show a significantly negative value (Table 3.3.5). Negative values of these tests can indicate recent population expansion, whereas statistics equalling 0 can suggest a lack of recent population expansion or decline (Tajima, 1989).

Table 3.3.5 Results of Tajima's D and Fu's $\mathrm{F}_{\mathrm{S}}$ tests. Values in bold are significant at the 5\% level.

\begin{tabular}{llllc}
\hline & Tajima's D & p-value & Fu's Fs test & p-value \\
\hline Abel & $\mathbf{- 1 . 9 8 6 2 8}$ & 0.003 & $\mathbf{- 2 4 . 6 0 7 8 2}$ & $<0.001$ \\
Banks & $\mathbf{- 2 . 2 5 2 5 9}$ & 0.002 & $\mathbf{- 1 4 . 8 5 2 2 7}$ & $<0.001$ \\
Cook & $\mathbf{- 1 . 9 9 4 8 4}$ & 0.008 & $\mathbf{- 2 4 . 2 7 0 8 8}$ & $<0.001$ \\
Northeastern & $\mathbf{- 1 . 8 5 6 0 6}$ & 0.011 & $\mathbf{- 2 4 . 8 3 5 0 7}$ & $<0.001$ \\
Portland & $\mathbf{- 1 . 5 7 9 8 6}$ & 0.049 & $\mathbf{- 8 . 2 5 9 9 5}$ & 0.001 \\
Raglan & -1.3375 & 0.107 & -3.02344 & 0.051 \\
Stewart Island & $\mathbf{- 1 . 8 0 3 4 4}$ & 0.014 & $\mathbf{- 2 4 . 9 8 5 5 3}$ & $<0.001$ \\
& & & & \\
All populations & $\mathbf{- 1 . 8 3 0 0 8}$ & 0.02771 & $\mathbf{- 1 7 . 8 3 3 5 6}$ & 0.00743 \\
\hline
\end{tabular}

The mismatch distribution analysis compared the expected and observed frequencies of pairwise differences (Figure 3.3.6). The raggedness statistic for the observed frequency plot is $r=0.0045$. A raggedness statistic of less than 0.03 is considered to be a smooth curve (Jobling et al., 2004). Smooth peaks in the observed frequency plot, as well as a unimodal distribution, can indicate a recent expansion in population size (Lopes et al., 2007). The Bayesian skyline plot showed a long period of stable population size followed by a slight decline, then a sharp population increase 150,000 years ago that appears to have been consistent since then (Figure 3.3.7).

Estimations of the effective population size of each province ranged from 800 to 3000 individuals, with a total size of around 8500 individuals. These calculated estimates appear to be too low when compared to the Bayesian skyline plot. It is possible that this is due to the presence of overlapping generations in N. celidotus: where more than one breeding generation is present in a mating system at a time. 


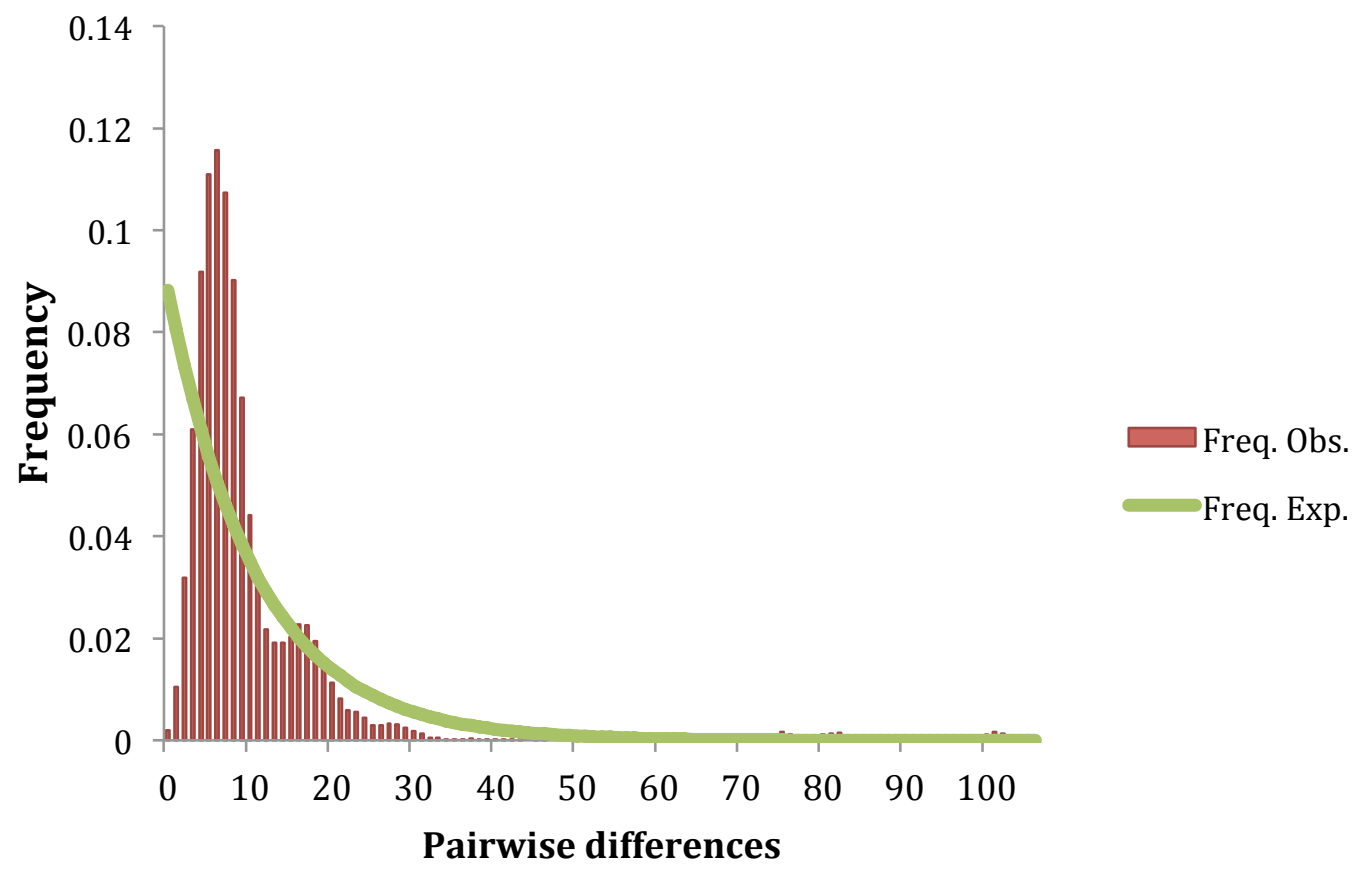

Figure 3.3.6 Mismatch distribution showing expected and observed frequencies of various pairwise differences.

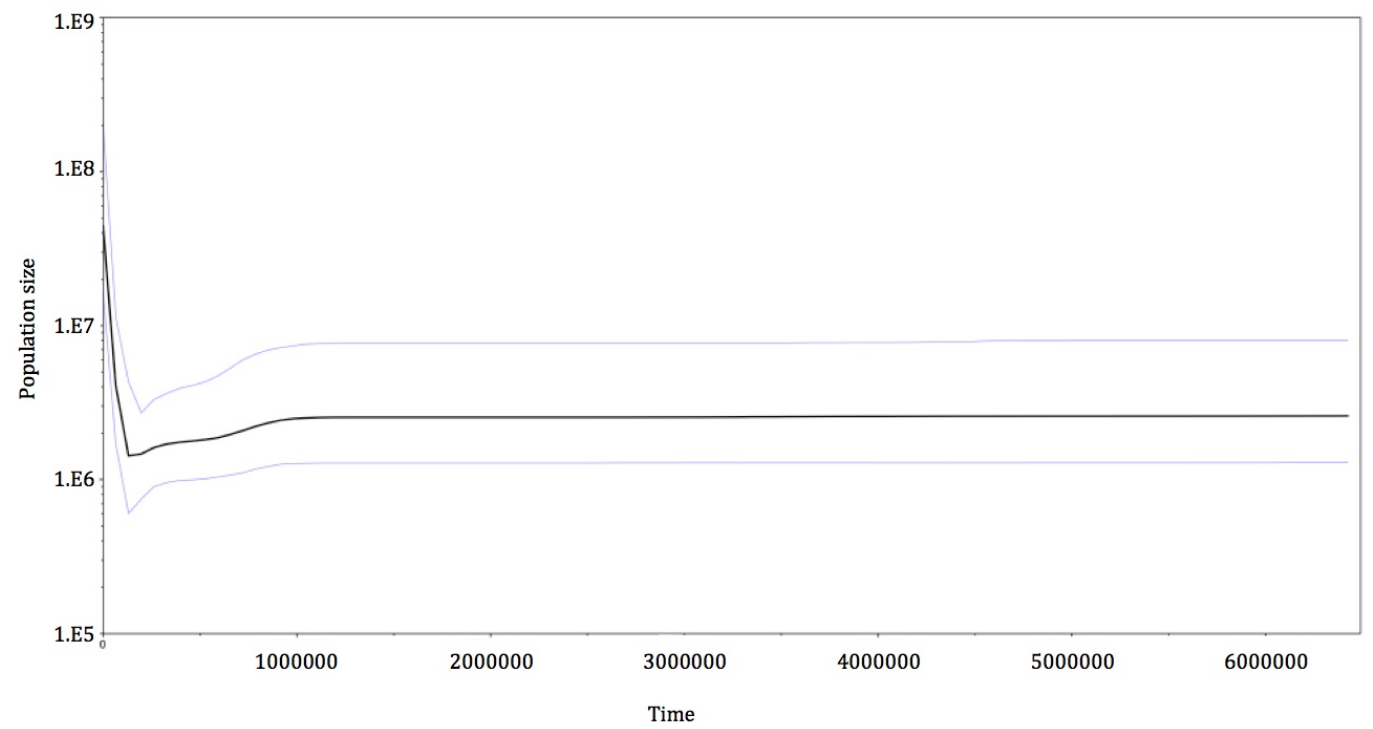

Figure 3.3.7 Bayesian skyline plot showing estimated population size and time (in years) since the present. Blue lines represent $95 \%$ confidence intervals. 


\subsubsection{Microsatellite DNA genotyping}

Six microsatellite loci were used to genotype 101 individuals from seven New Zealand provinces. Tests for homozygote excess showed some evidence for null alleles at the Spot13 locus, but no evidence was found for large allele dropout or scoring errors at the 95\% confidence interval at any loci. The summary statistics for each province are presented in Table 3.3.6. All loci were found to be highly polymorphic, with numbers of alleles ranging from 17 (Spot05 and Spot13) to 23 (Spot07). Expected heterozygosity ranged from 0.871 to 0.95 , and the observed heterozygosity ranged from 0.567 to 0.917 . The allele rarefaction plot for the most polymorphic locus, Spot07, is shown in Figure 3.3.8. The additional rarefaction plots are displayed in Appendix 1. Allele frequency plots are shown in Figure 3.3.9.

Individuals from the Raglan, Portland and Stewart Island provinces appear to deviate from Hardy-Weinberg equilibrium, however this is likely due to the low numbers of individuals sampled from these provinces. There is some evidence that the Spot11 locus also has some deviation from equilibrium, suggesting that this locus may not be neutral. There was no evidence of linkage disequilibrium observed between pairs of loci.

Table 3.3.6 Summary statistics of the microsatellite data collected. N: number of samples; $\mathrm{H}_{0}$ : observed heterozygosity; $\mathrm{H}_{\mathrm{E}}$ : expected heterozygosity; $\mathrm{A}_{\mathrm{avg}}$ : average number of alleles; $\mathrm{A}_{\mathrm{p}}$ : number of private alleles.

\begin{tabular}{llllll}
\hline Province & $\mathbf{N}$ & $\mathbf{H}_{\mathbf{0}}$ & $\mathbf{H}_{\mathbf{E}}$ & $\mathbf{A}_{\text {avg }}$ & $\mathbf{A}_{\mathbf{p}}$ \\
\hline Abel & 36 & 0.873 & 0.904 & 11.33 & 10 \\
Banks & 25 & 0.769 & 0.892 & 12.67 & 15 \\
Cook & 31 & 0.857 & 0.871 & 12.83 & 11 \\
Northeastern & 3 & 0.567 & 0.95 & 3.2 & 0 \\
Portland & 3 & 0.917 & 0.938 & 4 & 1 \\
Raglan & 2 & 0.625 & 0.875 & 3 & 0 \\
Stewart Island & 1 & --- & --- & -- & 0 \\
& & & & & \\
Total/Average & 101 & 0.758 & 0.891 & 19.5 & 27 \\
\hline
\end{tabular}


The allele rarefaction curves do not appear to reach a plateau for any of the microsatellite loci studied, which suggests that the sample sizes used in this study were too small to capture all the variation present in the population.

\section{Spot07}

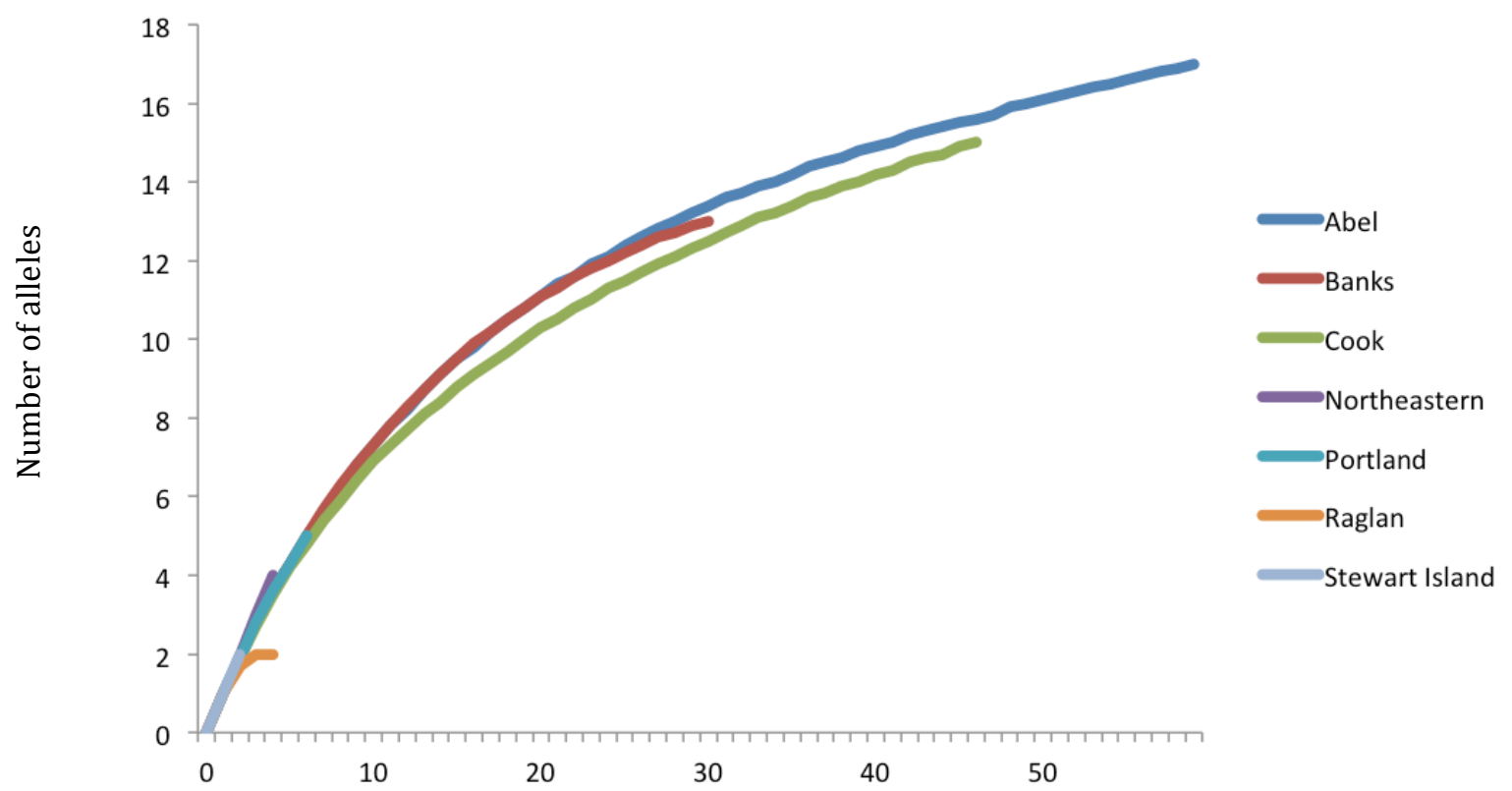

Number of individuals

Figure 3.3.8 Allele rarefaction curve for Spot07

Pairwise $\mathrm{F}_{\mathrm{ST}}$ comparisons between provinces showed no significant differences between the provinces studied (Table 3.3.7). Jost's D and Nei's D values reflected this result, showing no significant differences between provinces (Table 3.3.8). The population assignment analysis showed that individuals from the Cook province were most commonly assigned correctly ( $61 \%$ of individuals). $42 \%$ of individuals from the Abel province, and 36\% of individuals from the Banks province were correctly assigned (Table 3.3.9). 

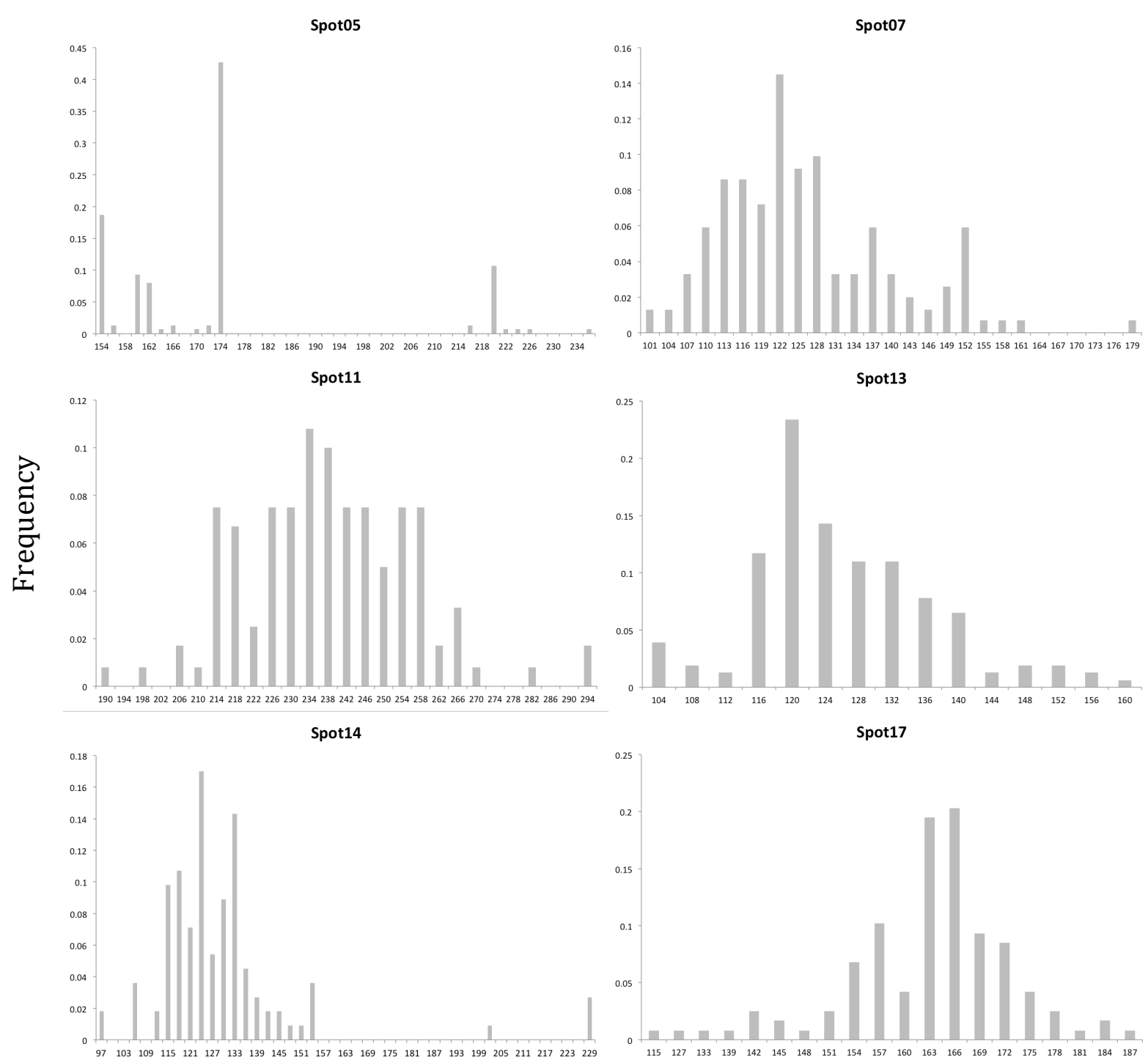

Allele (size in base pairs)

Figure 3.3.9 Allele frequency distribution of six microsatellite loci, combined over all sample locations.

The analyses of molecular variance (AMOVA) showed that the majority of variation could be attributed to variability within populations. This was the case in all the putative phylogeographic break scenarios that were tested, suggesting that none of the tested scenarios adequately explain the variability patterns that were seen (Table 3.3.10). Results of the Factorial Component Analysis (FCA) showed a lack of 
population clustering (Figure 3.3.11). The first five axes cumulatively explained $26 \%$ of the variation present.

The Bayesian structure analysis showed the most likely number of groups was four (Figure 3.3.11). However, it was suspected that the small sample sizes of the Northeastern, Portland, Raglan and Stewart Island provinces could be biasing the data, so in a subsequent analysis these individuals were removed from the analysis. The second analysis showed the highest Delta $\mathrm{K}$ value (and therefore most likely number of groups) was $\mathrm{k}=2$ (Figure 3.3.14).

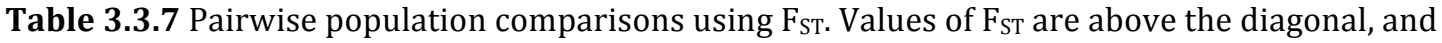
corresponding p-values are below the diagonal.

\begin{tabular}{lccccccc}
\hline & Abel & Banks & Cook & Northeastern & Portland & Raglan & Stewart Island \\
\hline Abel & & -0.002 & 0.004 & 0 & -0.008 & -0.004 & 0 \\
Banks & 0.578 & & -0.001 & 0.001 & -0.006 & 0.019 & 0 \\
Cook & 0.221 & 0.57 & & 0.026 & 0.014 & 0.054 & 0 \\
Northeastern & 0.435 & 0.45 & 0.131 & & 0.001 & -0.085 & 0 \\
Portland & 0.558 & 0.526 & 0.256 & 0.488 & & 0.014 & 0 \\
Raglan & 0.518 & 0.273 & 0.064 & 1 & 0.618 & & 0 \\
Stewart Island & 1 & 1 & 1 & 1 & 1 & 1 & \\
\hline
\end{tabular}

Table 3.3.8 Jost's $\mathrm{D}_{\text {est }}$ above the diagonal, $\mathrm{G}_{\mathrm{ST}}$ below the diagonal. Asterisks indicate sample sizes too small to be analysed without bias.

\begin{tabular}{lccccccc}
\hline & Abel & Banks & Cook & Northeastern & Portland & Raglan & Stewart Island \\
\hline Abel & & -0.018 & 0.024 & -0.042 & -0.059 & 0.099 & 0.274 \\
Banks & -0.002 & & -0.012 & -0.033 & 0.050 & 0.179 & 0.119 \\
Cook & 0.003 & -0.002 & & 0.114 & 0.132 & 0.394 & 0.369 \\
Northeastern & -0.005 & -0.004 & 0.016 & & 0.094 & -1.131 & 1.25 \\
Portland & $*$ & $*$ & $*$ & $*$ & & 0 & 1 \\
Raglan & $*$ & $*$ & $*$ & -0.063 & $*$ & & -1.333 \\
Stewart Island & 0.045 & 0.018 & 0.074 & 0.042 & 0.167 & -0.036 & \\
\hline
\end{tabular}

Table 3.3.9 Results of population assignment, in provinces where $\mathrm{N}<20$. Bold values indicate individuals correctly assigned to their original province.

\begin{tabular}{cccc}
\hline & \multicolumn{3}{c}{ Inferred population } \\
\hline Original population & Abel & Banks & Cook \\
\hline Abel & $\mathbf{1 5}$ & 9 & 12 \\
Banks & 5 & $\mathbf{9}$ & 11 \\
Cook & 6 & 6 & $\mathbf{1 9}$ \\
\hline
\end{tabular}




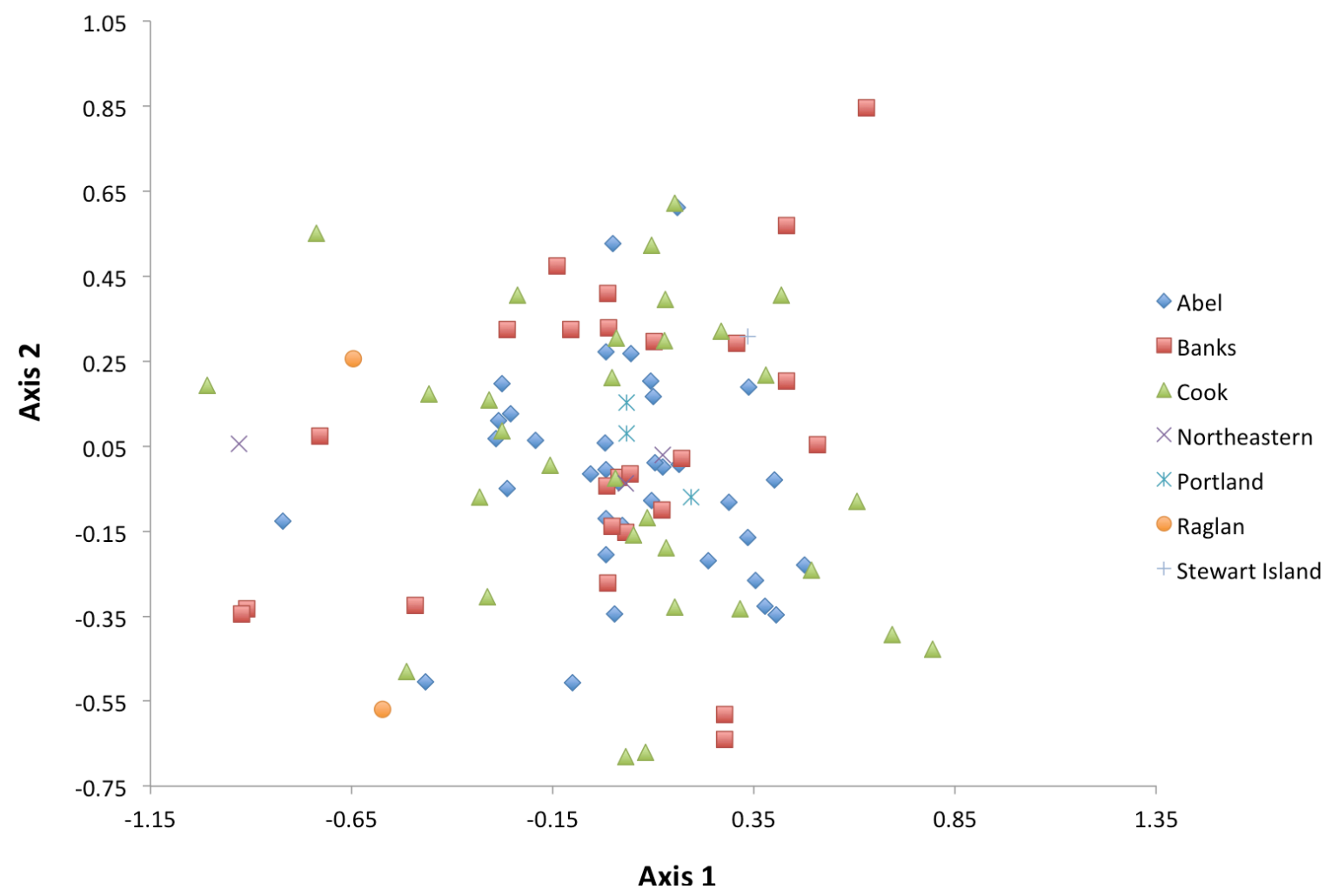

Figure 3.3.10 Factorial component analysis (FCA) showing axes 1 and 2 


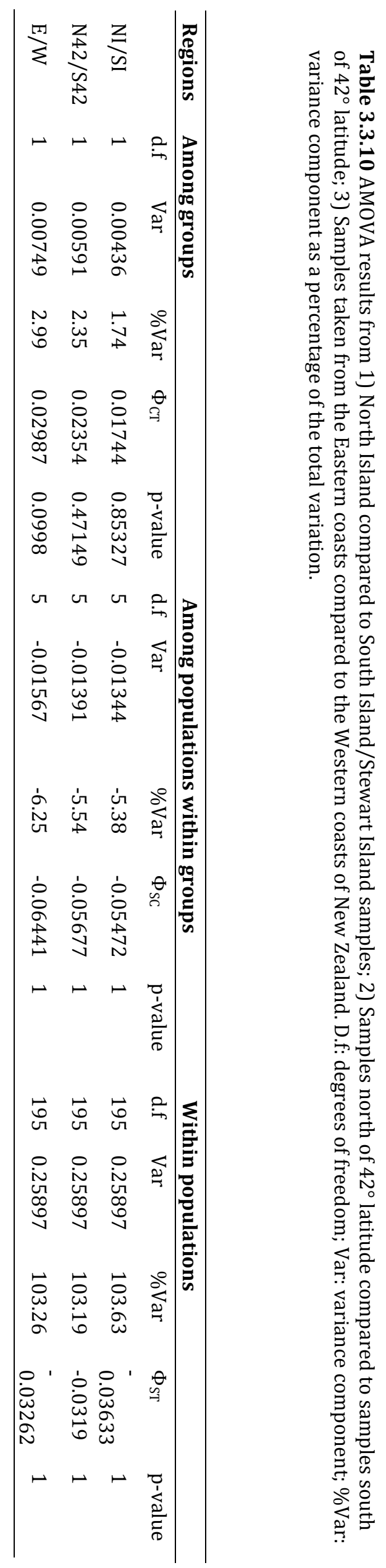



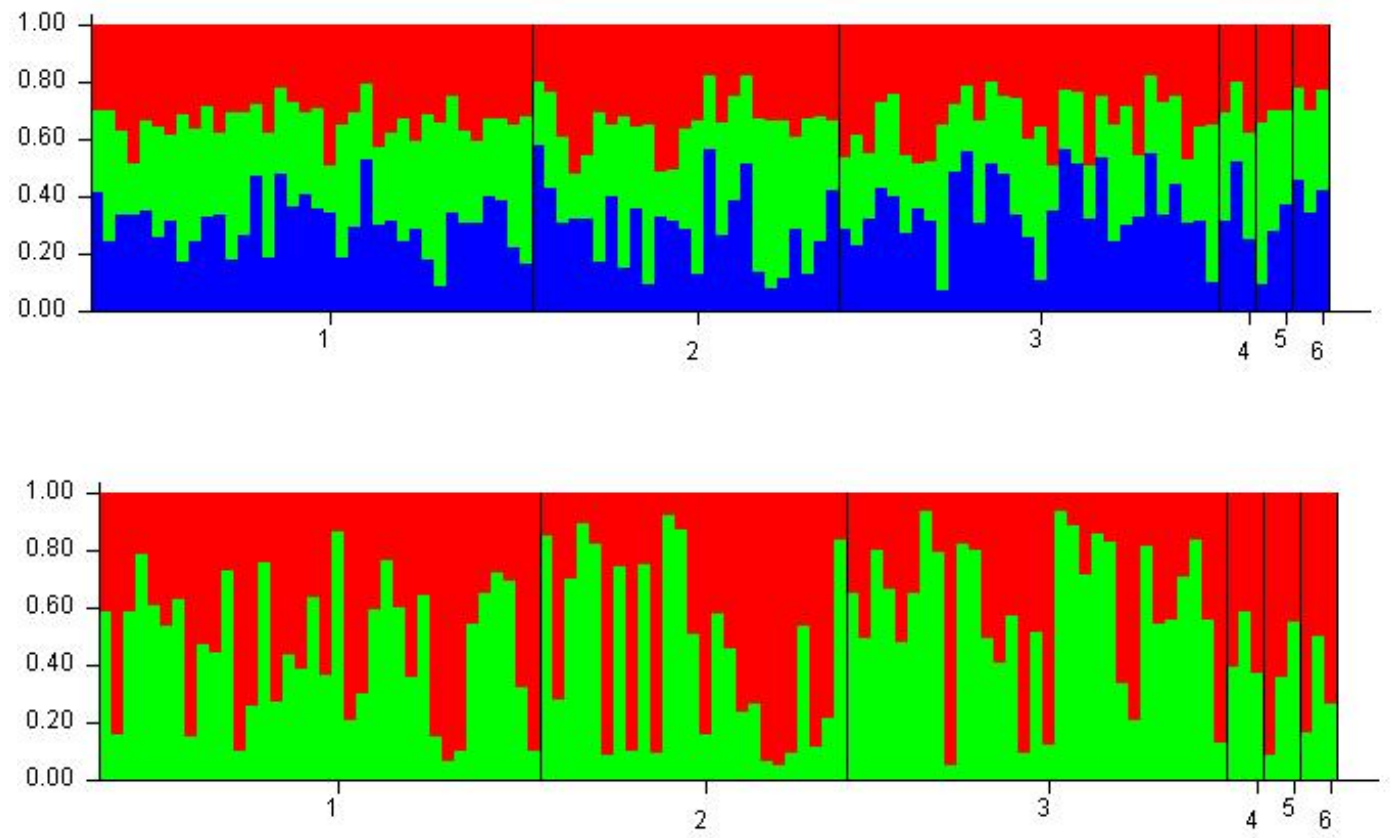

Figure 3.3.11 Results for Bayesian Structure plots for a) k=2; b) k=3. Each vertical line represents an individual, and the plots are ordered by province: 1: Abel; 2: Banks; 3: Cook; 4: Northeastern; 5: Portland; 6: Raglan.
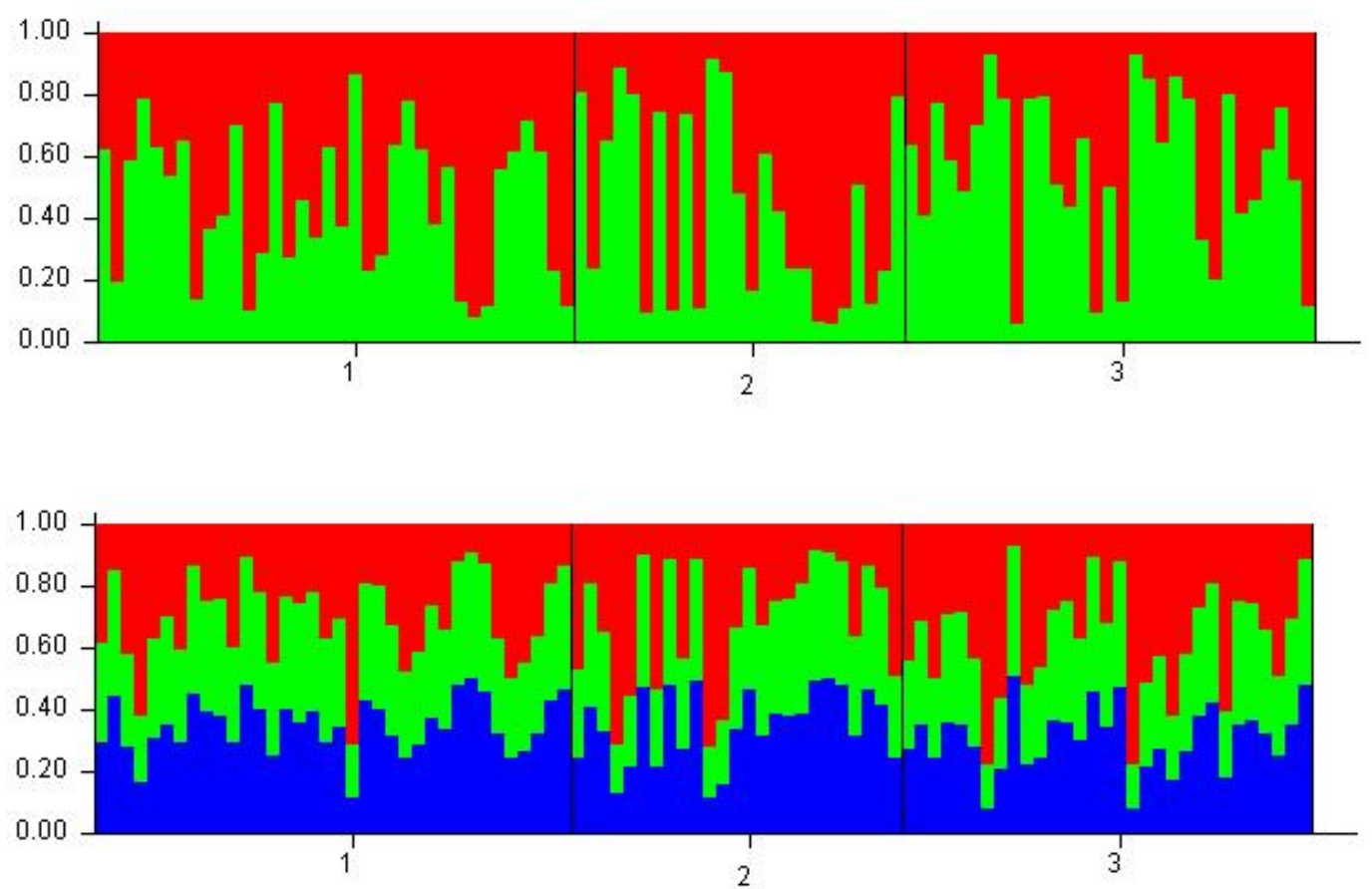

Figure 3.3.12 Results for Bayesian Structure analysis (where provinces with $\mathrm{N}<20$ are excluded) for a) $k=2$; b) $k=3$. Each vertical line represents an individual, and the plots are ordered by province: 1: Abel; 2: Banks; 3: Cook 


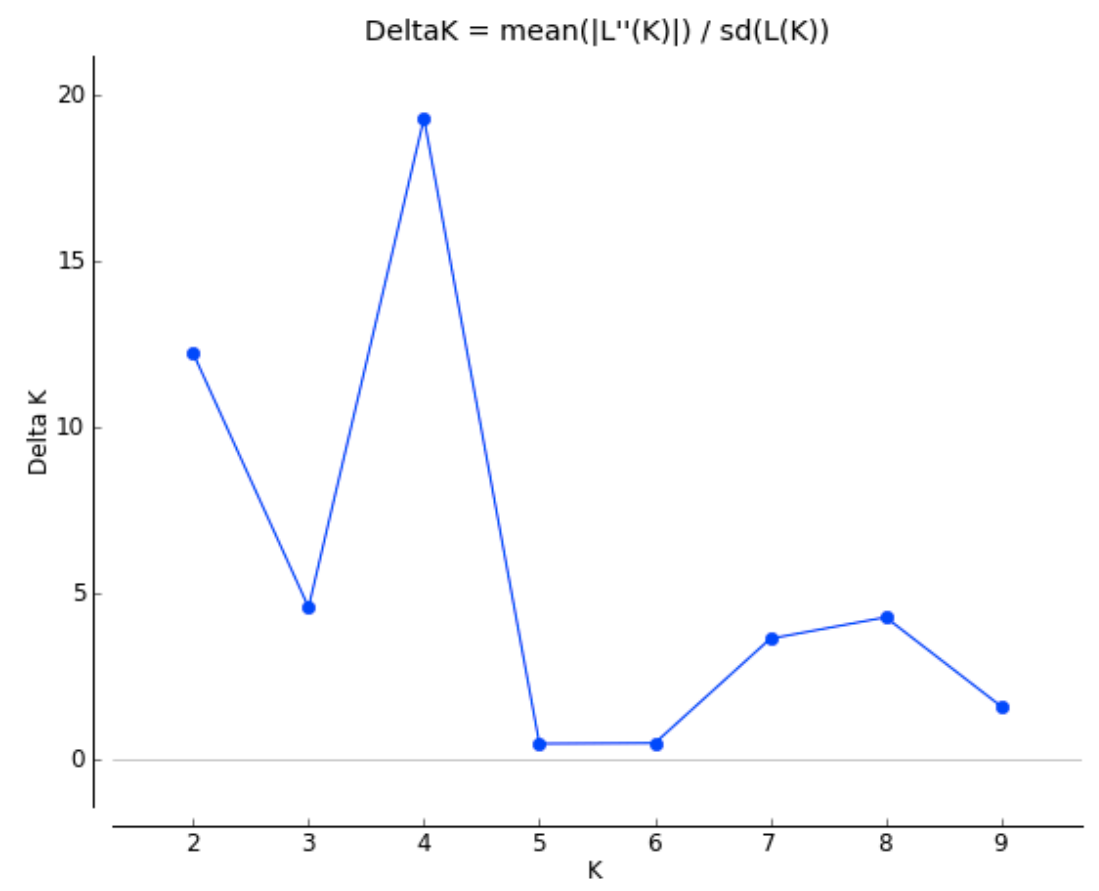

Figure 3.3.13 Delta K output from Structure analysis with all provinces included. The highest value of Delta $\mathrm{K}$ indicates the most probable number of groupings in the dataset.

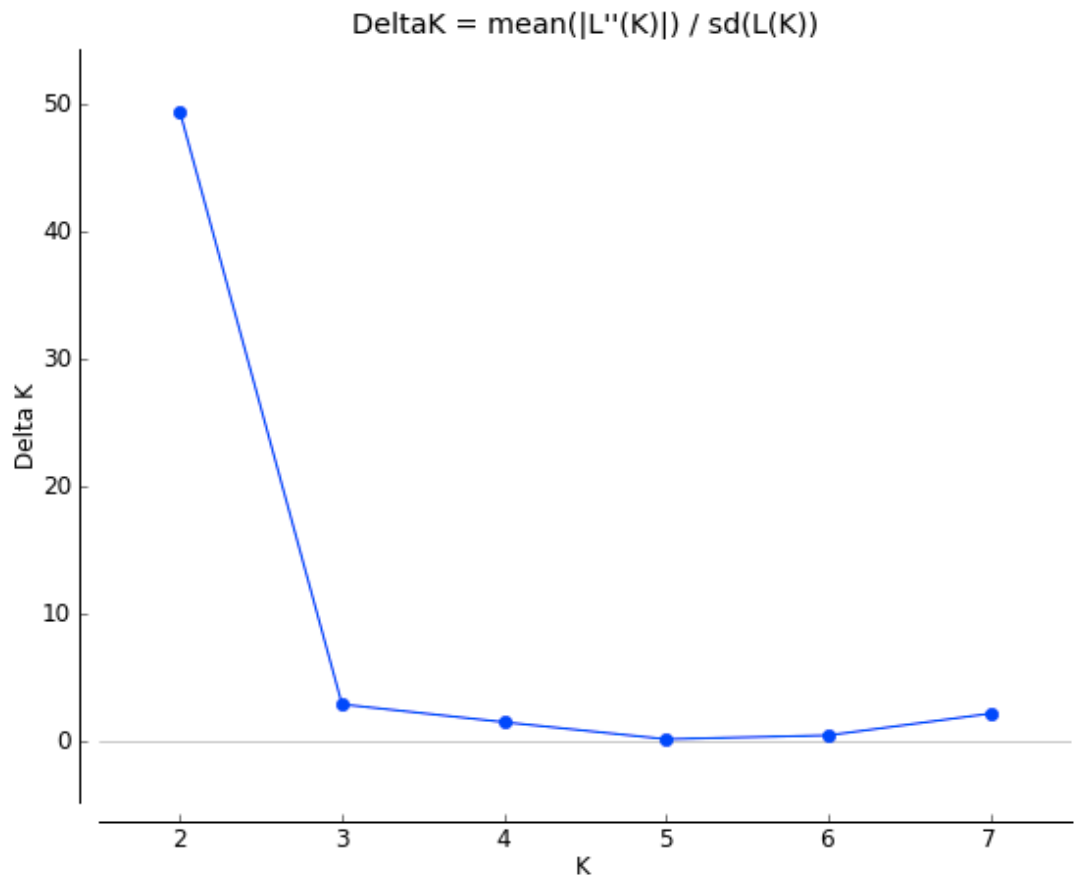

Figure 3.3.14 Delta K output from Structure analysis with only Abel, Banks and Cook provinces included. 


\subsection{Discussion}

The results of this study showed that there are extremely high levels of diversity in N. celidotus populations, and a lack of any apparent genetic differentiation among the different provinces of New Zealand.

\section{Genetic diversity}

Extremely high levels of haplotypic diversity were observed in the study of the mtDNA control region, with an average haplotypic diversity of $h=0.998$, which is close to the maximum possible value of $h=1.000$. The majority of the haplotypes observed were private (90.6\% across all provinces). The high diversity may have led to the haplotypic rarefaction plot not showing any flattening, which indicates that the sample sizes present were not sufficient to capture all of the variation present in the population.

The results of the microsatellite DNA genotyping also showed high diversity. Rarefaction plots for all loci show more signs of flattening than the mitochondrial DNA haplotype rarefaction plot, suggesting that the microsatellite DNA analysis has captured more of the variation present than the mitochondrial DNA sequence analysis. The populations with smaller sample sizes show less flattening in the rarefaction plots, since less genetic diversity can be detected when smaller samples are taken (Leberg, 2002). Additionally, no individuals were sampled from the West Coast of the South Island, or the Otago region. It is likely that obtaining additional genotypes from these regions will show additional genotypes in $N$. celidotus populations. Increasing sample sizes of individuals from all populations is necessary, if the variation in microsatellite DNA is to be fully discovered.

Studies of the control region of the mitochondrial genome tend to show high levels of diversity when compared to other parts of the genome. For example, a study that sequenced both the control region and the cytochrome oxidase I gene (CO1), another gene commonly used in population structure analyses, found an average haplotypic diversity of $h=0.984$ for the control region, and $h=0.639$ for the CO1 
gene, when analysing sequences from the same individuals (Ludt et al., 2012). The control region is a non-coding region of mtDNA, whereas the C01 gene is a proteincoding gene. It is suspected that since the control region is non-coding, it allows mutations to accumulate that may otherwise be deleterious in a coding gene, such as stop codons (Moritz, 1994). High haplotypic diversity in the control region has been observed in other wrasse species (eg. Chen et al., 2004, D’Arcy et al., 2013). Comparing the haplotype networks generated from these studies with the network constructed in this study reveals similar patterns: there are a very large number of haplotypes, and many of them are only found in one location (Appendix 2).

\section{Population structure}

The analyses of both the mitochondrial DNA sequences and the microsatellite DNA genotypes show a distinct lack of genetic population differentiation in $N$. celidotus. Analyses of molecular variance of both markers showed over 95\% of the variation present in a population was due to the differences within a population, rather than differences between populations. Additionally, no significant correlation was found when mtDNA genetic differentiation was compared to the geographic distances between sample locations ( $p=0.7495)$. Isolation-by-distance analyses have been suggested as being more effective methods to measure population differentiation in species with high dispersal potential (such as many marine fishes), instead of more traditional measures such as pairwise $\mathrm{F}_{\mathrm{ST}}$ comparisons (Palumbi, 2003). Isolation-by-distance methods can improve the sensitivity of $\mathrm{F}_{\mathrm{ST}}$ where only slight genetic differentiation is found (Palumbi, 2003). No isolation-bydistance pattern was observed in N. celidotus, but some parts of the New Zealand coastline still remain unsampled. Future sampling efforts to cover these gaps will provide a more comprehensive sample and give additional confidence to the findings of this study. A complete sample might enable the detection of some weak population structure, or rule out the presence of any population differentiation or isolation-by-distance patterns.

Knowing the specific details of the species' life cycle is important information to consider when interpreting patterns of genetic population structure. Correlations 
have been established between the pelagic larval duration (PLD) of a particular species and the observed population structure: species that have a long PLD tend to show less population structure, since there is greater opportunity for ocean currents to disperse larvae and mix with other populations (Ross et al., 2009). Notolabrus celidotus is thought to have a PLD that can last up to five months (Scott, 2010), and this study revealed a lack of population structure. Conversely, another wrasse species Larabicus quadrilineatus showed significant differentiation between populations in the Red Sea (Froukh \& Kochzius, 2007). The PLD of $L$. quadrilineatus is unknown, but the population structuring in this species was attributed to low larval dispersal capabilities and the demographic history of the species.

\section{Demographic history}

The significantly negative Tajima's D ( $\mathrm{p}=0.02771)$ and Fu's FS $(\mathrm{p}=0.00743)$ statistics indicate that $N$. celidotus populations have undergone a recent, large population expansion. This demographic history can also be observed in the mismatched distribution: the single smooth peak seen suggests a recently expanded population. The Bayesian skyline plot generated from the mitochondrial sequence data suggests that this population expansion began around 150,000 years ago, and has continued at the same rate up to the present day. This time estimate assumed that the mutation rate used was appropriate for $N$. celidotus and did not vary significantly through time.

Notolabrus celidotus individuals live for approximately seven years in the wild, and reach maturity at 3-4 years of age (Jones, 1984a). Since adults can spawn each season, it is likely that there are overlapping generations in $N$. celidotus: where more than one breeding generation is present at one time (Turner et al., 2002). Simulations have shown that the presence of overlapping generations in a species can promote the maintenance of genetic diversity in an environment with a fluctuating optimum, where the relative fitness of a particular phenotype changes over time (Ellner \& Hairston, 1994). To model the effective population size of a species with overlapping generations, more information about reproductive 
behaviour is required. The number of reproductive opportunities will influence the number of offspring each individual can produce, with those with more opportunities having the potential to produce more offspring. Ultimately, the success of each reproductive event, in terms of the proportion of offspring that successfully recruit, will determine the effective population size (Hedgecock \& Pudovkin, 2011).

Smaller effective populations sizes can result when only a small proportion of reproductive attempts are successful. The effective size and the census size of various populations can be estimated: visual counts of habitats can estimate the census size, while genetic studies can estimate the effective population size (Palstra \& Fraser, 2012). Additionally, studying the genetic differences between juveniles and adults can be used to determine if there is a large difference between the census and effective population sizes: if juveniles are generally found to be less genetically diverse than adults, this can indicate an effective population size much smaller than the census size. This variable reproductive success has been observed in a number of marine species that exhibit Type III survivorship (where the greatest mortality is experienced in early life), and it has been attributed to environmental conditions that limit the success of reproductive events, such as strong currents or weakly swimming larvae (Hedgecock \& Pudovkin, 2011). It is possible that there are discrepancies between the census and effective population sizes in $N$. celidotus, since it is a highly fecund species with many spawning opportunities. Future research could examine the genetic diversity of adult and juvenile populations, and determine the reproductive success of the species. 


\section{Chapter Four}

\section{General Discussion}

\section{Genetic diversity of Notolabrus celidotus}

This thesis research analysed the genetic population structure of N. celidotus by sampling new locations and reporting new genetic markers. Chapter two described the development of six novel microsatellite loci for analysis of $N$. celidotus. In chapter three, extremely high levels of haplotypic diversity were reported based on an analysis of the mitochondrial DNA control region $(h=0.998$ : the maximum value that can be obtained is $h=1.000$ ). No significant level of population structure was detected from either the mitochondrial DNA sequencing or the microsatellite DNA genotyping analyses. Analyses of the demographic history suggested that $N$. celidotus populations began to expand approximately 150,000 years ago.

Several studies of wrasses have reported high levels of genetic diversity in the mtDNA control region. This has been directly contrasted with the diversity found in other parts of the mitochondrial genome, such as the CO1 (cytochrome oxidase I) gene (Ludt et al., 2012). It has been suggested that the higher levels of diversity is because to the control region is non-coding, which means more mutations tend to persist because they are not removed by purifying selection (Messmer et al., 2012).

It has been hypothesised that in general, shallow-water species have lower levels of genetic diversity than deep-water species. The suggested reason is that the population size of shallow-water species is more sensitive to fluctuations in sea level arising from glacial cycles (Fauvelot et al., 2003). In species that inhabit coral reefs, species that inhabit the shallower lagoons were found to be less diverse than species that occupy the outer slopes of the reef, which tend to be more stable. This pattern seems to be restricted to coral reefs: the nature of these environments means they are highly susceptible to sea level fluctuations, and therefore repeated bottleneck events. Other habitats, such as rocky reefs and terrestrial lakes, do not 
seem to share this pattern of increasing genetic diversity with depth. Notolabrus celidotus are shallow-water fish (Jones, 1984b), yet showed extremely high levels of genetic diversity in this study. Similar results were shown in African cichlid lake fish, where more genetic diversity was detected in shallow-water species, compared to deeper-water species (Nevado et al., 2013). A possible explanation for the higher levels of diversity is the larger population sizes of shallow water species arising from higher primary productivity (Leffler et al., 2012).

Species with high levels of genetic diversity tend to be more adaptable to changes to their environment, because there are potentially more advantageous alleles in large populations. Less diverse populations have a lower chance of advantageous alleles being present, so may not be able to respond to environmental challenges (Nevo, 2001). A review of proxies for population fitness found that genetic diversity was positively correlated with the fitness of a species (Reed \& Frankham, 2003). Populations that have higher levels of heterozygosity are less likely to be vulnerable to inbreeding depression (Kardos et al., 2014). Based on these studies, the present research results suggest that Notolabrus celidotus is likely to be resilient to environmental changes due to its high genetic diversity and large population size. Understanding the potential resilience of populations is especially important if it is a commercially targeted species, but it is also useful to know the resilience of important ecosystem species (Folke et al., 2004).

Notolabrus celidotus forms an important part of rocky reef ecosystems. They provide a food source for larger, commercially valuable reef fish such as snapper and blue cod (Usmar, 2012), but also play a role in the health of the ecosystem. A trophic cascade in New Zealand rocky reef ecosystems has been identified between kelp, invertebrate grazers and predatory fish (Newcombe \& Taylor, 2010). Various epifaunal invertebrates feed on the kelp, which is the basis of many rocky reef habitats. Invertebrates can damage the kelp while feeding on it, and this reduces primary productivity. Notolabrus celidotus consumes these epifaunal invertebrates, and is able to suppress the populations enough to promote kelp health. Kelp forests support a wide variety of organisms, and form habitats for many commercially important fish species in New Zealand (Cole et al., 1990). 
While the life cycle and feeding habits of $N$. celidotus have been long known (Jones, 1984a), the broader role that this species plays in ecosystems is only now beginning to be understood: and it appears they are an important part of rocky reef ecosystems.

\section{Population structure of Notolabrus celidotus}

Life-history traits and environmental conditions both play an important part in determining connectivity and population structure (D'Arcy et al., 2013). Genetic methods can uncover large and small-scale population structure (Horne et al., 2013). Analysing a species' population structure can inform the management of fished stocks and marine reserves, and can identify cryptic species and levels of local recruitment (von der Heyden et al., 2014). Many factors can influence the degree of genetic structuring of fish populations, including their life history and habitat, historical events, and the marker chosen to study them (Selkoe et al., 2008).

Notolabrus celidotus are monandric hermaphrodites, which means there are one male and many female fish in each population (Allsop \& West, 2004; Jones, 1980). Males defend territories and the group of female fish that occupy the area (Jones, 1980). The reproductive system of a species is thought to have an influence on the degree of population structuring that is observed, due to the biased sex ratios that are often observed in hermaphroditic species (Planes \& Lenfant, 2002). However, a study has found no difference between levels of differentiation in gonochoristic (species that do not undergo a sex change) and hermaphroditic fish species, once the type of marker analysed and the dispersal ability were taken into account (Chopelet et al., 2009). It is suggested that while mating systems may be a factor in determining the genetic structure of a species, other factors such as dispersal ability are more significant (Barbosa et al., 2013). Although $N$. celidotus is a hermaphroditic species, it seems unlikely that this feature of its life history is related to the lack of population structure that has been observed. 
Genetic studies cannot always show small-scale population structure, due to the resolution limits of the molecular marker that is used. Other methods can detect finer-scale population structure (such as detecting self-recruitment to a particular reef), including otolith microchemistry or chemical tagging of larvae (Haney et al., 2007). Otolith microchemistry techniques involve analysing various elemental ratios of a fish's otolith, and comparing those to physical locations, or other individuals to identify the original habitat of that individual. These techniques have been used to identify nursery grounds of important commercially fished species (Morrison, 2008), which often cannot be identified by genetic studies alone. Otolith microchemistry analyses have been used alongside molecular markers in studies of commercially exploited fish stocks (Collins et al., 2013; Miller et al., 2005). It can be particularly useful in the management of commercially fished migratory species, since it can be used to identify natal habitats and migratory paths that are not detectable through genetic studies (Feyrer et al., 2007). Otolith microchemistry has also been used in species that are not commercially fished, to identify natal habitats and juvenile recruitment patterns (Feutry et al., 2012). Otolith microchemistry methods have not yet been used in any studies of $N$. celidotus populations, but the technique could offer better scope to detect population differentiation, self-recruitment or migration patterns.

\section{Notolabrus celidotus as a model species}

Model species can provide insight into the features of other closely-related species that are more difficult to study directly (Biermann et al., 2003). The ubiquitous distribution of $N$. celidotus makes it a potential model species for studying population structure in New Zealand: the expected level of connectivity can be inferred in fish species that have a similar pelagic larval duration, and occupy similar habitats to N. celidotus. Notolabrus fucicola is a sister species to N. celidotus and another abundant rocky reef fish, which occupies similar habitats and has a similar life history: there have even been observed occurrences of hybrid $N$. celidotus x N. fucicola individuals in the wild (Ayling, 1980). While the pelagic larval duration of $N$. fucicola is unknown, it is likely to be similar to $N$. celidotus, 
due to the close phylogenetic relationships of the two species (Russell, 1983). If the PLD is similar to that of $N$. celidotus, then it is likely that there will be high levels of population connectivity in N. fucicola. More broadly, the results of this study could be used to inform the expected levels of connectivity of species that have a PLD of at least 5-6 months, and are distributed throughout New Zealand.

Notolabrus celidotus has further potential to be a model species since it is not (and has never been) fished commercially. Certain fishing methods cause size-related selective pressure on fish species, when minimum size limits and the mesh size of nets only allow certain sized fishes to be captured. These methods can cause changes to the sex ratios, growth patterns and maturation time of a species, and have been observed in heavily fished species such as Atlantic cod and various salmon species (Hutchings \& Fraser, 2008). Fisheries-induced evolution affects different species in different ways, but there is a tendency for species to mature earlier, and at a smaller size; the individuals that reproduce before reaching minimum size limits have a selective advantage (Kendall \& Quinn, 2013). Since $N$. celidotus has never been commercially fished, population size fluctuations, sex ratios and growth-at-age can be studied in a species that has not been subject to fisheries-induced evolution. The changes in populations that occur can form a baseline that commercially targeted species can be compared with, in terms of population fluctuations and responses to environmental changes (Beninger \& Boldina, 2014). Tracking the population dynamics of N. celidotus through time can give indications as to how reef fish populations respond to environmental changes. The changes in populations may mirror those that may occur in commercially targeted species, and these changes can be implemented into stock management plans to prepare for environmental changes.

\section{Future directions}

In addition to $N$. celidotus and $N$. fucicola, New Zealand is home to many other species of wrasse (Russell, 1983). Wrasses commonly occupy similar habitats and often share life history characteristics (such as mating systems and spawning behaviour), which means the results from this study could apply to other wrasses 
(Westneat \& Alfaro, 2005). Species that have more life history characteristics in common with $N$. celidotus are more likely to show similar patterns of population connectivity and genetic diversity. The other New Zealand wrasse species are not as well studied as $N$. celidotus (Russell, 1983), so the results of this study can give information about the general trends that could be observed in other species. Additionally, the same microsatellite loci developed for N. celidotus in this study could be used to study other New Zealand wrasses, depending on the transferability of these loci ( $\mathrm{Li}$ et al., 2009). If the loci were found to be easily transferable between species, it would mean that the development costs associated with developing new microsatellite loci would be drastically reduced.

There are potential applications for N. celidotus in finfish aquaculture. Aquaculture is one of New Zealand's fastest growing primary industries, with the potential for a billion-dollar industry by 2025 (Alfaro et al., 2014). Aquaculturing finfish can pose risks of disease due to the high densities of cultured fish, and the potential of disease transmission to and from wild populations (Forrest et al., 2007). Kingfish (Seriola lalandi lalandi) has been identified as a potentially valuable aquaculture species, due to its high-value flesh and rapid growth (Symonds et al., 2014). However, kingfish are affected by several species of copepod ectoparasites, which can cause emaciation, anaemia and restriction of blood flow to the gills (Sharp et al., 2003). Infections can result in sickness or weight loss, which reduce the sale value of the fish. Recent research has examined the use of wrasses as cleaner fish in Norwegian salmon aquaculture, and wrasses have been used to successfully remove ectoparasites from aquacultured species (Skiftesvik et al., 2014). Notolabrus celidotus are generalist predators of invertebrates, so it is possible that these fish can act as cleaner fish in the same way. Another advantage of utilising $N$. celidotus as a cleaner fish is the reduced need for pesticides to reduce the parasite loads of kingfish (Sharp et al., 2004). Since kingfish aquaculture would most likely take place in marine cages or nets (Symonds et al., 2014), any pesticides will necessarily also be released into the ocean: and this is unlikely to be welcomed by the public (Burridge et al., 2014). If experiments find N. celidotus can successfully act as a cleaner fish, stock assessments will need to be implemented to ensure sustainable harvesting. Having a strong understanding of the genetic structure of 
$N$. celidotus will aid greatly in the management of the species: since there is high genetic connectivity between locations, small-scale stock boundaries may not need to be established to protect populations from over-fishing.

Genetic markers that are selectively neutral are often chosen for studies of population connectivity, due to the ability of these markers to show the relationships and connectivity between populations (Schlotterer, 2004). Neutral markers are advantageous in studies of population structure since they tend to be highly variable, and therefore can identify fine-scale differences between populations (Avise, 2004). However, analysing selectively variable molecular markers can identify potential sources of selective pressure, and may help to explain phenotypic differences between populations (Landguth \& Balkenhol, 2012). Different growth and maturity patterns have been observed between populations of N. celidotus in Auckland and Wellington: individuals in Wellington populations tend to mature later, and at a smaller size (Jones, 1980). So far, these differences have been attributed to the colder ocean environment in Wellington, and variation in adult density between these locations. It seems unlikely that genetic factors would play a part in these physiological differences, since no population structuring was detected: the differences are likely to be solely due to density-dependent and environmental differences between the sample locations. 


\section{Appendix}
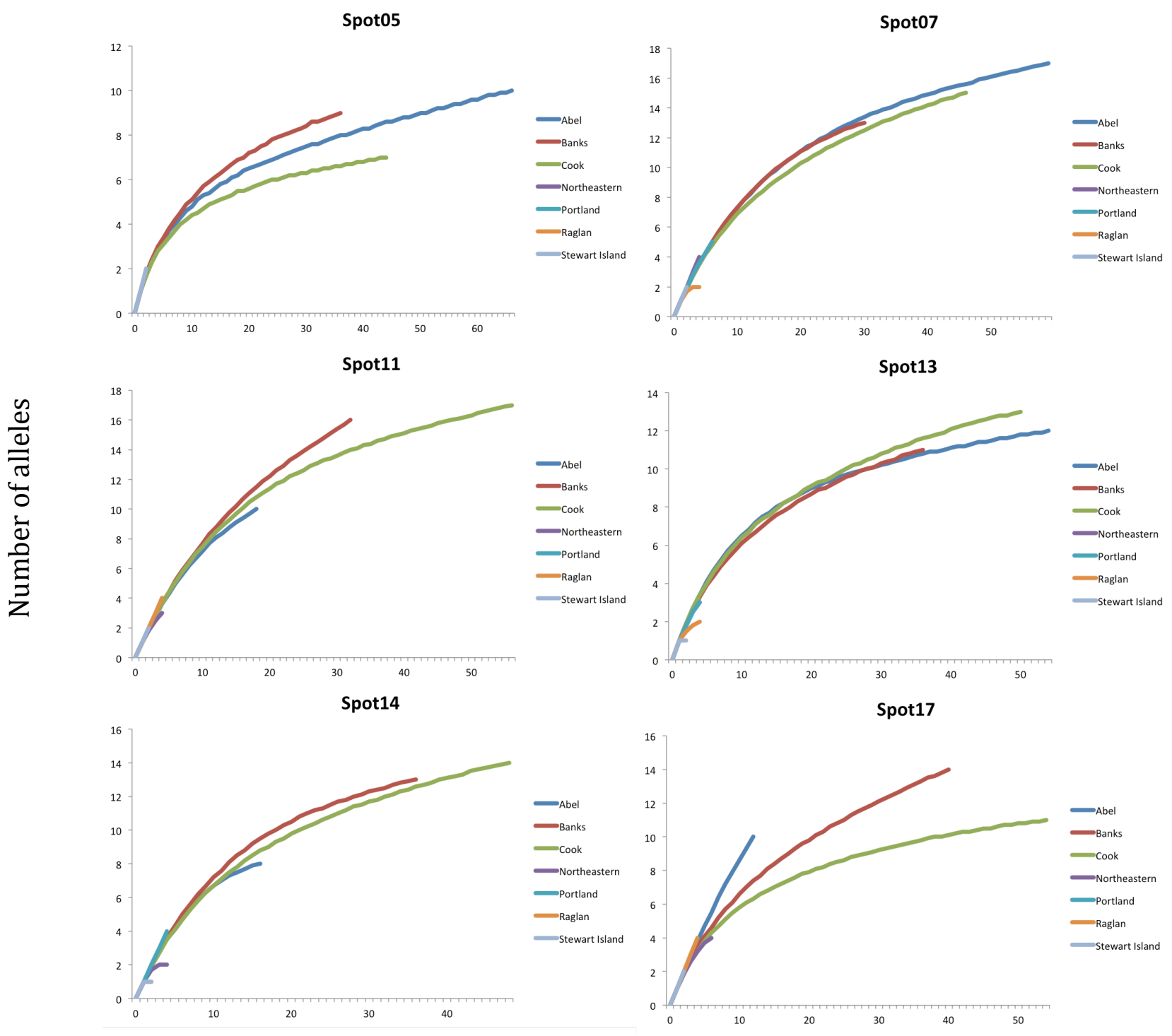

Number of individuals

Appendix 1 Allele rarefaction curves for all microsatellite loci. 


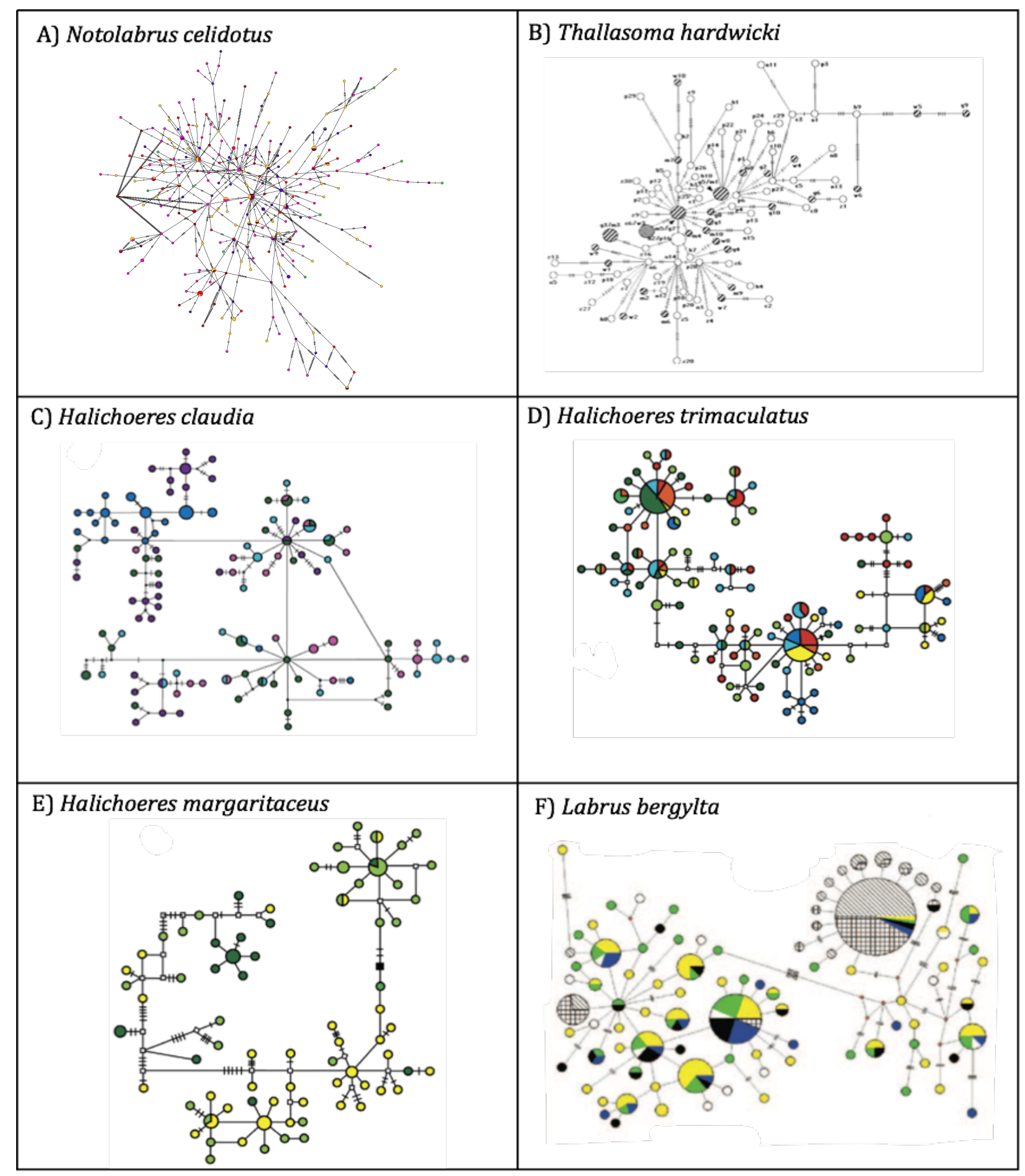

Appendix 2 Visual comparison of the haplotype network obtained for $N$. celidotus and those of different wrasse species. In all cases, each circle represents one haplotype, the colour of the circle represents the geographic origin, and the size of the circle indicates how many individuals share that haplotype. Networks adapted from Chen et al (2004) (B); Ludt et al (2012) (C - E) and D'Arcy et al (2013) (F). 


\section{References}

Abdelkrim, J., Robertson, B. C., Stanton, J.-A. L., \& Gemmell, N. J. (2009). Fast, costeffective development of species-specific microsatellite markers by genomic sequencing. Biotechniques, 46(3), 185-+. doi: 10.2144/000113084

Abdul-Muneer, P. M. (2014). Application of microsatellite markers in conservation genetics and fisheries management: recent advances in population structure analysis and conservation strategies. Genetics research international, 2014, 691759-691759. doi: 10.1155/2014/691759

Abesamis, R. A., \& Russ, G. R. (2005). Density-dependent spillover from a marine reserve: Long-term evidence. Ecological Applications, 15(5), 1798-1812. doi: 10.1890/05-0174

Alfaro, A. C., Jeffs, A. G., \& King, N. (2014). Enabling and driving aquaculture growth in New Zealand through innovation INTRODUCTION. New Zealand Journal of Marine and Freshwater Research, 48(3), 311-313. doi: 10.1080/00288330.2014.933115

Allsop, D. J., \& West, S. A. (2004). Sex-ratio evolution in sex changing animals. Evolution, 58(5), 1019-1027.

Almany, G. R., Berumen, M. L., Thorrold, S. R., Planes, S., \& Jones, G. P. (2007). Local replenishment of coral reef fish populations in a marine reserve. Science, 316(5825), 742-744. doi: 10.1126/science.1140597

Anderson, M. J., \& Millar, R. B. (2004). Spatial variation and effects of habitat on temperate reef fish assemblages in northeastern New Zealand. Journal of Experimental Marine Biology and Ecology, 305(2), 191-221. doi: 10.1016/j.jembe.2003.12.011

Apte, S., \& Gardner, J. P. A. (2002). Population genetic subdivision in the New Zealand greenshell mussel (Perna canaliculus) inferred from single-strand conformation polymorphism analysis of mitochondrial DNA. Molecular Ecology, 11(9), 1617-1628. doi: 10.1046/j.1365-294X.2002.01554.x

Avise, J. C. (2004). Molecular markers, natural history, and evolution. Second edition. Sunderland, USA: Sinauer Associates Inc.

Ayling, A. M. (1980). HYBRIDIZATION IN THE GENUS PSEUDOLABRUS-LABRIDAE. Copeia(1), 176-180.

Barbara, T., Palma-Silva, C., Paggi, G. M., Bered, F., Fay, M. F., \& Lexer, C. (2007). Cross-species transfer of nuclear microsatellite markers: potential and limitations. Molecular Ecology, 16(18), 3759-3767. doi: 10.1111/j.1365294X.2007.03439.x 
Barbosa, S. S., Klanten, S. O., Puritz, J. B., Toonen, R. J., \& Byrne, M. (2013). Very finescale population genetic structure of sympatric asterinid sea stars with benthic and pelagic larvae: influence of mating system and dispersal potential. Biological Journal of the Linnean Society, 108(4), 821-833. doi: 10.1111/bij.12006

Beldade, R., Jackson, A. M., Cudney-Bueno, R., Raimondi, P. T., \& Bernardi, G. (2014). Genetic structure among spawning aggregations of the gulf coney Hyporthodus acanthistius. Marine Ecology Progress Series, 499, 193-U433. doi: $10.3354 /$ meps 10637

Beninger, P. G., \& Boldina, I. (2014). Fine-scale spatial distribution of the temperate infaunal bivalve Tapes (= Ruditapes) philippinarum (Adams and Reeve) on fished and unfished intertidal mudflats. Journal of Experimental Marine Biology and Ecology, 457, 128-134. doi: 10.1016/j.jembe.2014.04.001

Benson, G. (1999). Tandem repeats finder: a program to analyze DNA sequences. Nucleic Acids Research, 27(2), 573-580. doi: 10.1093/nar/27.2.573

Berry, O., England, P., Fairclough, D., Jackson, G., \& Greenwood, J. (2012). Microsatellite DNA analysis and hydrodynamic modelling reveal the extent of larval transport and gene flow between management zones in an exploited marine fish (Glaucosoma hebraicum). Fisheries Oceanography, 21(4), 243254. doi: 10.1111/j.1365-2419.2012.00623.x

Bertness, M. D. (1989). INTRASPECIFIC COMPETITION AND FACILITATION IN A NORTHERN ACORN BARNACLE POPULATION. Ecology, 70(1), 257-268. doi: $10.2307 / 1938431$

Biermann, C. H., Kessing, B. D., \& Palumbi, S. R. (2003). Phylogeny and development of marine model species: strongylocentrotid sea urchins. Evolution \& Development, 5(4), 360-371. doi: 10.1046/j.1525-142X.2003.03043.X

Branch, T. A., Jensen, O. P., Ricard, D., Ye, Y., \& Hilborn, R. (2011). Contrasting Global Trends in Marine Fishery Status Obtained from Catches and from Stock Assessments. Conservation Biology, 25(4), 777-786. doi: 10.1111/j.15231739.2011.01687.x

Burridge, L. E., Lyons, M. C., Wong, D. K. H., MacKeigan, K., \& VanGeest, J. L. (2014). The acute lethality of three anti-sea lice formulations: AlphaMax (R), Salmosan (R), and Interox (R) Paramove (TM) 50 to lobster and shrimp. Aquaculture, 420, 180-186. doi: 10.1016/j.aquaculture.2013.10.041

Chen, C. A., Ablan, M. C. A., McManus, J. W., Bell, J. D., Tuan, V. S., Cabanban, A. S., \& Shao, K. T. (2004). Population structure and genetic variability of six bar wrasse (Thallasoma hardwicki) in northern South China sea revealed by mitochondrial control region sequences. Marine Biotechnology, 6(4), 312326. doi: 10.1007/s10126-003-0028-2 
Chistiakov, D. A., Hellemans, B., \& Volckaert, F. A. M. (2006). Microsatellites and their genomic distribution, evolution, function and applications: A review with special reference to fish genetics. Aquaculture, 255(1-4), 1-29. doi: 10.1016/j.aquaculture.2005.11.031

Choat, J. H., \& Ayling, A. M. (1987). THE RELATIONSHIP BETWEEN HABITAT STRUCTURE AND FISH FAUNAS ON NEW-ZEALAND REEFS. Journal of Experimental Marine Biology and Ecology, 110(3), 257-284. doi: 10.1016/0022-0981(87)90005-0

Chopelet, J., Waples, R. S., \& Mariani, S. (2009). Sex change and the genetic structure of marine fish populations. Fish and Fisheries, 10(3), 329-343. doi: 10.1111/j.1467-2979.2009.00329.x

Cole, R. G., Ayling, T. M., \& Creese, R. G. (1990). EFFECTS OF MARINE RESERVE PROTECTION AT GOAT ISLAND, NORTHERN NEW-ZEALAND. New Zealand Journal of Marine and Freshwater Research, 24(2), 197-210.

Collins, S. M., Bickford, N., McIntyre, P. B., Coulon, A., Ulseth, A. J., Taphorn, D. C., \& Flecker, A. S. (2013). Population Structure of a Neotropical Migratory Fish: Contrasting Perspectives from Genetics and Otolith Microchemistry. Transactions of the American Fisheries Society, 142(5), 1192-1201. doi: 10.1080/00028487.2013.804005

Coop, G., Witonsky, D., Di Rienzo, A., \& Pritchard, J. K. (2010). Using Environmental Correlations to Identify Loci Underlying Local Adaptation. Genetics, 185(4), 1411-1423. doi: 10.1534/genetics.110.114819

Cowman, P. F., Bellwood, D. R., \& van Herwerden, L. (2009). Dating the evolutionary origins of wrasse lineages (Labridae) and the rise of trophic novelty on coral reefs. Molecular Phylogenetics and Evolution, 52(3), 621-631. doi: 10.1016/j.ympev.2009.05.015

D'Arcy, J., Mirimin, L., \& FitzGerald, R. (2013). Phylogeographic structure of a protogynous hermaphrodite species, the ballan wrasse Labrus bergylta, in Ireland, Scotland, and Norway, using mitochondrial DNA sequence data. Ices Journal of Marine Science, 70(3), 685-693. doi: 10.1093/icesjms/fst018

Darriba, D., Taboada, G. L., Doallo, R., \& Posada, D. (2012). jModelTest 2: more models, new heuristics and parallel computing. Nature Methods, 9(8), 772772.

Dickey, A. M., Osborne, L. S., Shatters, R. G., Jr., Hall, P. M., \& McKenzie, C. L. (2013). Population Genetics of Invasive Bemisia tabaci (Hemiptera: Aleyrodidae) Cryptic Species in the United States Based on Microsatellite Markers. Journal of Economic Entomology, 106(3), 1355-1364. doi: 10.1603/ec12512

Dionne, M., Caron, F., Dodson, J. J., \& Bernatchez, L. (2008). Landscape genetics and 
hierarchical genetic structure in Atlantic salmon: the interaction of gene flow and local adaptation. Molecular Ecology, 17(10), 2382-2396. doi: 10.1111/j.1365-294X.2008.03771.x

Drenner, S. M., Clark, T. D., Whitney, C. K., Martins, E. G., Cooke, S. J., \& Hinch, S. G. (2012). A Synthesis of Tagging Studies Examining the Behaviour and Survival of Anadromous Salmonids in Marine Environments. Plos One, 7(3). doi: 10.1371/journal.pone.0031311

Drummond, A. J., Suchard, M. A., Xie, D., \& Rambaut, A. (2012). Bayesian Phylogenetics with BEAUti and the BEAST 1.7. Molecular Biology and Evolution, 29(8), 1969-1973. doi: 10.1093/molbev/mss075

Dudgeon, C. L., Blower, D. C., Broderick, D., Giles, J. L., Holmes, B. J., Kashiwagi, T., ... Ovenden, J. R. (2012). A review of the application of molecular genetics for fisheries management and conservation of sharks and rays. (vol 80, pg 1789, 2012). Journal of Fish Biology, 80(7), 2649-2649. doi: 10.1111/j.10958649.2012.03364.x

Earl, D. A., \& vonHoldt, B. M. (2012). STRUCTURE HARVESTER: a website and program for visualizing STRUCTURE output and implementing the Evanno method. Conservation Genetics Resources, 4(2), 359-361. doi: 10.1007/s12686-011-9548-7

Ellis, J. S., Gilbey, J., Armstrong, A., Balstad, T., Cauwelier, E., Cherbonnel, C., . . . Stevens, J. R. (2011). Microsatellite standardization and evaluation of genotyping error in a large multi-partner research programme for conservation of Atlantic salmon (Salmo salar L.). Genetica, 139(3), 353-367. doi: $10.1007 / \mathrm{s} 10709-011-9554-4$

Ellner, S., \& Hairston, N. G. (1994). ROLE OF OVERLAPPING GENERATIONS IN MAINTAINING GENETIC-VARIATION IN A FLUCTUATING ENVIRONMENT. American Naturalist, 143(3), 403-417. doi: 10.1086/285610

Ensing, D., Crozier, W. W., Boylan, P., O'Maoileidigh, N., \& McGinnity, P. (2013). An analysis of genetic stock identification on a small geographical scale using microsatellite markers, and its application in the management of a mixedstock fishery for Atlantic salmon Salmo salar in Ireland. Journal of Fish Biology, 82(6), 2080-2094. doi: 10.1111/jfb.12139

Excoffier, L., \& Lischer, H. E. L. (2010). Arlequin suite ver 3.5: a new series of programs to perform population genetics analyses under Linux and Windows. Molecular Ecology Resources, 10(3), 564-567. doi: 10.1111/j.17550998.2010.02847.x

Fauvelot, C., Bernardi, G., \& Planes, S. (2003). Reductions in the mitochondrial DNA diversity of coral reef fish provide evidence of population bottlenecks resulting from Holocene sea-level change. Evolution, 57(7), 1571-1583. 
Feutry, P., Tabouret, H., Maeda, K., Pecheyran, C., \& Keith, P. (2012). Diadromous life cycle and behavioural plasticity in freshwater and estuarine Kuhliidae species (Teleostei) revealed by otolith microchemistry. Aquatic Biology, 15(3), 195-204. doi: 10.3354/ab00423

Feyrer, F., Hobbs, J., Baerwald, M., Sommer, T., Yin, Q.-Z., Clark, K., . . B Bennett, W. (2007). Otolith microchemistry provides information complementary to microsatellite DNA for a migratory fish. Transactions of the American Fisheries Society, 136(2), 469-476. doi: 10.1577/t06-044.11

Folke, C., Carpenter, S., Walker, B., Scheffer, M., Elmqvist, T., Gunderson, L., \& Holling, C. S. (2004). Regime shifts, resilience, and biodiversity in ecosystem management. Annual Review of Ecology Evolution and Systematics, 35, 557581. doi: 10.1146/annurev.ecolsys.35.021103.105711

Forrest, B., Keeley, N., Gillespie, P., Hopkins, G., Knight, B., \& Govier, D. (2007). Review of the ecological effects of marine finfish aquaculture: final report. Prepared for the Ministry of Fisheries. Cawthron Report No. 1285. 71p.

Froukh, T., \& Kochzius, M. (2007). Genetic population structure of the endemic fourline wrasse (Larabicus quadrilineatus) suggests limited larval dispersal distances in the Red Sea. Molecular Ecology, 16(7), 1359-1367. doi: 10.1111/j.1365-294X.2007.03236.x

Galarza, J. A., Carreras-Carbonell, J., Macpherson, E., Pascual, M., Roques, S., Turner, G. F., \& Rico, C. (2009). The influence of oceanographic fronts and early-lifehistory traits on connectivity among littoral fish species. Proceedings of the National Academy of Sciences of the United States of America, 106(5), 14731478. doi: $10.1073 /$ pnas.0806804106

Gardner, M. J., Chaplin, J. A., \& Shaw, K. M. (2011). Development and characterisation of novel microsatellite loci for the baldchin groper (Choerodon rubescens) and cross-amplification in seven other labrid species. Conservation Genetics Resources, 3(3), 461-466. doi: 10.1007/s12686-010-9379-y

Gigliarelli, L., Puletti, M. E., Giannetto, D., Franchi, E., Lanfaloni, L., Panara, F., . . Lucentini, L. (2012). Isolation of microsatellite markers in Squalius lucumonis (Bianco, 1983) and cross-species amplification within the family Cyprinidae and other freshwater fish species. Italian Journal of Zoology, 79(2), 169-174. doi: 10.1080/11250003.2011.642900

Guichoux, E., Lagache, L., Wagner, S., Chaumeil, P., Leger, P., Lepais, O., . . Petit, R. J. (2011). Current trends in microsatellite genotyping. Molecular Ecology Resources, 11(4), 591-611. doi: 10.1111/j.1755-0998.2011.03014.x

Guindon, S., \& Gascuel, O. (2003). A simple, fast, and accurate algorithm to estimate large phylogenies by maximum likelihood. Systematic Biology, 52(5), 696704. doi: $10.1080 / 10635150390235520$ 
Handley, L. J. L., Estoup, A., Evans, D. M., Thomas, C. E., Lombaert, E., Facon, B., . . Roy, H. E. (2011). Ecological genetics of invasive alien species. Biocontrol, 56(4), 409-428. doi: 10.1007/s10526-011-9386-2

Haney, R. A., Silliman, B. R., \& Rand, D. M. (2007). A multi-locus assessment of connectivity and historical demography in the bluehead wrasse (Thalassoma bifasciatum). Heredity, 98(5), 294-302. doi: 10.1038/sj.hdy.6800940

Harrison, H. B., Feldheim, K. A., Jones, G. P., Mansour, H., Perumal, S., Williamson, D. H., \& Berumen, M. L. (2014). Validation of microsatellite multiplexes for parentage analysis in a coral reef fish (Lutjanus carponotatus, Lutjanidae). Conservation Genetics Resources, 6(4), 803-806. doi: 10.1007/s12686-0140226-4

Hedgecock, D., \& Pudovkin, A. I. (2011). SWEEPSTAKES REPRODUCTIVE SUCCESS IN HIGHLY FECUND MARINE FISH AND SHELLFISH: A REVIEW AND COMMENTARY. Bulletin of Marine Science, 87(4), 971-1002. doi: 10.5343/bms.2010.1051

Holleley, C. E., \& Geerts, P. G. (2009). Multiplex Manager 1.0: a cross-platform computer program that plans and optimizes multiplex PCR. Biotechniques, 46(7), 511-+. doi: 10.2144/000113156

Horne, J. B., \& van Herwerden, L. (2013). Long-term panmixia in a cosmopolitan Indo-Pacific coral reef fish and a nebulous genetic boundary with its broadly sympatric sister species. Journal of Evolutionary Biology, 26(4), 783-799. doi: 10.1111/jeb.12092

Huey, J. A., Crook, D. A., Macdonald, J. I., Schmidt, D. J., Marshall, J. C., Balcombe, S. R., . . . Hughes, J. M. (2014). Is variable connectivity among populations of a continental gobiid fish driven by local adaptation or passive dispersal? Freshwater Biology, 59(8), 1672-1686. doi: 10.1111/fwb.12373

Hughes, J. M., Huey, J. A., \& Schmidt, D. J. (2013). Is realised connectivity among populations of aquatic fauna predictable from potential connectivity? Freshwater Biology, 58(5), 951-966. doi: 10.1111/fwb.12099

Hutchings, J. A., \& Fraser, D. J. (2008). The nature of fisheries- and farming-induced evolution. Molecular Ecology, 17(1), 294-313. doi: 10.1111/j.1365294X.2007.03485.X

Iacchei, M., Ben-Horin, T., Selkoe, K. A., Bird, C. E., Garcia-Rodriguez, F. J., \& Toonen, R. J. (2013). Combined analyses of kinship and FST suggest potential drivers of chaotic genetic patchiness in high gene-flow populations. Molecular Ecology, 22(13), 3476-3494. doi: 10.1111/mec.12341

Jennings, T. N., Knaus, B. J., Mullins, T. D., Haig, S. M., \& Cronn, R. C. (2011). Multiplexed microsatellite recovery using massively parallel sequencing. Molecular Ecology Resources, 11(6), 1060-1067. doi: 10.1111/j.1755- 
0998.2011.03033.x

Jensen, J. L., Bohonak, A. J., \& Kelley, S. T. (2005). Isolation by distance, web service. Bmc Genetics, 6. doi: 10.1186/1471-2156-6-13

Jobling, M. A., Hurles, M. E., \& Tyler-Smith, C. (2004). Human evolutionary genetics: origins, peoples \& disease. New York: Garland Publishing.

Jones, G. P. (1980). GROWTH AND REPRODUCTION IN THE PROTOGYNOUS HERMAPHRODITE PSEUDOLABRUS-CELIDOTUS (PISCES, LABRIDAE) IN NEW-ZEALAND. Copeia(4), 660-675.

Jones, G. P. (1984a). POPULATION ECOLOGY OF THE TEMPERATE REEF FISH PSEUDOLABRUS-CELIDOTUS BLOCH AND SCHNEIDER (PISCES, LABRIDAE) .1. FACTORS INFLUENCING RECRUITMENT. Journal of Experimental Marine Biology and Ecology, 75(3), 257-276. doi: 10.1016/0022-0981(84)90170-9

Jones, G. P. (1984b). THE INFLUENCE OF HABITAT AND BEHAVIORAL INTERACTIONS ON THE LOCAL-DISTRIBUTION OF THE WRASSE, PSEUDOLABRUS-CELIDOTUS. Environmental Biology of Fishes, 10(1-2), 4357. doi: $10.1007 / \mathrm{bf00001661}$

Jones, G. P. (1988). ECOLOGY OF ROCKY REEF FISH OF NORTHEASTERN NEWZEALAND - A REVIEW. New Zealand Journal of Marine and Freshwater Research, 22(3), 445-462.

Jost, L. (2008). G(ST) and its relatives do not measure differentiation. Molecular Ecology, 17(18), 4015-4026. doi: 10.1111/j.1365-294X.2008.03887.x

Kalia, R. K., Rai, M. K., Kalia, S., Singh, R., \& Dhawan, A. K. (2011). Microsatellite markers: an overview of the recent progress in plants. Euphytica, 177(3), 309-334. doi: 10.1007/s10681-010-0286-9

Kang, J.-H., Park, J.-Y., \& Jo, H.-S. (2012). Rapid Development of Microsatellite Markers with 454 Pyrosequencing in a Vulnerable Fish, the Mottled Skate, Raja pulchra. International Journal of Molecular Sciences, 13(6), 7199-7211. doi: $10.3390 /$ ijms13067199

Kang, J. H., Yang, S. G., Moon, T. S., Park, J. Y., \& Choi, T. J. (2013). Development of microsatellite markers for the kelp grouper Epinephelus bruneus by 454 pyrosequencing and transfer to related species. Genetics and Molecular Research, 12(4), 5485-5493. doi: 10.4238/2013.November.13.1

Kardos, M., Allendorf, F. W., \& Luikart, G. (2014). Evaluating the role of inbreeding depression in heterozygosity-fitness correlations: how useful are tests for identity disequilibrium? Molecular Ecology Resources, 14(3), 519-530. doi: 10.1111/1755-0998.12193

Kearse, M., Moir, R., Wilson, A., Stones-Havas, S., Cheung, M., Sturrock, S., . . . 
Drummond, A. (2012). Geneious Basic: An integrated and extendable desktop software platform for the organization and analysis of sequence data. Bioinformatics, 28(12), 1647-1649. doi: 10.1093/bioinformatics/bts199

Kendall, N. W., \& Quinn, T. P. (2013). Size-selective fishing affects sex ratios and the opportunity for sexual selection in Alaskan sockeye salmon Oncorhynchus nerka. Oikos, 122(3), 411-420. doi: 10.1111/j.1600-0706.2012.20319.x

Kinitz, T., Quack, M., Paulus, M., Veith, M., Bergek, S., Strand, J., . . . Hochkirch, A. (2013). Strong isolation-by-distance in the absence of genetic population structure in the eelpout (Zoarces viviparus, Linnaeus 1758). Ecological Indicators, 27, 116-122. doi: 10.1016/j.ecolind.2012.12.001

Kolleck, J., Yang, M., Zinner, D., \& Roos, C. (2013). Genetic Diversity in Endangered Guizhou Snub-Nosed Monkeys (Rhinopithecus brelichi): Contrasting Results from Microsatellite and Mitochondrial DNA Data. Plos One, 8(8). doi: 10.1371/journal.pone.0073647

Kool, J. T., Moilanen, A., \& Treml, E. A. (2013). Population connectivity: recent advances and new perspectives. Landscape Ecology, 28(2), 165-185. doi: $10.1007 / \mathrm{s} 10980-012-9819-\mathrm{z}$

Koressaar, T., \& Remm, M. (2007). Enhancements and modifications of primer design program Primer3. Bioinformatics, 23(10), 1289-1291. doi: 10.1093/bioinformatics/btm091

Laikre, L., Palm, S., \& Ryman, N. (2005). Genetic population structure of fishes: Implications for coastal zone management. Ambio, 34(2), 111-119. doi: 10.1639/0044-7447(2005)034[0111:gpsofi]2.0.co;2

Landguth, E. L., \& Balkenhol, N. (2012). Relative sensitivity of neutral versus adaptive genetic data for assessing population differentiation. Conservation Genetics, 13(5), 1421-1426. doi: 10.1007/s10592-012-0354-x

Leberg, P. L. (2002). Estimating allelic richness: Effects of sample size and bottlenecks. Molecular Ecology, 11(11), 2445-2449. doi: 10.1046/j.1365294X.2002.01612.x

Leffler, E. M., Bullaughey, K., Matute, D. R., Meyer, W. K., Segurel, L., Venkat, A., . . Przeworski, M. (2012). Revisiting an Old Riddle: What Determines Genetic Diversity Levels within Species? Plos Biology, 10(9). doi: 10.1371/journal.pbio.1001388

Li, Q., Liu, S., \& Kong, L. (2009). Microsatellites within genes and ESTs of the Pacific oyster Crassostrea gigas and their transferability in five other Crassostrea species. Electronic Journal of Biotechnology, 12(3). doi: 10.2225/vol12issue3-fulltext-9

Librado, P., \& Rozas, J. (2009). DnaSP v5: a software for comprehensive analysis of 
DNA polymorphism data. Bioinformatics, 25(11), 1451-1452. doi: 10.1093/bioinformatics/btp187

Lopes, I. F., Mino, C. I., \& Del Lama, S. N. (2007). Genetic diversity and evidence of recent demographic expansion in waterbird populations from the Brazilian Pantanal. [Diversidade genetica a evidencias de expansao demografica recente nas populacoes de aves aquaticas do Pantanal brasileiro]. Brazilian Journal of Biology, 67(4, Suppl. S), 849-857. doi: 10.1590/s151969842007000500007

Lowe, W. H., \& Allendorf, F. W. (2010). What can genetics tell us about population connectivity? Molecular Ecology, 19(15), 3038-3051. doi: 10.1111/j.1365294X.2010.04688.x

Ludt, W. B., Bernal, M. A., Bowen, B. W., \& Rocha, L. A. (2012). Living in the Past: Phylogeography and Population Histories of Indo-Pacific Wrasses (Genus Halichoeres) in Shallow Lagoons versus Outer Reef Slopes. Plos One, 7(6). doi: 10.1371/journal.pone.0038042

Luo, W., Nie, Z., Zhan, F., Wei, J., Wang, W., \& Gao, Z. (2012). Rapid Development of Microsatellite Markers for the Endangered Fish Schizothorax biddulphi (Gunther) Using Next Generation Sequencing and Cross-Species Amplification. International Journal of Molecular Sciences, 13(11), 1494614955. doi: 10.3390/ijms131114946

Mantel, N. (1967). DETECTION OF DISEASE CLUSTERING AND A GENERALIZED REGRESSION APPROACH. Cancer Research, 27(2P1), 209-\&.

McManus, M. A., \& Woodson, C. B. (2012). Plankton distribution and ocean dispersal. Journal of Experimental Biology, 215(6), 1008-1016. doi: 10.1242/jeb.059014

Meglecz, E., Costedoat, C., Dubut, V., Gilles, A., Malausa, T., Pech, N., \& Martin, J.-F. (2010). QDD: a user-friendly program to select microsatellite markers and design primers from large sequencing projects. Bioinformatics, 26(3), 403404. doi: 10.1093/bioinformatics/btp670

Meirmans, P. G., \& Hedrick, P. W. (2011). Assessing population structure: F-ST and related measures. Molecular Ecology Resources, 11(1), 5-18. doi: 10.1111/j.1755-0998.2010.02927.x

Meirmans, P. G., \& Van Tienderen, P. H. (2004). GENOTYPE and GENODIVE: two programs for the analysis of genetic diversity of asexual organisms. Molecular Ecology Notes, 4(4), 792-794. doi: 10.1111/j.1471-8286.2004.00770.x

Messmer, V., Jones, G. P., Munday, P. L., \& Planes, S. (2012). CONCORDANCE BETWEEN GENETIC AND SPECIES DIVERSITY IN CORAL REEF FISHES ACROSS THE PACIFIC OCEAN BIODIVERSITY GRADIENT. Evolution, 66(12), 3902-3917. doi: 10.1111/j.1558-5646.2012.01725.x 
Miah, G., Rafii, M. Y., Ismail, M. R., Puteh, A. B., Rahim, H. A., Islam, K. N., \& Latif, M. A. (2013). A Review of Microsatellite Markers and Their Applications in Rice Breeding Programs to Improve Blast Disease Resistance. International Journal of Molecular Sciences, 14(11), 22499-22528. doi: $10.3390 /$ ijms141122499

Miller, J. A., Banks, M. A., Gomez-Uchida, D., \& Shanks, A. L. (2005). A comparison of population structure in black rockfish (Sebastes melanops) as determined with otolith microchemistry and microsatellite DNA. Canadian Journal of Fisheries and Aquatic Sciences, 62(10), 2189-2198. doi: 10.1139/f05-133

Moland, E., Olsen, E. M., Knutsen, H., Garrigou, P., Espeland, S. H., Kleiven, A. R., . . Knutsen, J. A. (2013). Lobster and cod benefit from small-scale northern marine protected areas: inference from an empirical before - after controlimpact study. Proceedings of the Royal Society B-Biological Sciences, 280(1754). doi: 10.1098/rspb.2012.2679

Mora, C., Treml, E. A., Roberts, J., Crosby, K., Roy, D., \& Tittensor, D. P. (2012). High connectivity among habitats precludes the relationship between dispersal and range size in tropical reef fishes. Ecography, 35(1), 89-96. doi: 10.1111/j.1600-0587.2011.06874.x

Morgan, T. S., \& Rogers, A. D. (2001). Specificity and sensitivity of microsatellite markers for the identification of larvae. Marine Biology, 139(5), 967-973.

Moritz, C. (1994). APPLICATIONS OF MITOCHONDRIAL-DNA ANALYSIS IN CONSERVATION - A CRITICAL-REVIEW. Molecular Ecology, 3(4), 401-411. doi: 10.1111/j.1365-294X.1994.tb00080.x

Morrison, M. A. (2008). Tracking snapper origins. Water and Atmosphere, 16(4).

Nei, M. (1987). Molecular Evolutionary Genetics. New York: Columbia University Press.

Nevado, B., Mautner, S., Sturmbauer, C., \& Verheyen, E. (2013). Water-level fluctuations and metapopulation dynamics as drivers of genetic diversity in populations of three Tanganyikan cichlid fish species. Molecular Ecology, 22(15), 3933-3948. doi: 10.1111/mec.12374

Nevo, E. (2001). Evolution of genome-phenome diversity under environmental stress. Proceedings of the National Academy of Sciences of the United States of America, 98(11), 6233-6240. doi: 10.1073/pnas.101109298

Newcombe, E. M., \& Taylor, R. B. (2010). Trophic cascade in a seaweed-epifauna-fish food chain. Marine Ecology Progress Series, 408, 161-167. doi: $10.3354 /$ meps08589

Okumus, I., \& Ciftci, Y. (2003). Fish population genetics and molecular markers: II Molecular markers and their applications in fisheries and aquaculture. 
Turkish Journal of Fisheries and Aquatic Sciences, 3(1), 51-79.

Ovenden, J. R. (2013). Crinkles in connectivity: combining genetics and other types of biological data to estimate movement and interbreeding between populations. Marine and Freshwater Research, 64(3), 201-207. doi: $10.1071 / \mathrm{mf} 12314$

Paetkau, D., Calvert, W., Stirling, I., \& Strobeck, C. (1995). MICROSATELLITE ANALYSIS OF POPULATION-STRUCTURE IN CANADIAN POLAR BEARS. Molecular Ecology, 4(3), 347-354. doi: 10.1111/j.1365-294X.1995.tb00227.x

Palstra, F. P., \& Fraser, D. J. (2012). Effective/census population size ratio estimation: a compendium and appraisal. Ecology and Evolution, 2(9), 23572365. doi: $10.1002 /$ ece3.329

Palumbi, S. R. (2003). Population genetics, demographic connectivity, and the design of marine reserves. Ecological Applications, 13(1), S146-S158.

Parsons, D. M., Morrison, M. A., Thrush, S. F., Middleton, C., Smith, M., Spong, K. T., \& Buckthought, D. (2013). The influence of habitat structure on juvenile fish in a New Zealand estuary. Marine Ecology-an Evolutionary Perspective, 34(4), 492-500. doi: 10.1111/maec.12050

Perez-Matus, A., \& Shima, J. S. (2010). Density- and trait-mediated effects of fish predators on amphipod grazers: potential indirect benefits for the giant kelp Macrocystis pyrifera. Marine Ecology Progress Series, 417, 151-U168. doi: $10.3354 /$ meps08820

Peters, J. L., Bolender, K. A., \& Pearce, J. M. (2012). Behavioural vs. molecular sources of conflict between nuclear and mitochondrial DNA: the role of male-biased dispersal in a Holarctic sea duck. Molecular Ecology, 21(14), 3562-3575. doi: 10.1111/j.1365-294X.2012.05612.x

Pineda, J., Hare, J. A., \& Sponaugle, S. (2007). Larval Transport and Dispersal in the Coastal Ocean and Consequences for Population Connectivity. Oceanography, $20(3), 22-39$.

Pinsky, M. L., Palumbi, S. R., Andrefouet, S., \& Purkis, S. J. (2012). Open and closed seascapes: Where does habitat patchiness create populations with high fractions of self-recruitment? Ecological Applications, 22(4), 1257-1267.

Planes, S., \& Lenfant, P. (2002). Temporal change in the genetic structure between and within cohorts of a marine fish, Diplodus sargus, induced by a large variance in individual reproductive success. Molecular Ecology, 11(8), 15151524. doi: 10.1046/j.1365-294X.2002.01521.X

Portnoy, D. S., \& Heist, E. J. (2012). Molecular markers: progress and prospects for understanding reproductive ecology in elasmobranchs. Journal of Fish Biology, 80(5), 1120-1140. doi: 10.1111/j.1095-8649.2011.03206.x 
Pritchard, J. K., Stephens, M., \& Donnelly, P. (2000). Inference of population structure using multilocus genotype data. Genetics, 155(2), 945-959.

Reed, D. H., \& Frankham, R. (2003). Correlation between fitness and genetic diversity. Conservation Biology, 17(1), 230-237. doi: 10.1046/j.15231739.2003.01236.x

Reid, K., Hoareau, T. B., \& Bloomer, P. (2012). High-throughput microsatellite marker development in two sparid species and verification of their transferability in the family Sparidae. Molecular Ecology Resources, 12(4), 740-752. doi: 10.1111/j.1755-0998.2012.03138.x

Rice, W. R. (1989). ANALYZING TABLES OF STATISTICAL TESTS. Evolution, 43(1), 223-225. doi: $10.2307 / 2409177$

Ross, P. M., Hogg, I. D., Pilditch, C. A., \& Lundquist, C. J. (2009). Phylogeography of New Zealand's coastal benthos. New Zealand Journal of Marine and Freshwater Research, 43(5), 1009-1027.

Russell, B. C. (1983). THE FOOD AND FEEDING-HABITS OF ROCKY REEF FISH OF NORTHEASTERN NEW-ZEALAND. New Zealand Journal of Marine and Freshwater Research, 17(2), 121-145.

Sambrook, J., Fritsch, E. F., \& Maniatis, T. (1989). Molecular cloning: a laboratory manual. New York: Cold Spring Harbor Laboratory Press.

Schlotterer, C. (2004). The evolution of molecular markers - just a matter of fashion? Nature Reviews Genetics, 5(1), 63-69. doi: 10.1038/nrg1249

Scott, S. (2010). Phylogeography of the common New Zealand wrasse species, Notolabrus celidotus, and the phylogenetics of the pseudolabrine tribe. Unpublished Master's thesis, Victoria University of Wellington, Wellington, New Zealand.

Selkoe, K. A., Henzler, C. M., \& Gaines, S. D. (2008). Seascape genetics and the spatial ecology of marine populations. Fish and Fisheries, 9(4), 363-377. doi: 10.1111/j.1467-2979.2008.00300.x

Selkoe, K. A., \& Toonen, R. J. (2011). Marine connectivity: a new look at pelagic larval duration and genetic metrics of dispersal. Marine Ecology Progress Series, 436, 291-305. doi: 10.3354/meps09238

Sharp, N. J., Diggles, B. K., Poortenaar, C. W., \& Willis, T. J. (2004). Efficacy of Aqui-S, formalin and praziquantel against the monogeneans, Benedenia seriolae and Zeuxapta seriolae, infecting yellowtail kingfish Seriola lalandi lalandi in New Zealand. Aquaculture, 236(1-4), 67-83. doi: 10.1016/j.aquaculture.2004.02.005 
Sharp, N. J., Poortenaar, C. W., Diggles, B. K., \& Willis, T. J. (2003). Metazoan parasites of yellowtail kingfish, Seriola lalandi lalandi, in New Zealand: prevalence, intensity, and site preference. New Zealand Journal of Marine and Freshwater Research, 37(2), 273-282.

Shears, N. T., Smith, F., Babcock, R. C., Duffy, C. A. J., \& Villouta, E. (2008). Evaluation of biogeographic classification schemes for conservation planning: Application to New Zealand's coastal marine environment. Conservation Biology, 22(2), 467-481. doi: 10.1111/j.1523-1739.2008.00882.x

Skiftesvik, A. B., Blom, G., Agnalt, A.-L., Durif, C. M. F., Browman, H. I., Bjelland, R. M., . . . Mortensen, S. (2014). Wrasse (Labridae) as cleaner fish in salmonid aquaculture - The Hardangerfjord as a case study. Marine Biology Research, 10(3), 289-300. doi: 10.1080/17451000.2013.810760

Symonds, J. E., Walker, S. P., Pether, S., Gublin, Y., McQueen, D., King, A., . . Bruce, M. (2014). Developing yellowtail kingfish (Seriola lalandi) and hapuku (Polyprion oxygeneios) for New Zealand aquaculture. New Zealand Journal of Marine and Freshwater Research, 48(3), 371-384. doi: 10.1080/00288330.2014.930050

Tajima, F. (1989). STATISTICAL-METHOD FOR TESTING THE NEUTRAL MUTATION HYPOTHESIS BY DNA POLYMORPHISM. Genetics, 123(3), 585-595.

Tamura, K., Stecher, G., Peterson, D., Filipski, A., \& Kumar, S. (2013). MEGA6: Molecular Evolutionary Genetics Analysis Version 6.0. Molecular Biology and Evolution, 30(12), 2725-2729. doi: 10.1093/molbev/mst197

Taylor, P. D., Fahrig, L., Henein, K., \& Merriam, G. (1993). CONNECTIVITY IS A VITAL ELEMENT OF LANDSCAPE STRUCTURE. Oikos, 68(3), 571-573. doi: $10.2307 / 3544927$

Treangen, T. J., \& Salzberg, S. L. (2012). Repetitive DNA and next-generation sequencing: computational challenges and solutions. Nature Reviews Genetics, 13(1), 36-46. doi: 10.1038/nrg3117

Treml, E. A., Roberts, J. J., Chao, Y., Halpin, P. N., Possingham, H. P., \& Riginos, C. (2012). Reproductive Output and Duration of the Pelagic Larval Stage Determine Seascape-Wide Connectivity of Marine Populations. Integrative and Comparative Biology, 52(4), 525-537. doi: 10.1093/icb/ics101

Turner, T. F., Wares, J. P., \& Gold, J. R. (2002). Genetic effective size is three orders of magnitude smaller than adult census size in an abundant, estuarinedependent marine fish (Sciaenops ocellatus). Genetics, 162(3), 1329-1339.

Unsworth, R. K. F., De Leon, P. S., Garrard, S. L., Jompa, J., Smith, D. J., \& Bell, J. J. (2008). High connectivity of Indo-Pacific seagrass fish assemblages with mangrove and coral reef habitats. Marine Ecology Progress Series, 353, 213- 
Untergasser, A., Cutcutache, I., Koressaar, T., Ye, J., Faircloth, B. C., Remm, M., \& Rozen, S. G. (2012). Primer3-new capabilities and interfaces. Nucleic Acids Research, 40(15). doi: 10.1093/nar/gks596

Usmar, N. R. (2012). Ontogenetic diet shifts in snapper (Pagrus auratus: Sparidae) within a New Zealand estuary. New Zealand Journal of Marine and Freshwater Research, 46(1), 31-46. doi: 10.1080/00288330.2011.587824

Van Oosterhout, C., Hutchinson, W. F., Wills, D. P. M., \& Shipley, P. (2004). MICROCHECKER: software for identifying and correcting genotyping errors in microsatellite data. Molecular Ecology Notes, 4(3), 535-538. doi: 10.1111/j.1471-8286.2004.00684.x

von der Heyden, S., Beger, M., Toonen, R. J., van Herwerden, L., Antonette JuinioMenez, M., Ravago-Gotanco, R., . . Bernardi, G. (2014). The application of genetics to marine management and conservation: examples from the IndoPacific. Bulletin of Marine Science, 90(1), 123-158. doi: 10.5343/bms.2012.1079

Waldbieser, G. C., \& Bosworth, B. G. (2013). A standardized microsatellite marker panel for parentage and kinship analyses in channel catfish, Ictalurus punctatus. Animal Genetics, 44(4), 476-479. doi: 10.1111/age.12017

Wallis, G. P., \& Trewick, S. A. (2009). New Zealand phylogeography: evolution on a small continent. Molecular Ecology, 18(17), 3548-3580. doi: 10.1111/j.1365294X.2009.04294.x

Wang, J., Yu, X., Zhao, K., Zhang, Y., Tong, J., \& Peng, Z. (2012). Microsatellite Development for an Endangered Bream Megalobrama pellegrini (Teleostei, Cyprinidae) Using 454 Sequencing. International Journal of Molecular Sciences, 13(3), 3009-3021. doi: 10.3390/ijms13033009

Waters, J. M., Fraser, C. I., \& Hewitt, G. M. (2013). Founder takes all: densitydependent processes structure biodversity. Trends in Ecology \& Evolution, 28(2), 78-85. doi: 10.1016/j.tree.2012.08.024

Waters, J. M., \& Roy, M. S. (2004). Phylogeography of a high-dispersal New Zealand sea-star: does upwelling block gene-flow? Molecular Ecology, 13(9), 27972806. doi: 10.1111/j.1365-294X.2004.02282.x

Weir, B. S., \& Cockerham, C. C. (1984). ESTIMATING F-STATISTICS FOR THE ANALYSIS OF POPULATION-STRUCTURE. Evolution, 38(6), 1358-1370. doi: $10.2307 / 2408641$

Welsford, D. C., Jordan, A. R., \& Smolenski, A. J. (2004). Description and genetic identification of the early life-stages of Notolabrus fucicola and N-tetricus from Tasmanian waters, Australia, with notes on their newly-settled 
juveniles. New Zealand Journal of Marine and Freshwater Research, 38(2), 267-277.

Westneat, M. W., \& Alfaro, M. E. (2005). Phylogenetic relationships and evolutionary history of the reef fish family Labridae. Molecular Phylogenetics and Evolution, 36(2), 370-390. doi: 10.1016/j.ympev.2005.02.001

Willis, T. J., \& Anderson, M. J. (2003). Structure of cryptic reef fish assemblages: relationships with habitat characteristics and predator density. Marine Ecology Progress Series, 257, 209-221. doi: 10.3354/meps257209

Zavodna, M., Bagshaw, A., Brauning, R., \& Gemmell, N. J. (2014). The Accuracy, Feasibility and Challenges of Sequencing Short Tandem Repeats Using NextGeneration Sequencing Platforms. Plos One, 9(12). doi: 10.1371/journal.pone.0113862 